\title{
WestVirginiaUniversity
}

THE RESEARCH REPOSITORY @ WVU

Graduate Theses, Dissertations, and Problem Reports

2005

\section{Understanding mindfulness: Implications for instruction and learning}

Todd Lyle Stoops

West Virginia University

Follow this and additional works at: https://researchrepository.wvu.edu/etd

\section{Recommended Citation}

Stoops, Todd Lyle, "Understanding mindfulness: Implications for instruction and learning" (2005).

Graduate Theses, Dissertations, and Problem Reports. 3436.

https://researchrepository.wvu.edu/etd/3436

This Dissertation is protected by copyright and/or related rights. It has been brought to you by the The Research Repository @ WVU with permission from the rights-holder(s). You are free to use this Dissertation in any way that is permitted by the copyright and related rights legislation that applies to your use. For other uses you must obtain permission from the rights-holder(s) directly, unless additional rights are indicated by a Creative Commons license in the record and/ or on the work itself. This Dissertation has been accepted for inclusion in WVU Graduate Theses, Dissertations, and Problem Reports collection by an authorized administrator of The Research Repository @ WVU.

For more information, please contact researchrepository@mail.wvu.edu. 
Understanding Mindfulness: Implications for Instruction and Learning Todd Lyle Stoops

\author{
Dissertation submitted to the \\ College of Human Resources and Education \\ at West Virginia University \\ in fulfillment of the requirements for the degree of
}

Doctor of Education

In Educational Psychology

Robert Marinelli, Ed.D.

Daniel Hursh, Ed.D.

Neal Shambaugh, Ph.D.

Jon Reed, J.D.

Richard Walls, Ph.D., Chair

Department of Advanced Educational Studies, Educational Psychology Program

Morgantown, West Virginia

2005 
Abstract

Understanding Mindfulness: Implications for Instruction and Learning

Todd L. Stoops

This Dissertation examines the literature concerning Mindfulness as it relates to Educational Psychology and overviews a research study conducted to add empirical research on Mindfulness instruction and learning. The literature review is divided into three categories of Mindfulness which are defined and discussed according to applications and implications for education. These three categories are (a) Mindfulness as a meditative practice for teachers and in its use in teacher education programs, (b) clinical and therapeutic applications of Mindfulness in contemporary psychology, and (c) Mindfulness in Educational Psychology. Established constructs from the literature of psychology and education are related to the concepts of Mindfulness, and examples are given. The main focus of this review seeks to examine Mindfulness as an instructional strategy and educational goal. Contrasting perspectives on the effectiveness and value of Mindfulness in education are presented. The Dissertation also includes the method section, results section, and discussion section of a research study conducted to answer two research questions on Mindfulness with implications for instruction and learning. The research questions follow. (1) Does a student's propensity for Mindfulness have an effect on learning when a student participates in Mindful Instruction and meditation? (2) Does Mindful Instruction and meditation affect a student's state of Mindfulness? This research study was novel in its attempts to combine the traditional, Buddhist form of Mindfulness meditation defined by Hanh (1991) with the Mindfulness education defined by Langer (1989). Results of the analyses for this study suggest that propensity for Mindfulness is dispositional (trait-like), and the level of propensity (High versus Low) had some effect on participants' content test scores. Limitations in the current study are discussed. The findings implicate (a) the role and influence of Mindfulness as a behavior trait and (b) the effect of previous knowledge on a student's propensity for Mindfulness. The implications for instruction suggest a need for further research (a) on long-term and applied Mindfulness Instruction in actual classrooms and (b) on a combined Hanh (1991) and Langer (1989) form of Mindfulness Instruction. 


\section{Acknowledgements}

I am very mindful of all the assistance and support from my committee members and others in my life. To Dr. Richard T. Walls, thank you so much for the consistency of patience, encouragement, and masterful teaching. To Dr. Robert Marinelli, thank you for teaching me about my life and disability. I am grateful to my other committee members and other excellent teachers in my life including Thich Nhat Hanh, Dr. Dan Hursh, Dr. Jon Reed, Dr. Neal Shambaugh, Dr. Julie Skinner Vargas, the late Dr. Bagby, and Dr. Ellen Langer. Candy Long, Linda Winiarski, and Ann Crabtree continuously offer academic and personal support. I give an incredible THANK YOU to my former students, co-workers, classmates, etc. for learning with me. Thank you Dr. Joel Weinberg for keeping me alive through this dissertation and beyond. Keep up the good work Joel!

I wish to thank my Mom, Dad, Tim, Karen, Lilly, Madelyn, and T.D. for being with me patiently through my years of schooling. Betty Jane Rogers was my inspiration to finish my doctorate and continues to inspire me to live life fully. I would not have made it through college without Larry and Louann Wentz and the entire family! Thank you to all my mothers (Sherrell, Barb, Jane, Kay, Hilda, Willa, Sue, etc.) who fed me and watched over me throughout college.

Thank you Jodi Helmick for making me aware of Mindfulness and for constant laughter! Thanks to ALL my friends for all the fun through this crazy school experience. Thanks to Craig Deppen Auge for the endless source of encouragement, inspiration, and love in my education and life. 
Table of Contents

Chapter 1 LITERATURE REVIEW, RESEARCH QUESTIONS, AND

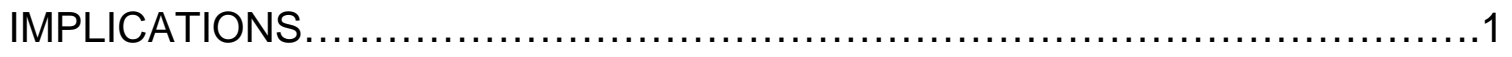

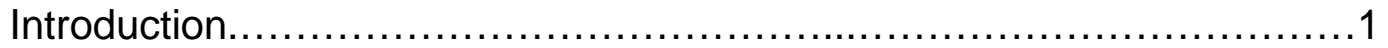

Mindfulness: Definitions and Applications..........................

Mindfulness in Teacher Education Programs.......................... 5

Applications of Mindfulness in Therapeutic and Clinical Settings...........

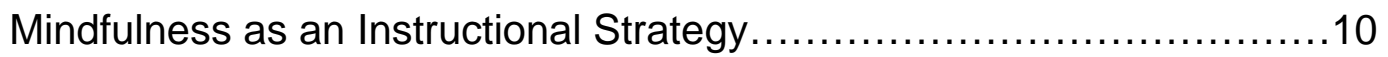

Premature Cognitive Commitments............................... 12

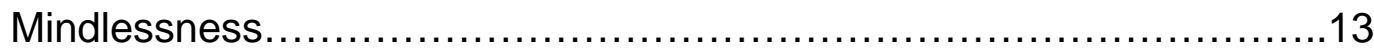

Mindfulness: Novel Distinctions and Context......................... 14

Mindfulness Rooted in Educational Foundations......................18

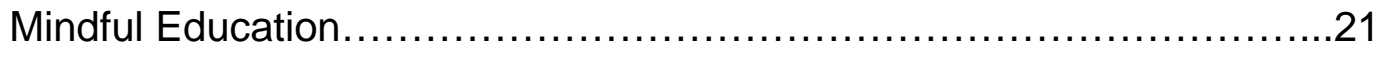

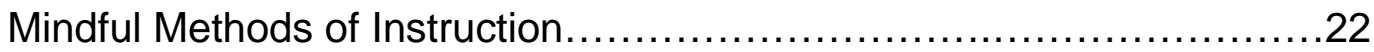

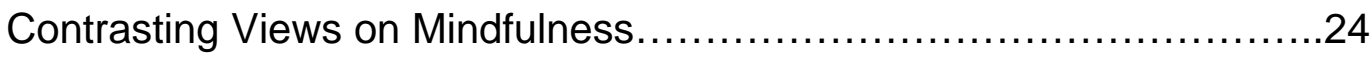

Potential Value of Mindfulness in Education...........................26

Research Questions...........................................27

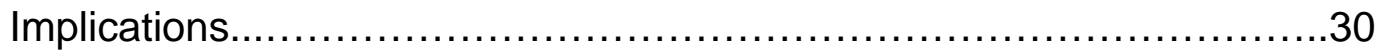

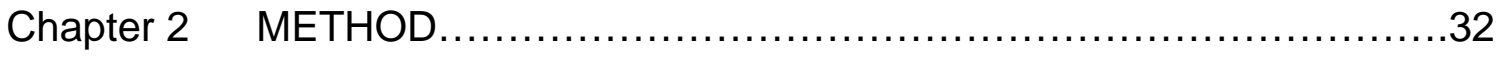

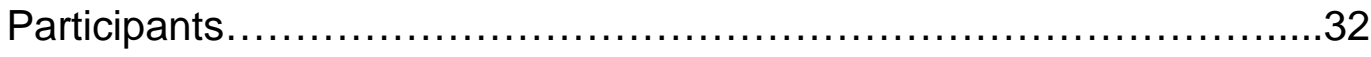

Instruments....................................................

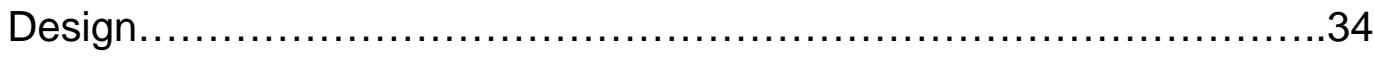

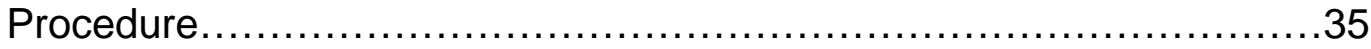


Analysis.

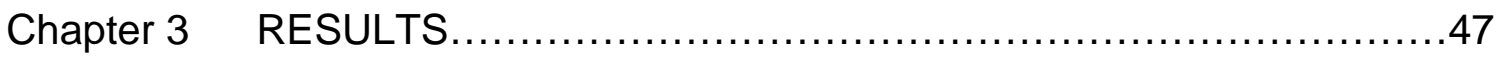

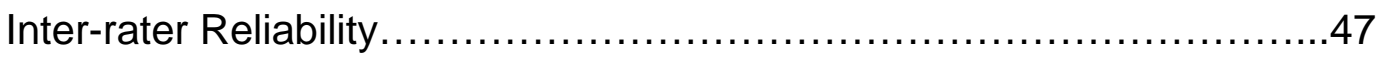

Interaction of Mindfulness Groups with Mindful and Non-Mindful

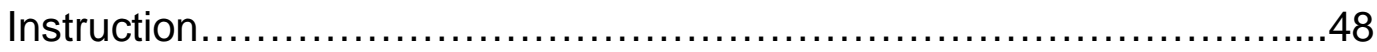

Effects of Previous Knowledge of Subject Matter (Math and Disability)...52 Test-Retest Consistency on the Langer Mindfulness Scale (LMS) and Correlation to the Mindfulness Attention-Awareness Scale (MAAS) .......59 Interaction of Mindfulness Groups with Topic.............................61 Effects of Mindful and Non-Mindful Instruction on the Modified Guilford Test of Alternate Uses.................................................. 64

Effects of Mindful and Non-Mindful Instruction on the Embedded Measures of Mindfulness ..............................................6

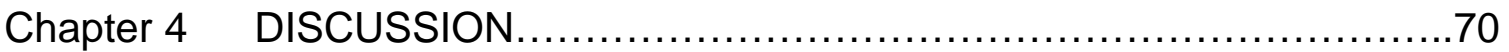

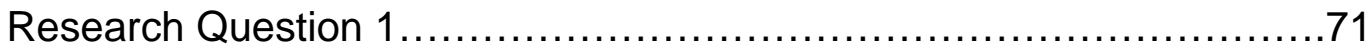

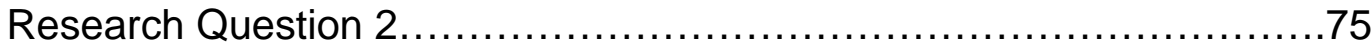

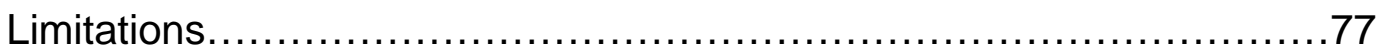

Implications for Learning and Instruction............................... 83

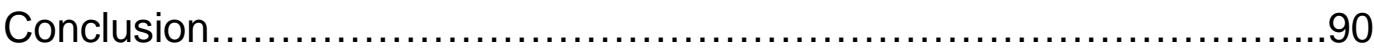

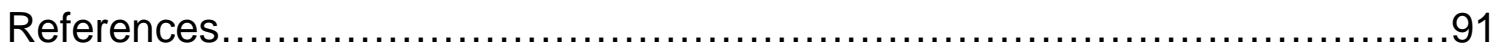

Appendix A LANGER MINDFULNESS SCALE .............................101

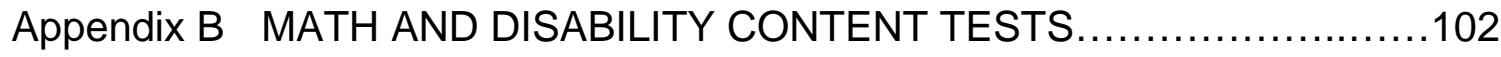

Appendix C MODIFIED GUILFORD TEST OF ALTERNATIVE USES.........109 
Appendix D EMBEDDED MEASURES OF MINDFULNESS

Appendix E DIRECTIONS, CRITERIA, AND CONTENT OF MINDFUL AND NON-MINDFUL INSTRUCTION ON MATH ..........................113

Appendix F DIRECTIONS, CRITERIA, AND CONTENT OF MINDFUL AND NON-MINDFUL INSTRUCTION ON DISABILITY .....................118

Appendix G MINDFULNESS ATTENTION-AWARENESS SCALE ..............123

Appendix H CHECKLISTS FOR MINDFUL INSTRUCTION OF MATH AND

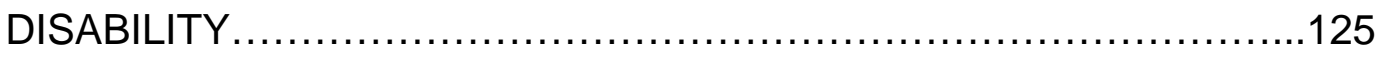

Appendix I CHECKLISTS FOR NON-MINDFUL INSTRUCTION OF MATH

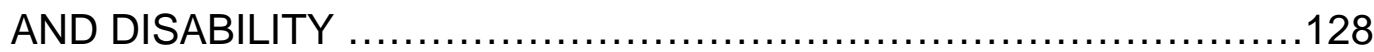

Appendix J RECRUITMENT MATERIAL FOR STUDY $\ldots \ldots \ldots \ldots \ldots \ldots \ldots \ldots \ldots \ldots \ldots$

Appendix K EMAIL CORRESPONDENCE TO PARTICIPANTS ................132 Appendix L EXTRA CREDIT SLIPS FOR STUDENTS PARTICIPATING IN

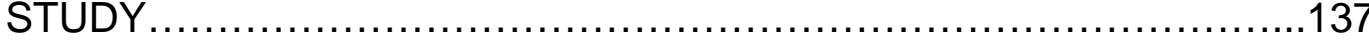




\section{List of Tables}

Table 1. Propensity for Mindfulness by Mindfulness Groups by Instruction Type

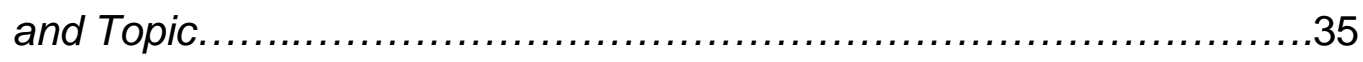

Table 2. Analysis of Variance for Interaction of Mindfulness Groups with Mindful and Non-Mindful Instruction ......................................50

Table 3. Number of Participants by Mindfulness Groups for Rating Groups by

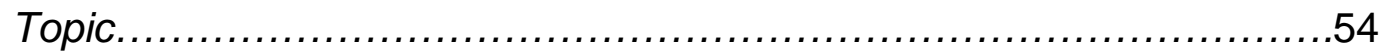




\section{List of Figures}

Figure 1. Means for Mindfulness Groups (High Mindfulness versus Low Mindfulness) for Both Content Tests (Math and Disability) $\ldots \ldots \ldots \ldots \ldots . \ldots 50$

Figure 2. Means for both groups of participants by Instruction Type............51

Figure 3. Mean Score on Tests (Disability and Math) with Mindful and Non -Mindful Instruction by Mindfulness Groups..........................51

Figure 4. Level of Previous Knowledge and Mean Scores for Math Content

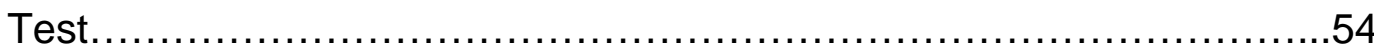

Figure 5. Level of Previous Knowledge and Mean Scores for Disability Content

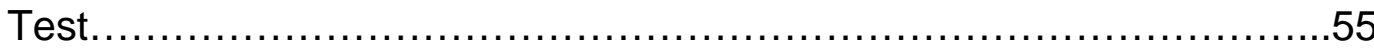

Figure 6. Mean Scores for Math Content Test for Math Level Groups by

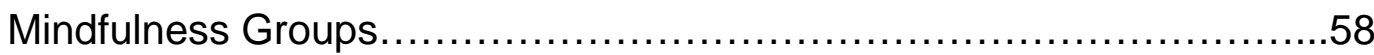

Figure 7. Mean Scores for Disability Content Test for Disability Level Groups by

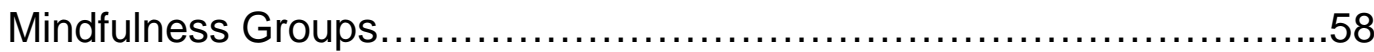

Figure 8. Mean Scores for Both Topics (Math and Disability) by Mindfulness Groups (High Mindfulness versus Low Mindfulness) ..................63

Figure 9. Mean scores for Modified Guilford by Instruction Type and Mindfulness Groups....................................................66

Figure 10. Mean Scores of Embedded Measures of Mindfulness for Math Topic by Instruction Type (Mindful versus Non-Mindful) ....................68

Figure 11. Mean Scores of Embedded Measures of Mindfulness for Disability topic by Instruction Type and Mindfulness Groups 


\section{Mindfulness Education}

\section{Chapter 1}

Literature Review, Research Questions, and Implications

\section{Introduction}

The last 20 years have seen the growth of Mindfulness, both in applications to psychology in clinical and educational settings and to society as a form of meditative practice. During this time, considerable development and research on Mindfulness have produced numerous studies, articles, and publications. In psychology, Mindfulness is being used as a therapeutic intervention to treat a variety of disorders and disabilities as well as in other clinical applications. Specifically, in educational psychology, Mindfulness is being used as an instructional strategy to more effectively produce "successful" learners who are more creative, better problem-solvers, and who are capable of transferring skills and knowledge of new information for increased learning (Langer \& Moldoveanu, 2000). In society, Mindfulness is being popularized as a personalized meditative practice that allows the individual (a) to live less constrained by life's demands and (b) to subsequently free oneself from stress and worry.

Due to the emphasis and purpose of this literature review in examining Mindfulness as an instructional strategy and educational tool, the main focus of this review is how Mindfulness relates to educational psychology. Three categories with varying degrees of pertinence and application to educational psychology are (a) Mindfulness as beneficial in teacher education programs, (b) clinical and therapeutic applications of Mindfulness in contemporary psychology, 


\section{Mindfulness Education}

and (c) Mindfulness in educational psychology and its subsequent use as an instructional strategy in the classroom. These educational components of Mindfulness (in teacher education, in application of psychology, and in classroom instruction) are reviewed first. Subsequently, they are integrated as they may contribute to an augmented theory and practice of educational psychology.

\section{Mindfulness: Definitions and Applications}

Just as Mindfulness can be applied to a variety of settings, Mindfulness is defined differently according to each of these settings. Though these definitions differ, there exist some underlying commonalities among all three of the settings discussed in this paper, (teacher education programs, clinical and therapeutic settings, and classroom/instructional settings) and their subsequent application of Mindfulness. As a general definition, Webster's Dictionary defined Mindfulness as "1 a: bearing or keeping in mind: aware...b: inclined to be aware (as of events occurring around you" (Merriam Webster's Third New International Dictionary, 1993). The following section is devoted to defining Mindfulness according to these three settings (teacher education programs, clinical and therapeutic settings, and classroom/instructional settings) where Mindfulness can occur and a brief description of how Mindfulness is applied and used in each setting.

Mindfulness as a part of Asian psychology has its earliest roots as a Buddhist tradition (Gilbert, 1973). The first definition is derived from the renowned Buddhist teacher Thich Nhat Hanh. Thich Nhat Hanh has been a 


\section{Mindfulness Education}

tremendous influence in bringing Mindfulness to popular society through numerous presentations and publications (Hanh, 1976, 1987, 1990a, 1990b, 1991, 1997, 2001). He has been recognized as a world leader in peace, even garnering a nomination for the Nobel Peace Prize by Dr. Martin Luther King, Jr, and is looked upon as a great spiritual teacher. In his book Peace is Every Step, Hanh (1991) defined Mindfulness as awareness of the present moment. Hanh suggested that awareness of the self in the present moment is the "foundation of a happy life" (p. 48). In this and his many other books on Mindful living, Hanh uses Mindfulness as a meditation technique involving conscientious breathing in order to bring the person back to the present moment. Bringing the person to the present moment and focusing the person in the now, allows the person to maintain awareness of the person's present behavior, thoughts, and feelings. It is this definition and application of Mindfulness that has found a place in teacher education programs. Further discussion can be found below on how Mindfulness has become useful in increasing teachers' (a) awareness of their presence in the classroom, (b) contemplation of personal teaching style and efficacy, and (c) psychological well-being. Hanh's definition of Mindfulness is also the basis for the second definition and application of Mindfulness in psychology as described below.

Hanh's definition and practice of Mindfulness has been further examined and applied to the second category which dominates the field of research and literature, applications of Mindfulness in psychology. In contemporary psychology, Mindfulness has been defined and adapted "as an approach for 
increasing awareness and responding skillfully to mental processes that contribute to emotional distress and maladaptive behavior" (Bishop, Lau, \& Shapiro, 2004, p. 230). Mindfulness as a behavioral therapeutic intervention is called Mindfulness-Based Stress Reduction (MBSR) Therapy. In 1979, Dr. J. Kabat-Zinn founded The Center for Mindfulness in Medicine, Health Care, and Society (CFM) at the University of Massachusetts, the first such center dedicated to the use of Mindfulness as a therapeutic intervention. Kabat-Zinn (2003) defined Mindfulness operationally as "the awareness that emerges through paying attention on purpose, in the present moment, and non-judgmentally to the unfolding of experience moment by moment” (p. 145). The last 10 years have also seen the adaptation of the behavior-oriented MBSR to a cognitive-based therapy called Mindfulness-Based Cognitive Therapy (MBCT). Further applications to specific disabilities, disorders, and settings where MBSR and MBCT have been proven effective are discussed below. Implications for using MBSR/MBCT in the classroom setting for students and educational relevance of MBSR/MBCT are presented below as well.

The third definition of Mindfulness is directly related to educational psychology and is the focus of this literature review. Mindfulness in educational psychology has been largely defined according to the work of Dr. Ellen Langer, Social Psychology Professor at Harvard University. Langer (1993) defined Mindfulness as "a state of mind that results from drawing novel distinctions, examining information from new perspectives, and being sensitive to context" ( $p$. 44). The focus of this literature review is an attempt to examine the components 
that constitute a Mindful education. A Mindful approach to learning, teaching, or any activity has three characteristics: the continuous creation of new categories; openness to new information, and an implicit awareness of more than one perspective (Langer, 1997). By examining Mindfulness from the psychological and educational perspective, I am drawing upon established constructs from the literature of psychology and education (e.g., mental set, critical thinking) as they relate to the concepts of Mindfulness. From these perspectives, it is my hope to expand the current literature involving Mindfulness in order to promote its usefulness and effectiveness as an instructional strategy.

\section{Mindfulness in Teacher Education Programs}

As discussed above, the application of Mindfulness as taught by Thich Naht Hanh is finding a place in teacher education programs. This form of Mindfulness of bringing the person to the present moment and focusing the person in the "now" allows the person to maintain awareness of his or her present behavior, thoughts, and feelings. For this reason, Mindfulness is being used as a reflective self-study in some teacher education programs. For example, Jack Miller from the University of Toronto has incorporated Mindfulness in his graduate teacher education courses (Miller, 2004). Over the last 15 years, over 1,200 novice student teachers as well as experienced teachers in his graduate teacher education courses have practiced Mindfulness and recorded their experiences in journals. Miller's reviews and findings from these journals as well as evaluations from the graduate students support the notion that practicing 
Mindfulness has increased (a) the awareness of the student teacher's presence, (b) contemplation of the student teacher's self-efficacy, and (c) the student teacher's own psychological well-being (Miller, 2004). Similar to Miller's use of Mindfulness in his teacher education programs, Mindfulness has been used in graduate level counseling courses as a means of integrating and clarifying the students' views on counseling (Rybak \& Russell-Chapin, 1998).

In a study of education majors and experienced teachers, teacher presence, the manner in which the teacher presented information and interacted with students was attributed to be the greatest influence in successful classroom management (Long \& Biggs, 1999). Certainly, increasing a teacher's awareness (possibly through Mindfulness as suggested by Miller) of his or her teacher presence in the classroom would positively contribute and affect such influence. Similarly, teacher self-efficacy beliefs have repeatedly been associated with positive teaching behaviors and student outcomes (Henson, 2001). Increasing contemplation through Mindfulness of teacher self-efficacy beliefs should be of benefit as well. However, a positive relationship between (a) the increase of teacher awareness (i.e., Mindfulness) of teacher presence and (b) the increase of contemplation (i.e., Mindfulness) of teacher self-efficacy beliefs to improved classroom management or teaching behavior or student outcome has yet to be studied empirically. Studies have been conducted, though, that suggest Mindfulness increases psychological well-being (Brown \& Ryan, 2003; Grossman, Niemann, \& Schmidt, 2004). Thus, an implication for using Mindfulness in an educational environment could result in an increase of 
psychological well-being of both teacher and student. A possible implication for teachers using Mindfulness could be to increase the teacher's awareness of his/her presence in the classroom. Mindfulness also may have benefit in increasing teacher contemplation and reflection of self-efficacy beliefs to improve classroom management and positive teaching behavior for the ultimate purpose of better student outcome.

One additional note on the increasing use of Mindfulness in teacher education programs can be the incorporation of Mindfulness into other educational curriculum. One of the most widely used textbooks for counseling students in their internship, practicum, or field placement suggested using "Mindfulness Meditation" as taught by Thich Nhat Hanh as an effective way to manage stress and emotional self-care (Baird, 2005).

Applications of Mindfulness in Therapeutic and Clinical Settings

As noted above, Dr. Kabat-Zinn (2003) developed Mindfulness-Based Stress Reduction (MBSR) Therapy in 1979. Initially, he offered MBSR through the outpatient stress reduction clinic for two reasons. The first reason was to use MBSR as a training means for the relief of suffering for medical patients. The second reason was to use MBSR as a model, should the program prove successful and effective, for other institutions and possible transfer to other contexts where stress is prevalent. Both rationales apparently have been justified as evidence of MBSR's success can be seen through numerous studies and publications as well as the numerous hospitals, clinics, schools, workplaces, 
law schools, adult/juvenile prisons, and the variety of other settings where MBSR has been introduced (Kabat-Zinn, 2003).

Mindfulness Based Stress Reduction (MBSR) Therapy has demonstrated promising results in treating numerous psychological conditions, disorders, and disabilities as a psychotherapeutic treatment. MBSR Therapy has demonstrated positive results in treating individuals with anxiety (Kabat-Zinn, et al. 1992; Miller, Fletcher, \& Kabat-Zinn, 1995) and depression (Ramel, Goldin, \& Carmona, 2004; Teasdale, et al. 2000), Fibromyalga (Kaplan, Goldenberg, \& Galvin-Nadeau, 1993), Chronic Pain (Kabat-Zinn, 1982, as cited in Bishop, et al., 2004; KabatZinn, Lipworth, \& Burney, 1985, as cited in Bishop, et al., 2004; Kabat-Zinn, Lipworth, Burney, \& Sellers, 1986, as cited in Bishop, et al., 2004), and in the psychotherapeutic treatment of women with breast cancer (Carlson, Speca, Patel, \& Goodey, 2004; Tacon, Caldera, \& Ronaghan, 2004). These are just a few examples of the conditions and instances where MBSR Therapy has demonstrated effectiveness. Other examples where MBSR Therapy has positively changed or influenced behaviors and/or quality of life issues include MBSR's effectiveness for individuals with Psoriasis, Obsessive Compulsive Disorder, Prostrate Cancer, Borderline Personality Disorder, Addictions to Drugs/Alcohol, Mental Retardation, and Aggressive or Maladaptive Behaviors. Grossman, Niemann, and Schmidt (2004) reported in their meta-analysis of Mindfulness Based Stress Reduction and Health Benefits on 64 empirical studies related to MBSR alone. It should be noted that of the 64 empirical studies, only 20 met criteria of acceptable quality or relevance to be included in the meta- 


\section{Mindfulness Education}

analysis. Reports were excluded due to (1) insufficient information about interventions, (2) poor quantitative health evaluation, (3) inadequate statistical analysis, (4) Mindfulness not being the central component of intervention, or (5) the setting of intervention or sample composition deviating too widely from the health-related MBSR program.

Mindfulness Based Cognitive Therapy (MBCT), a cognitive therapy adaptation of Kabat-Zinn's behavioral MBSR was designed to be used to prevent relapse and recurrence of depression in those who are in recovery (Segal, Williams, \& Teasdale, 2002). Studies suggest that MBCT is in fact an effective way to treat depression and prevent relapse (Ma \& Teasdale, 2004; SchererDickson, 2004). MBCT has just recently begun to be studied for effectiveness in treating other similar types of conditions or therapeutic needs such as suicidal patients (Williams \& Swales, 2004). It should be noted that the articles and applications of MBSR and MBCT mentioned above are only a fraction of the literature and research that is currently available and being undertaken. The inclusion of this section is solely for illustrating educational potentials for students and teachers.

Implications for MBSR and MBCT in educational settings are numerous. Though Mindfulness would appear to be limited to students of average or aboveaverage cognition, there is evidence that Mindfulness-based interventions can be effective for modifying maladaptive behaviors for lower functioning and behaviorally challenged students (Singh, Wahler, Adkins, \& Myers, 2003). The possibility then exists that Mindfulness-based interventions may be useful in 


\section{Mindfulness Education}

public education settings in modifying maladaptive or aggressive behavior. Some success for college students with disabilities in practicing Mindfulness meditation in alleviating stress also has been documented (Holland, 2004). Thus, teaching Mindfulness meditation may have positive effects on students with disabilities, especially to those students with disabilities where MBSR has been proven effective. MBSR also has been effectively used in medical education programs to assist medical students deal with the stresses of medical training (Rosenzweig, Reibel, Greeson, Brainard, \& Hojat, 2003; Shapiro, Schwartz, \& Bonner, 1998). The possibility exists that MBSR may be useful in other educational programs besides medical education programs that require significant coping skills.

\section{Mindfulness as an Instructional Strategy}

As stated above, Mindfulness as an instructional strategy was pioneered by Dr. Ellen Langer (Langer, 1989). Currently and historically, Dr. Langer and her colleagues have done much of the research in developing Mindfulness as an educational tool (Brown \& Langer, 1990; Chanowitz \& Langer, 1981; Grant, Langer, \& Falk, 2004; Langer \& Brown, 1992; Langer, Hatem, Joss, \& Howell, 1989; Langer \& Moldoveanu, 2000; Langer, Perlmuter, Chanowitz, \& Rubin, 1988). Langer (1993) defined Mindfulness as "a state of mind that results from drawing distinctions, examining information from new perspectives, and being sensitive to context" and "an open, creative, probabilistic state of mind in which the individual might be led to finding differences among things thought similar 


\section{Mindfulness Education}

and similarities among things thought different” (p. 44). In a more recent definition, Langer (2000) defined Mindfulness as "a flexible state of mind in which we are actively engaged in the present, noticing new things and sensitive to context” (p. 220). Mindfulness involves the process of drawing novel distinctions in instruction, examining information from new perspectives, and being sensitive to context (Langer 1993). In practicing Mindful instruction, teachers need to best utilize methods that support the above-mentioned cognitive processes in terms of thinking and learning. Examples of applying Mindful methods of instruction are discussed later.

The components of a Mindful education are described and expanded below. These three components are examination of (a) Premature Cognitive Commitments, (b) Mindlessness, and (c) Mindfulness: Novel Distinctions and Context. Since Mindful instruction requires the student to examine information from new perspectives, previous learning and knowledge can hinder novel ways of looking at information. This previous learning or knowledge, called Premature Cognitive Commitments by Langer (1993), allows the students to prematurely connect new information to familiar and existing ideas without first considering novel ways of applying or using the information. To further define what constitutes Mindfulness in education, the contrasting Mindlessness in education is explained to justify the components necessary for mindfulness education to occur. As explained in greater detail under the sub-heading Mindlessness, Mindlessness in education is characterized by little to no mental engagement for students and learning by rote memorization. Critical thinking skills are not 
nurtured or developed, and the student may be required to answer with simple yes or no or multiple choice answers rather than problem solving. Student behavior is automatic, and processing is not deep or involving. Another component of Mindfulness in education, explained below, builds on the notion of drawing novel distinctions with newly presented information. Drawing these novel distinctions creates new contexts for the student's existing knowledge of information or words.

\section{(a) Premature Cognitive Commitments}

A Premature Cognitive Commitment is "a rigid belief that results from the mindless acceptance of information as true without consideration of alternative versions of that information" (Langer, 1993, p. 45). In many instances of instruction, a student automatically "commits" information in preconceived and predetermined ways. For example, when a student is given a pencil, the preconceived or predetermined use of the pencil is to write. Writing or instruction to write would most likely be the behavior which the student expects to follow. However, pencils have other uses, such as puncturing holes in paper for example, that are not often considered first. The Gestalt psychologist Karl Duncker (as cited in Bruning, Schraw, \& Ronning, 1995) termed this phenomenon as "functional fixedness." Functional fixedness is "a condition that arises when we lose the ability to view familiar objects in a novel way" (Bruning, et al., 1995, p. 185). In Duncker's experiments involving individuals using everyday objects for problem solving, he was able to illustrate the profound 


\section{Mindfulness Education}

impact of preexisting knowledge and how that knowledge inhibits novel solutions or uses of objects during problem solving (Bruning et al., 1995). In psychology, a relevant term that is used is "mental set or mindsets." Luchins (as cited in Chen \& Mo, 2004) found that once a mathematical problem could be solved without thinking, participants continued using the same solutions even when presented with a simpler solution. Premature Cognitive Commitments frequently occur when the information presented initially appears irrelevant and/or the information is given in absolute rather than conditional language (Chanowitz \& Langer, 1981; Langer, Perlmuter, Chanowitz, \& Rubin, 1988).

\section{(b) Mindlessness}

Chanowitz and Langer (1981) demonstrated that if information is presented in a manner that initially appears irrelevant, it subsequently encourages mindlessness. To better understand what is meant by thinking or behaving mindfully, one can see a clearer definition by conversely describing behavior which is mindless. When a person acts mindlessly, the "behavior is rule and routine governed" (Langer, 2000). Langer, Bashner, and Chanowitz (1985) further defined Mindlessness as "passive information-processing in which the individual rather automatically relies on distinctions previously drawn, instead of engaging in active categorizing and new distinction making" (p. 113). Mindlessness has three defining characteristics in which (a) information is trapped in categories or distinctions created through past learning, (b) automaticity of behavior occurs, and (c) the individual is acting from a single 
perspective (Langer, 1989). When a person is Mindful, he/she views a situation from multiple perspectives, sees information presented in the situation as novel, attends to the context in which the person is perceiving the information, and eventually creates new categories through which the information is understood (Langer, 1997).

(c) Mindfulness: Novel Distinctions and Context

Studies suggest that drawing novel distinctions can lead to positive effect in students, including greater sensitivity to one's environment, more openness to new information, the creation of new categories for structuring perception, and increased awareness of multiple perspectives in problem solving (Langer \& Brown, 1992; Langer \& Piper, 1987). Mindful instruction requires that the teacher present information in a manner that requires students to construct new applications or cognitive structures. By drawing novel distinctions about the information being taught or presented, the student is then required to expand their existing schema or create new schemas. In their studies analogous to the work of Luchins and Luchins, Chen and Mo (2004) found that exposure to less variant problems led to faster initial learning, but narrower and greater fixed schemas (mental set). However, exposure to variant procedures led to slower initial learning, but broader and more flexible schemas. This suggested that novelty in instruction has the long-term benefit of producing better problem solvers capable of adapting and successfully responding to the ever changing and uncertain complexities in education and life. 


\section{Mindfulness Education}

Langer, Bashner, and Chanowitz (1985) also found that instruction increased the number of distinctions, created greater cognitive flexibility, greater understanding, and actually reduced prejudice. In their research study on increasing distinctions among people deviant from the typical of society (people with disabilities in this instance), the participants given information with greater distinctions actually had reduced erroneous and indiscriminate prejudice. My experiences in teaching about disability mindfully have had similar results. For example, in teaching a course on disability, I required my students to examine the usage of terms relating to disability familiar to their everyday speech. Illustrating with examples from newspapers or by discussing the historical background of some terms (e.g., handicap), I was able to teach the students appropriate use of terminology when referring to people with disabilities by increasing the discrimination between the words. Subsequently, students demonstrated a decrease in undesirable discrimination by using appropriate speech that was less offensive or derogatory toward people with disabilities when speaking about disability. In her chapter titled, "Mindfulness/Mindlessness: A New Perspective on Disability," Langer and Chanowitz (as cited in Yuker, 1988) called for increasing the differences and distinctions among people with disabilities for the purpose of achieving greater understanding of disability for people without disabilities.

A critical aspect of Mindfulness, according to Langer, is sensitivity to context. Langer (1993) suggested instruction that is independent of context to better equip students for other situations. Mindful instruction, whereby the 


\section{Mindfulness Education}

information presented is looked upon independent of its typical or usual context, promotes critical thinking and problem solving skills by forcing the students to use alternate means of finding an answer. Critical thinking refers to "the deliberate use of skills and strategies that increase the probability of a desirable outcome" (Halpern, 1998, p. 449). Critical thinking involves "solving problems, formulating inferences, calculating likelihoods, and making decisions" (Halpern, 1988. p. 450-451). Mindfulness promotes these skills by providing a level of uncertainty in education thus requiring alternative solutions to be considered and tried. When students are presented information in an environment independent of context, they are unable to rely solely upon their previous perspectives of the information and are forced to problem solve.

The research that has been conducted seems to support the need for instruction that is independent of context, especially when the educational goal is for increased creative and problem-solving behaviors. In their study of uncertainty in education, Langer et al. (1989) demonstrated that conditional teaching (use of words such as can or could) rather than absolute teaching (use of words or phrases such as this is a bicycle) produced solutions that are more creative. The importance of critical thinking skills in attaining and transferring knowledge is well documented in educational research and literature (as cited in Langer, 1993). In their landmark study of artistic creativity, Getzels and Czikszentmihalyi (1976) found that students who considered more options during the initial stages of problem finding were more original in their solutions. Since Mindfulness allows students to choose the path or process by which they derive 


\section{Mindfulness Education}

an answer, the students then have greater autonomy in their learning experience. Schwartz and Martin (2004) suggest that students given the opportunity to invent their own learning products are better equipped for learning.

Another positive attribute of Mindfulness, besides its capacity to increase creative and problem solving behaviors, is the level of attention that comes in focusing in the present moment. Bishop, et al. (2004) in part defined Mindfulness as the self-regulation of attention. Many times in educational settings, students are required to "pay attention" to the some aspect of the instruction (e.g., teacher, movie). This suggests that the students hold the stimuli constant. By viewing information from multiple perspectives, studies have shown that concentration increases (Carson, Shih, \& Langer, 2001; Levy, Jennings, \& Langer, 2001). As Langer (1993) stated:

Familiar stimuli are only familiar as long as we hold the stimuli constant. If we view the same stimuli from a novel perspective, we are likely to find that novelty makes concentration more attractive. (p. 48) By possibly reexamining what behaviors teachers are asking of their students when asked to "pay attention," more effective means of increasing students' concentration may occur. The implications for students to mindfully look at information from multiple perspectives and in novel ways may then increase student learning and lessen disruptive behaviors which occur when students are sometimes asked to "pay attention." 


\section{Mindfulness Education}

\section{Mindfulness Rooted in Educational Foundations}

The processes and concepts that constitute a Mindful education are not without basis in the Foundations of Educational Psychology. Mindfulness in comparison to Mindlessness can be seen in aspects of Lev S. Vygotsky's work in education. Vygotsky's relative term for Mindfulness can be found in his use of the phrase "consciously aware" or "consciousness" in describing the need for children to understand the meaning (not simply the sense) of concepts that had been used in a nonconscious way (as cited in Tudge \& Scrimsher, 2003). This "nonconcious" behavior is the Mindlessness and automaticity of behavior which Langer described (Langer, 1989). As Vygotsky noted in his study of preschool children, the child "has already acquired the entire grammar of his native language. Nevertheless, while he declines and conjugates, he does not know that he declines and conjugates" (Rieber \&Carton, 1987, p. 205). For example, Mindful instruction might then be able to make a student aware of the rules of

grammar by applying these rules to an existing knowledge and use of grammar.

Some aspects of Mindfulness can be found in Constructivism as well. Constructivism was part of the main theoretical framework of Jerome Bruner. Constructivism, as defined by Bruner (1960), states that learning is an active process in which learners construct new ideas or concepts based upon their current and/or past knowledge. While Langer and Moldoveanu (2000) defined Mindfulness as "the process of drawing novel distinctions" (p. 1), they suggested that "actively drawing these distinctions makes us more aware of the context and perspective of our actions than if we rely upon distinctions and categories drawn 
in the past (p. 1-2). Though it appears that the two definitions are incompatible with respect to the basis of constructing these new distinctions, I would argue that there is commonality.

First, though Bruner's definition bases the construction of these new ideas or concepts on current/past knowledge, it is inconceivable that a student could not bring some current/past knowledge to an educational setting. For example, a student must always bring his or her knowledge of language to discern meaning in instruction. However, I feel it is the "reliance" upon these past distinctions and categories of meaning that Langer is addressing and emphasizing as detrimental to a Mindful learning experience. Similar to Constructivism, Mindfulness creates new categories, whereas Mindlessness relies on old ones (Langer, 1993).

Second, commonality also exists in both definitions as they similarly describe the active processes by which learning takes place whereby the learner creates new ideas or concepts. John Dewey, one of America's early and formidable educators, acknowledged the goal of education is not the end product, but the process (as cited in Eby, 1952). Dewey surmised that there is no end or goal when education is completed. "The process of education is a continuous process." He continued by adding this rather Buddhist Mindful thought that "education is the process of living, here and now" (Eby, p. 61). Bruner (1966) shared the view that education and learning are static and should be purposeful when he stated, "Knowing is a process, not a product" (Bruner, p. 72). 
Mindfulness is very similar to Constructivism when implemented as an instructional strategy. Constructivism maintains that instruction must be concerned with the experiences and contexts that make the student willing and able to learn (readiness). With its awareness in the present moment, independence from context, and process and problem-solving approach, Mindful instruction and learning are very Constructivist indeed. A Mindful education thus involves mental engagement, introspection, flexibility in thinking, and goaldirected learning where the goal is achieved and learned in process. A Mindful education occurs when learners construct knowledge for themselves.

Still yet, Bruner's more recent work and the work of other contemporary educational psychologists add support to these underlying concepts of Mindfulness. Bruner (1990) suggested the importance of narrative in an individual's early acquisition of language and learning. Narrative, he describes, is "one of the most ubiquitous and powerful discourse forms in human communication" (p. 77). A requirement of narrative is "early readiness to mark the unusual and to leave the usual unmarked-to concentrate attention and information processing on the offbeat" (p.78). The relevance to the student as individual, the drawing of novel distinctions, and flexibility of Mindfulness then might assist in the development of narrative. Bruner (1996) similarly recognized the importance of Mindfulness in maintaining mental abilities longer by engaging older people in the responsibility of their environment.

Similarly, Mindfulness is finding value in the work of other contemporary educational psychologists. In Teaching for Thoughtfulness, Barell (1995) 
described Langer's concept of Mindfulness as "meaning conscious, deliberate thought about goals, strategies and opinions" and applies its usefulness to his work on Thoughtfulness. Barell (1995) defines Thoughtfulness as the need for educators to "help students recognize the attitudes they have toward themselves as thinkers and their attitudes toward others" and continues by adding Mindfulness "is a very valuable concept for our work" (p. 6).

\section{Mindful Education}

Mindfulness as an individualized or personalized style of instructional strategy appears to have some support from educational research. Boggiano, Main, and Katz (1988) found that children with higher perceptions of competence and personal control reported more intrinsic interest in school-related activities and a greater preference for more challenging activities. Moreover, use of controlling directives has been found to impair creativity, intrinsic motivation, and enjoyment (Koestner, Ryan, \& Bernieri, 1984). However, Koestner, Ryan, and Bernieri's (1984) study suggested that it is not the fact of constraints that adversely affects the student per se, but rather the psychological and affective meaning of those constraints that predicts their impact.

Will White (1998) suggested that Mindful instruction and learning can be achieved through experiential education or the "process through which a learner constructs knowledge, skill, and value from direct experience" (p. 3). Each learner in Mindful education individually constructs meaning as he or she learns. In constructing meaning, learning is achieved. Still, others question whether 
Mindfulness is a cognitive ability, a personality trait, or cognitive style (Sternberg, 2000). Only by additional research will the understanding of what constitutes a Mindful education be fully understood. With understanding, implications and applications of Mindfulness as an effective educational tool then can be achieved to increased student success.

\section{Mindful Methods of Instruction}

Different teaching methods can cultivate Mindfulness in students. One teaching method that can possibly promote Mindful learning is through conditional instruction. Langer (1989) defined conditional instruction as instruction that "allows the processing of information with some uncertainty." In their studies on conditional versus absolute instruction, Langer and Piper (1987) argued that instruction which is a "conditional or probabilistic view of the world would enable subsequent cognitive flexibility" (p. 281). Absolute instruction, conversely, implies instruction whereby information and language are presented in discrete categories (e.g., absolute terms) with an unchanging, non-evolving view of the category (e.g., an absolute view of a term's definition) or process. Langer and Piper's (1987) study suggested that absolute instruction perpetuates Mindless behavior in students. This and its subsequent replication study (Langer, Hatem, Joss, \& Howell, 1989) suggested that conditional instruction in fact does foster Mindful learning. Students were able to think of more creative uses for objects, cognitively adapt to changes in information, and were better able to use information in other contexts. Similarly, conditional instruction was 
found to be also effective when the information presented was unfamiliar, rather than familiar. However, Boggiano, Main, and Katz (1988) suggested that "a confident teacher using conditional language should imply to students that the uncertainty is an attribute of the information conveyed and not an attribute of the person" (p. 141).

Other benefits for conditional instruction have been noted in the research as well. In his extensive studies of on-line instruction, Patrick Fahy (1999) suggested that in order to increase attention and maintain learner focus, create moderate uncertainty about what is about to happen next or what the eventual outcome of a presentation will be. While the research suggests positive results in creativity by using conditional rather than absolute language, Mindful instruction of content also appears to have positive consequences in student learning.

Another method for employing Mindfulness in teaching is using relevance as a tool. Studies conducted by Lieberman and Langer (as cited in Langer, 1997) demonstrated that students making the material meaningful to themselves were able to retain the information and use it in more creative ways. Similarly, material that was presented with and without immediate relevance showed that those students with immediate relevance to the material processed the information whereas those with no pertinent relevance to the material had trouble even recalling information. Thus, the context (relevant or not relevant) of initial exposure to information limits its subsequent use (Chanowitz \& Langer, 1981). 


\section{Contrasting Views on Mindfulness}

While the research on the efficacy of Mindfulness looks promising, the relative newness of the concept, contrasting research and literature, and a lack of empirical studies from educators and researchers not associated with Dr. Langer prevent Mindfulness from being accepted unequivocally as an effective educational tool and concept. Having just been developed over the last 20 years, Mindfulness has yet to be legitimized through time as a "tried and true" instructional method and not simply an example of a passing ideology for instruction. Also, research and literature exist that do not support the principles of Mindfulness or the research findings of Dr. Langer. For example, in a replication study of Mindlessness by Langer, Blank, and Chanowitz, Folkes (1985) found that "although everyday social interactions may often be less than completely mindful, they do not appear to be as mindless (automatic) as might have been surmised from the results reported by Langer et al. "

Cunningham and Thorkildsen (1996) found no statistical significance in their study of Mindful activities related to the acquisition, application, and transfer of complex knowledge in comparison to a more traditional instructional method. Similarly, Benassi, Mahler, and Asdigian (1993) concluded from their study that the concept of Mindfulness is not adequately supported by the empirical evidence collected to date. Please note that much research on Mindfulness has been completed, reviewed, and analyzed since the publication of this article.

Still, students may not universally accept Mindfulness as well. In his 15 years of including Mindfulness in his teacher education programs, Miller (2004) 


\section{Mindfulness Education}

encountered two students who chose not to participate in the Mindfulness program. One student was a fundamentalist, and the other student refusing to participate in the Mindfulness program had recently had a severe traumatic experience and did not feel comfortable with the level of introspection that Mindfulness would bring. Thus, there is the possibility that the connotation of Mindfulness to Buddhism may hinder acceptance of Mindfulness as an instructional strategy. Worthington and Sandage (2001) found in their analysis of the literature pertaining to therapy and religion that highly religious clients appear to desire therapy that respects, if not integrates, their religion. Similarly, Greenberg and Witztum (1991) identified resistance to the process of assessment and therapy in strictly religious patients as one of the major problems in the interaction between therapist and client. For example, a fundamentalist may find a therapeutic or instructional approach such as Mindfulness difficult. For the fundamentalist, excessive reliance on the self rather than reliance on God for change or learning may conflict with his or her religious ideology. It should be noted, however, that Buddhist philosophy and values are not necessarily taught when incorporated into therapeutic or educational settings.

Reiss (2000) concluded too that people with high curiosity, low order, and high independence would be most strongly motivated to embrace Mindful thinking. He noted that people of low curiosity, high order, and low independence may experience discomfort when asked to break from traditional learning or to think more independently. 


\section{Mindfulness Education}

\section{Potential Value of Mindfulness in Education}

Ritchhart and Perkins (2000) suggested that the real educational potential of Mindfulness lies not in the immediacy of higher test scores, but in developing the "flexible transfer of skills and knowledge to new contexts, the development of deep understanding, student motivation and engagement, the ability to think critically and creatively and the development of more self-directed learners" (p. 29). Ultimately, is it not the goal of education to promote transferable high-order cognitive skills within the learner so that all information, irrelevant of context, can be manipulated for greater understanding? Macaulay and Cree (1999) concurred with this notion in their statement that, "A prime ability involved in transfer of learning is that which allows the student to identify similarities between the new or novel situation and previous situations" (p. 187). Mindful instruction, then, has the potential to be useful in developing these skills.

In forming the curriculum for the National Institute for Literacy, Marilyn Gillespie stated the underlying principle that, "Effective learning requires not only the acquisition but also active application of knowledge, skills, and processes. To encourage transfer to other contexts, effective learning requires the acquisition of a complex knowledge base including content knowledge, skills, and cognitive and metacognitive strategies" (Gillepsie, 2002, p. 1). A study by Wong (1994) suggested that mediated Mindfulness was effective in promoting the transfer of learned strategies in students with learning disabilities. 


\section{Research Questions}

The current study attempts to examine whether there are instructional or learning implications in education based on the level of a student's propensity for Mindfulness after participating in Mindful Instruction and meditation. Research Question 1: Does a student's propensity for Mindfulness have an effect on learning when a student participates in Mindful Instruction and meditation.

Research Question 2: Does Mindful Instruction and meditation affect a student's state of Mindfulness. The theory of Mindfulness as an instructional tool and its usefulness as an instructional strategy are relatively recent, with much more research and discussion needed. Mindfulness in educational psychology needs further explanation in regard to its cognitive and behavioral constructs. Better understanding of the psychological nature of Mindfulness will help successfully apply this concept to education in order to reach its full potential as an effective instructional strategy and goal.

While much of the research has focused on Mindfulness merely as a short-term state of consciousness, there is some evidence that embedding Mindfulness as an enduring trait or quality may have benefit for the learner. Ritchhart and Perkins (2000) examined aspects of Mindfulness both as a disposition (trait) and as a state. They explored Mindfulness as a state through their use of conditional teaching in their qualitative case studies. Conditional teaching (Langer, Hatem, Joss, \& Howell, 1989) is instruction that "allows the processing of information with some uncertainty." Their example of conditional teaching is meant to model how to develop the disposition of Mindfulness. 


\section{Mindfulness Education}

However, Mindfulness has also been repeatedly referred to as a "subjective state" (Langer \& Moldoveanu, 2000), a "flexible state" (Langer, 2000), and as a "state of mind" (Langer, 2000). Whether Mindfulness is a state or a disposition (trait), how do we create Mindful learning experiences for students so that they are better able to examine information from new perspectives, problem solve using critical thinking skills, and transfer learning to new situations? One possibility for engaging students to use such skills and behaviors could be combining the traditional form of Mindfulness meditation as defined by Hanh (1991) with the Mindfulness applied in education as defined by Langer (1993). For the purposes of this paper and current research study, this combined use of the traditional form of Mindfulness meditation and Langer's application of Mindfulness in education is referred to as Mindful Instruction and meditation or just Mindful Instruction. Could the use of a combined Mindful Instruction and meditation possibly affect a student's learning? Also, does a student's propensity for Mindfulness have an effect on learning when a student participates in Mindful Instruction and meditation? Examining the effects of Mindful Instruction and meditation on a student's propensity for Mindfulness may help identify the level of impact that such instruction and meditation can have on learning.

Sufficiently validated and appropriate assessment tools have only recently been developed to measure the construct of Mindfulness. Brown and Ryan (2003) developed the Mindful Attention-Awareness Scale (MAAS) to measure the disposition of Mindfulness. The MAAS measures the traditional form of Mindfulness as defined by Hanh (1991). Langer has developed the Langer 
Mindfulness Scale (LMS) to measure an individual's propensity for Mindfulness. Webster's Dictionary defined propensity as "A natural inclination; innate or inherent tendency" (Merriam Webster's Third New International Dictionary, 1981). The LMS measures four domains: novelty-seeking, engagement, novelty producing, and flexibility (Langer Mindfulness Scale, 2005). More research is needed to determine whether Mindful Instruction can lead to developing Mindfulness as a disposition. Ritchhart and Perkins (2000) identify three instructional practices to develop Mindfulness as a disposition: (a) looking closely, (b) exploring possibilities and perspectives, and (c) introducing ambiguity.

If an individual's propensity for Mindfulness is a disposition (trait), individuals would score relatively consistent from test to retest on the LMS provided that the time period between testing is sufficiently spaced. If Mindfulness is also a "state of mind" (state), then perhaps Mindful Instruction and meditation could influence a student to have temporary (state-like) Mindfulness. This could be assessed behaviorally by using assessment and psychometric tools that measure components of Mindfulness such as attention, awareness, and fluency (cognitive flexibility). These measures of Mindfulness may give an indication of whether Mindful Instruction and meditation affects the Mindfulness behavior of students. Effectiveness of the Mindful Instruction and meditation on learning could be measured by the accuracy and number of correct responses on tests that cover the content of a given topic. 


\section{Mindfulness Education}

\section{Implications}

Implications for education in understanding the effects of Mindful Instruction and meditation are numerous. If a student with high or low levels of propensity for Mindfulness shows increased learning after Mindful Instruction and meditation, then modifying instruction to promote the student's propensity to engage in Mindful learning may increase student problem-solving and criticalthinking skills. Similarly, if Mindful Instruction and meditation can create a "statelike" (state) of Mindfulness in some students, curriculum that adequately challenges the student to maintain awareness and attention may increase learning for those students who otherwise find the learning process difficult. Thus, applying methods of instruction and incorporating meditation techniques into the classroom to create Mindful learners might enhance and increase student learning. Mindful Instruction and meditation could help produce Mindful students who are able to creatively process and apply new information (by drawing novel distinctions and examine information from new perspectives) and transfer information to new contexts (by being sensitive to context). And if instruction creates a state of Non-Mindfulness in students, educators may want to re-evaluate curriculum which students do not fully process. This failure to process information meaningfully may become apparent by failed attempts to recall information or by not developing skills learned in education and applying these skills to everyday real-life problems.

The focus of this literature review was an attempt to examine the components that constitute a Mindful education. By looking at Mindfulness 
broadly from three settings (teacher education programs, clinical and therapeutic settings, and classroom/instructional settings) and examining their subsequent applications, it was my desire to find educational components from each and establish some commonality that broadly constitutes Mindful education. Most notably, these settings and applications share a metacognitive quality emphasizing flexible awareness of the present moment. However, the differences in these settings and applications must be noted as well. For example, Langer's use of Mindfulness as an instructional strategy relies on external stimuli (e.g., instructional materials or aids, curriculum) and focuses less on the internal processes of reflection and contemplation of traditional Mindfulness found in teacher education programs or in Mindfulness Based Stress Reduction or Mindfulness Based Cognitive Therapy. Langer (1989) also emphasized the very different historical and cultural backgrounds between the two forms of Mindfulness (i.e., Mindfulness applied to the educational setting and Hanh's traditional practice of Mindfulness). Nevertheless, Mindfulness, at the present moment, appears to be an increasingly popular instructional method that many counselors, teachers, and people in society are using to further learning and education, whether the content is academics or personal well-being. 


\section{Chapter 2}

Method

\section{Participants}

Undergraduate students $(n=72)$ were selected to participate in this study. These 72 undergraduate students were selected from returned responses of the Langer Mindfulness Scale (LMS) questionnaire sent to the various residence halls, introductory psychology courses, and introductory educational psychology courses. Half of the students selected $(n=34)$ had scored high on the LMS, suggesting that these students have a high level of propensity for Mindfulness. These students had scores $>116$. The remaining students selected $(n=38)$ had scored low on the LMS, suggesting that these students have a low level of propensity for Mindfulness. These students had scores $<110$. Thus, it was necessary to obtain at least 120 LMS initial returns so that students scoring relatively high and low may be identified for the research. Overall, 190 LMS questionnaires were returned from which the participants were selected. From the 190 questionnaires, participants were selected from the 40 highest scores (High Mindfulness Group) and the 40 lowest scores (Low Mindfulness Group). Participants were compensated fifteen dollars $(\$ 15.00)$ for completing all aspects of the study. Participants in some Psychology and Educational Psychology classes were given extra credit in addition to the monetary compensation for completing all aspects of the research study (See Appendix L). Institutional Review Board approval was obtained, and ethical principles were observed in the conduct of the investigation. 


\section{Instruments}

Students were asked to complete the 21 question Langer Mindfulness Scale (LMS) as a test-retest. The LMS questionnaire is shown in Appendix A. The LMS takes about five minutes to complete. This 21 question scale assesses four domains: novelty-seeking, engagement, novelty producing, and flexibility. The LMS assesses individual differences in the propensity for Mindfulness. High or low scores from a large sample of LMS questionnaires could be indicative of a high or low propensity for Mindfulness. Two content tests, based on the Mindful and Non-Mindful Instruction of two topics (Math and Disability) were given to all 72 participants. These two content tests are found in Appendix B. The content tests of the two topics (Math and Disability) are the same for both Mindfulness Groups (High Mindfulness and Low Mindfulness). Each content test is comprised of 30 possible answers.

In addition to the two content tests, participants were asked to complete two measures of Mindfulness. The "Modified Guilford Test of Alternative Uses" was the first measure of Mindfulness and used to measure the fluency construct of Mindfulness. Participants were shown four everyday items (brick, newspaper, shoe, and paperclip) and asked to list as many possible uses for each item. Participants were assessed on the total number of responses for each item. The "Modified Guilford Test of Alternative Uses" is located in Appendix C. The second measure of Mindfulness used was embedded statements or phrases in the content tests and on a Math pre-test. These embedded measures of 
Mindfulness were counterintuitive to logic. For example, in the Math content test, a word problem states:

An airplane traveling from Charleston, West Virginia to Erie, Pennsylvania crashes with 12 Massachusetts' citizens aboard. The Pennsylvania border is 350 miles from Charleston, West Virginia. The plane was off the radar screen, but the plane fell from the sky somewhere around the West Virginia-Pennsylvania border. If the plane's take off was gradual and the plane fell 400 miles straight down from the sky having already logged 500 miles, in what state would the survivors be buried and why?

The word survivor is counterintuitive to the participant who will want to logically answer the question using the Pythagorean Theorem about the plane crash. Assessment occurred when the participant demonstrated or did not demonstrate his or her awareness of the counterintuitive phrase or statement. A description and listing of embedded measures for Mindfulness are in Appendix D.

\section{Design}

The research design is a $2 \times 2 \times 2$ mixed design with one betweensubjects independent variable and two within-subjects independent variables. Mindfulness Groups (High Mindfulness versus Low Mindfulness) is a betweensubjects independent variable. Instruction Type (Mindful Instruction versus NonMindful Instruction) is a within-subjects independent variable. Topic (Math 
versus Disability) is a within-subjects independent variable. The dependent variables were scores on content tests (Math and Disability) and scores on two measures of Mindfulness ("Modified Guilford Test of Alternative Uses" and the embedded measures of Mindfulness). This design is depicted in Table 1.

Table 1

Propensity for Mindfulness by Mindfulness Groups by Instruction Type and Topic Instruction Type

\begin{tabular}{cccccc} 
& \multicolumn{2}{c}{ Mindful Instruction } & & \multicolumn{2}{c}{ Non-Mindful Instruction } \\
\cline { 2 - 3 } \cline { 5 - 6 } \cline { 5 - 6 } Mindfulness Groups & Disability & Math & & \multicolumn{2}{c}{ Dopic } \\
\cline { 2 - 3 } High Mindfulity & Math \\
Low Mindlessness & $1-16$ & $35-54$ & & $35-54$ & $1-16$ \\
\hline
\end{tabular}

Note. The 72 participants are indicated in the block diagram above. As may be noted, participants 1-16 received Mindful Instruction in Disability and Non-Mindful Instruction in Math.

\section{Procedure}

The students recruited for this study were from the campus of West Virginia University, the state's major research land-grant institution. Through the college newspaper, flyers, and postings on the introductory psychology and 


\section{Mindfulness Education}

educational psychology list-serves, students were recruited for possible participation in this study. Recruitment material is found in Appendix J. The primary investigator emailed a Langer Mindfulness Scale (LMS) to prospective participants, a demographic section to complete, and two opportunities for students to self-rate his or her level of previous knowledge of both Topics (Math and Disability). Email correspondence to prospective participants is found in Appendix K. Participants were selected from high or low scores on the LMS and classified into one of two Mindfulness Groups (High Mindfulness versus Low Mindfulness). High or low scores are indicative of persons who report a propensity for High Mindfulness or Low Mindfulness. A person with a high score (>116) on the LMS was classified as having a high propensity for Mindfulness and put in the High Mindfulness Group. A person with a low score on the LMS (< 110) was classified as having a low propensity for Mindfulness and put into the Low Mindfulness Group. The exact range of scores for each classification was determined after the responses of the initial 190 LMS questionnaires sent to potential participants were scored. The range of scores for students categorized into the High Mindfulness Group was between 117 and 139. The range of scores for students categorized into the Low Mindfulness Group was between 87 and 109. The maximum score on the LMS is 147.

The High Mindfulness and Low Mindfulness Groups were divided into four Groups based on the level of the participant's propensity for Mindfulness and the Type of Instruction (Mindful versus Non-Mindful) by topic (Math and Disability) the participant received. Each group took part in two Types of Instruction 
(Mindful versus Non-Mindful) on two Topics (Math and Disability). Group 1 (Participants 1-16) consisted of participants with the propensity for High Mindfulness who received Mindful Instruction in Disability and Non-Mindful Instruction in Math (see 1-16 in Table 1). Group 2 (Participants 17-34) consisted of participants with the propensity for Low Mindfulness who received Mindful Instruction in Disability and Non-Mindful Instruction in Math (see 17-34 in Table 1). Group 3 (Participants 35-54) consisted of students with the propensity for High Mindfulness who received Mindful Instruction in Math and Non-Mindful Instruction in Disability (see 35-54 in Table 1). Group 4 (Participants 55-72) are students with the propensity for Low Mindfulness who received Mindful Instruction in Math and Non-Mindful Instruction in Disability (see 55-72 in Table 1). Criteria for the Mindful Instruction for both Topics (Math and Disability) are listed in Appendix E and Appendix F respectively and included a 10-minute Mindfulness meditation prior to the start of the instruction. Criteria for the NonMindful Instruction for both Topics (Math and Disability) are listed in Appendix E and Appendix F respectively and did not have Mindfulness meditation.

Participants were notified by email that they had been selected to participate in the research study. This email notification required the chosen participant to confirm by way of a reply email whether he or she would participate in the study. This email notification also included the date and location where the research would take place, criteria for being compensated, a brief overview of what participating in the study involved, and the group number assigned to the student. The researcher then sent a reminder email the day before the 


\section{Mindfulness Education}

participant was expected to attend the study. Email correspondence is found in Appendix K. The Mindful and Non-Mindful Instruction took place in a classroom regularly used for teaching at West Virginia University. During this two-hour meeting, students were asked to complete (a) a retest of the Langer Mindfulness Scale (LMS), (c) the Mindfulness Attention-Awareness Scale (MAAS), (b) an Instruction in Math (Mindful or Non-Mindful), (c) a pre-test in Math, (d) a content test for the Math topic, (e) one measure of Mindfulness ("Modified Guilford Test of Alternative Uses”), (f) an Instruction in Disability (Mindful or Non-Mindful), and (g) a content test for the Disability topic. After completing all components of the meeting, students were excused from the classroom and given monetary compensation (fifteen dollars) upon exiting.

Upon arrival at the designated classroom and time, participants were presented a brief overview of the meeting. During this overview, participants were told the format and schedule of the meeting and thanked for their time, effort, and patience in participating in the study. Participants were given a copy of Internal Review Board (IRB) approval stating participants' rights for participating in the research study. Participants then were asked to retake the LMS. The LMS is located in Appendix A. After all students had completed the LMS, participants were given the MAAS to complete. The MAAS can be found in Appendix G.

Participants were instructed (either Mindful or Non-Mindful) in Math on the subject of the Pythagorean Theorem. Upon completion of the Math Instruction, participants completed the first measure of Mindfulness, the "Modified Guilford 
Test of Alternate Uses." The "Modified Guilford Test of Alternate Uses" is located in Appendix C. The participants then were asked to complete a Math pre-test that had two embedded measures of Mindfulness within the test. These embedded measures of Mindfulness can be found in Appendix D. Participants were given a content test on the Math Instruction. This content test on Math can be found in Appendix B. After the content tests on Math, students received the second Instruction (either Mindful or Non-Mindful) on Disability. The subject of the Disability Instruction was using People First Language which is the appropriate use of language when talking to or about people with disabilities. After completion of the Disability Instruction, students completed a content test on the Disability Instruction. This content test on Disability is located in Appendix B.

All variations of Mindfulness Groups (High Mindfulness and Low Mindfulness) receiving both Types of Instruction (Mindful and Non-Mindful) for each of the two Topics (Math and Disability) were present in the study. Each of the Topics (Math and Disability) with the Type of Instruction (Mindful or NonMindful) for each of the Mindfulness Groups (High Mindfulness or Low Mindfulness) are (a) Non-Mindful Math followed by Mindful Disability (High Mindfulness Group), (b) Mindful Math followed by Non-Mindful Disability (High Mindfulness Group), (c) Non-Mindful Math followed by Mindful Disability (Low Mindfulness Group), and (d) Mindful Math followed by Non-Mindful Disability (Low Mindfulness Group). 


\section{Mindfulness Education}

The instructor of the Math Topic was a graduate student who regularly teaches the subject matter (Pythagorean Theorem) to undergraduates. The instructor of the Disability Topic was the researcher of this study and has taught disability-related courses at the university as well. Each instructor taught a total of four instructions (two Mindful Instructions and two Non-Mindful Instructions) for his or her given Topic. The Math instructor was trained by the researcher on how to teach the Mindful and Non-Mindful Instruction. A checklist was used to insure that the Mindful Instruction and Non-Mindful Instruction met the Mindful or NonMindful criteria set for each Topic's content. The checklists for the Mindful Instruction of Math and Disability and the Non-Mindful Instruction of Math and Disability are found in Appendix $\mathrm{H}$ and Appendix I respectively. These checklists of criteria for the Mindful Instruction and Non-Mindful Instruction, as well as the content (Math and Disability), were developed by the researcher and the instructors with guidelines from the researcher's dissertation committee. The directions, criteria, and content of the Mindful Instruction and Non-Mindful Instruction for both Math and Disability are found in Appendix E and Appendix F respectively.

Each instructional lesson (Math and Disability) was videotaped by the researcher and observed by two trained observers. These two impartial observers attended a two-hour training session on identifying Mindful Instruction and Non-Mindful Instruction and how to use the checklist of criteria. The observers were taught by role-playing and examples. The researcher and trained observers used the checklist (based on the criteria of Mindful Instruction 


\section{Mindfulness Education}

and Non-Mindful Instruction) to insure that the same content was covered by both instructions and that both instructions met the Mindful and Non-Mindful Instruction criteria found in Appendix E and Appendix F). The researcher and trained observers reviewed the checklist after each session to determine that all instruction and content criteria were met. The videotape from that session was reviewed in determining whether the criteria had or had not been met.

After each session, the primary investigator and two trained observers consulted and evaluated the instruction for (a) consistency of content taught and (b) meeting the Mindful or Non-Mindful Instruction criteria. The researcher and two observers concluded after each session that all the criteria for Mindful and Non-Mindful instruction were met. Upon examining and scoring all assessment instruments, the researcher and two observers agreed too that tests for each session demonstrate that the same subject matter (Math and Disability) for both Types of Instruction (Mindful and Non-Mindful) was taught.

The Math Instruction covered the Topic of the Pythagorean Theorem. Each instruction included an explanation of the Pythagorean Theorem in a 25 minute lesson. Unlike the Non-Mindful Instruction on Math, the Mindful Instruction on Math began with a 10-minute Mindfulness meditation played for the participants. Participants were asked to engage in the meditation as a part of the instruction. This meditation was played from a recording on a web-based interfaith web-site (Mindfulness meditation, 2005). The Mindful Instruction also involved the instructor's use of conditional language (e.g., use of words like could or can) with instruction that problem solves with ideas generated from the 
students. The examples were relevant and relatable to the everyday life experiences of the students. The Non-Mindful Instruction on Math was rule and number based with equations being memorized and examples with no real relevance to the students' lives. For a further examination of the content information and the components and criteria that constitute the Math Instruction as Mindful Instruction or Non-Mindful Instruction, see Appendix E.

The content test on Math required students to be able to compute as well as apply the concept of the Pythagorean Theorem. For example, students were given a triangle with numbers on two of its three sides. The students were required to find the missing number for the unknown side. Similarly, students were given word problems involving the Pythagorean Theorem to solve. The same content test was used for both Types of Instruction (Mindful and NonMindful) of Math Topic for both Mindfulness Groups (High Mindfulness and Low Mindfulness). The Math content test can be found in Appendix B.

The content of the Disability Topic involved definitions associated with disability (handicap, impairment, etc.) and proper use of People First Language (PFL). People First Language (PFL) is the proper use of language and communication when referring to or talking about people with disabilities. PFL demonstrates respect in communicating about disability by emphasizing the person first and the disability second, thus focusing on the individual and not what could be perceived as focusing on a person's weaknesses or differences. An example of using PFL is referring to a person as "a child with a congenital disability" rather than "a child with a birth defect." Though the content of the 


\section{Mindfulness Education}

information was the same, the Instruction (Mindful versus Non-Mindful) was different. The Mindful Instruction on Disability began with a 10-minute Mindfulness meditation (Mindfulness meditation, 2005). Participants were asked to engage in the meditation as a part of the instruction. This was played for the participants from a recording on a web-based interfaith web-site. Using the same recording allowed for consistency with all Mindfulness Groups (High Mindfulness and Low Mindfulness) receiving the same meditation. The Mindful Instruction of Disability allowed students to generate examples of phrases (i.e., Mindful Instruction) that reflect the use of PFL. The Non-Mindful Instruction on Disability presented examples of phrases that do and do not reflect use of PFL but in a yes or no format (i.e., Non-Mindful Instruction). For a further examination of the content information and the components and criteria that constitute the Instruction as Mindful Instruction or Non-Mindful Instruction, see Appendix F. The Disability content test required participants to identify examples of proper use of PFL in a fictional news story. The content tests were graded according to the number and accuracy of correct identifications. The same content test was given to both Types of Instruction (Mindful and Non-Mindful) of Disability Topic for both Mindfulness Groups (High Mindfulness and Low Mindfulness). The Disability content test can be found in Appendix B.

Analysis

The analyses involved descriptive and inferential statistics designed to answer the research questions. Inter-rater reliability of all assessment 
instruments was calculated using point-by-point agreement. The formula for Inter-rater Reliability $=[($ Disagreements $) /($ Total Number of Responses $)] \mathrm{X}$ 100\%. Discrepancies were resolved by discussion and mutual agreement. Statistical Analysis System Version 9.1 (SAS) was used to compute the data. A two-way analysis of variance was performed on the interaction of Mindfulness Groups (High Mindfulness versus Low Mindfulness) with Instruction Type (Mindful versus Non-Mindful). Mindfulness Groups was a between-subjects independent variable and Instruction Type was a within-subjects independent variable in a $2 \times 2$ mixed-model analysis of variance. Scores on the content tests was the dependent variable. A two-way analysis of variance was conducted on the interaction of Mindfulness Groups (High Mindfulness versus Low Mindfulness) with Topic (Math versus Disability). Mindfulness Groups was a between-subjects independent variable and Topic was a within-subjects independent variable in a $2 \times 2$ mixed-model analysis of variance. Scores on the content tests was the dependent variable. A one-way analysis of variance was completed on each Topic (Math and Disability). Scores on the content tests was the dependent variable on each one-way analysis of variance.

In order to examine the effects of a participant's previous knowledge of subject matter (Math and Disability) on Topics (Math and Disability), 4 two-way analyses of variance and 2 one-way analyses of variance were conducted. The Math content test scores or the Disability content test scores was the dependent variable in all analyses involving participant's previous knowledge of subject matter (Math and Disability). Mindfulness Groups was a between-subjects 
independent variable and Self-Rating Groups was a between-subjects independent variable in the four $2 \times 2$ analyses of variance. Self-Rating Groups was the between-subjects independent variable in each one-way analysis of variance. Two Tukey tests were calculated to determine the level of significance among the different Self-Rating Groups for each Topic (Math and Disability).

Test-retest consistency of the Langer Mindfulness Scale and correlation to the Mindfulness Attention-Awareness Scale was calculated. A Pearson ProductMoment Correlation was computed to assess the test-retest consistency of the LMS. Test-retest consistency of the pre-LMS and post-LMS was proposed to have a strong relationship, suggesting that an individual's propensity for Mindfulness is a disposition (trait) provided that the time period between testing is sufficiently spaced. Pearson Product-Moment Correlations also were computed to assess (a) the correlation between the Langer Mindfulness Scale (pre-test) and the Mindfulness Attention-Awareness Scale and (b) the correlation between the Langer Mindfulness Scale (post-test) and the Mindfulness AttentionAwareness Scale.

In order to examine the effects of Instruction Type (Mindful versus NonMindful) on the "Modified Guilford Test of Alternate Uses," a two-way analysis of variance was conducted. Mindfulness Groups (High Mindfulness versus Low Mindfulness) was a between-subjects independent variable and Instruction Type was a between-subjects independent variable in a $2 \times 2$ analysis of variance. The scores on the "Modified Guilford Test of Alternate Uses" was the dependent variable. 


\section{Mindfulness Education}

In order to examine the effects of Instruction Type (Mindful versus NonMindful) on the embedded measures of Mindfulness, 2 two-way analyses of variance and a one-way analysis of variance were performed. One two-way analysis of variance was for the embedded measures of Mindfulness in the Math Topic. The other two-way analysis of variance was for the embedded measures of Mindfulness in the Disability Topic. Mindfulness Groups was a betweensubjects independent variable and Instruction Type was a within-subjects independent variable in a two $2 \times 2$ mixed-model analysis of variance. Scores on the embedded measures of Mindfulness for each Topic (Math and Disability) was the dependent variable for each two-way analysis of variance. A one-way analysis of variance also was performed on the total score of the embedded measures (Math + Disability) after both Types of Instruction (Mindful and NonMindful). The combined scores of the embedded measures (Math + Disability) was the dependent variable. 


\section{Mindfulness Education}

\section{Chapter 3}

\section{Results}

The investigation was designed to determine the effects of (a) Mindfulness Instruction and (b) the propensity of Mindfulness on learning. Mindfulness Groups (High Mindfulness versus Low Mindfulness) are proposed to interact with Type of Instruction (Mindful versus Non-Mindful) replicated across Topics. Additional analyses considered the potential effects of Mindfulness Instruction and the propensity of Mindfulness (a) on previous knowledge of subject matter (Math and Disability), (b) on the test-retest consistency of the Langer Mindfulness Scale and correlation to the Mindfulness Attention-Awareness Scale), (c) on Topic test scores (Math and Disability), (d) on the "Modified Guilford Test of Alternate Uses," and (e) on embedded measures of Mindfulness.

\section{Inter-rater Reliability}

Inter-rater reliability was calculated for each assessment instrument used in the research study. The assessment instruments that were scored for the study included the (a) embedded measures of Mindfulness for Math and Disability, (b) the pre-LMS, post-LMS, and MAAS, (c) the "Modified Guilford Test of Alternate Uses," and (d) the content tests for Math and Disability. Inter-rater reliability of all assessment instruments was calculated using point-by-point agreement. The researcher and a doctoral student scored all tests except the Math content test. The Math content test was scored by the Math instructor of the Math Topic and a Math graduate teaching assistant. The researcher trained 
all graders in individual two hour meetings outlining the conditions for grading a response correct or incorrect. The researcher masked all tests for any identifying information, including the participant's Mindfulness Group (High Mindfulness Group or Low Mindfulness Group) and the Type of Instruction (Mindful or Non-Mindful) the participant received. The inter-rater reliability for each assessment instrument was (a) $99.5 \%$ for the embedded measures of Mindfulness for Math Topic, (b) $92.4 \%$ for the embedded measures of Mindfulness for Disability Topic, (c) $100 \%$ for the pre-LMS, post-LMS, and MAAS, (d) $91.5 \%$ for the Math content test, and (e) $52.1 \%$ for the Disability content test. The reasons for the low inter-rater reliability for the Disability content test were two consistent errors in grading by the doctoral student. Had these two consistent errors not occurred, inter-rater reliability would have been $85.4 \%$. The formula used in this study was Inter-rater Reliability $=$ [(Disagreements) / (Total Number of Responses)] X 100\%. Discrepancies were resolved by discussion and mutual agreement.

Interaction of Mindfulness Groups with Mindful and Non-Mindful Instruction (Research Question 1, First Part)

Does a student's level of propensity for Mindfulness have an effect on learning when a student participates in Mindful Instruction and meditation? In Research Question 1, Mindfulness Groups (High Mindfulness versus Low Mindfulness) was proposed to interact with Mindful Instruction and meditation. Each Mindfulness Group (High Mindfulness and Low Mindfulness) was 
determined by the Langer Mindfulness Scale scores (High Mindfulness > 116 and Low Mindfulness < 110). The High Mindfulness Groups and Low Mindfulness Groups were homogeneous groups of participants with similar levels of propensity for Mindfulness. Both Mindfulness Groups (High Mindfulness and Low Mindfulness) participated in two types of Instruction (Mindful and NonMindful). Mindfulness Groups was a between-subjects independent variable and Instruction Type was a within-subjects independent variable in a $2 \times 2$ mixedmodel analysis of variance. The dependent variable was scores on the content test (Range 0 to 30 for each test).

This two-way analysis of variance yielded a statistically significant main effect for Mindfulness Groups, $F(1,70)=5.21, p<.05$. This main effect is illustrated in Figure 1. As may be noted there, the High Mindfulness Group scored higher on the content tests than the Low Mindfulness Group. The main effect for Instructional Type was not statistically significant, $F(1,69)=0.20$, NS, as shown in Figure 2. The interaction of Mindfulness Groups by Instruction Type was statistically non-significant, $F(1,69)=1.70$, NS, depicted in Figure 3. Thus, the data suggest that the participant's propensity for Mindfulness and subsequent classification into the High Mindfulness or Low Mindfulness Group was a statistically significant variable in determining higher or lower test scores. But as the data suggest, the main effect of Instruction Type and the interaction of Instruction Type by Mindfulness Groups played no statistical significance in determining scores on either content test. Analysis of variance results for each main effect and the interaction can be found in Table 2 . 
Table 2

Analysis of Variance for Interaction of Mindfulness Groups with Mindful and NonMindful Instruction

\begin{tabular}{lllll} 
Source & $d f$ & $M S$ & $F$ & $P$ \\
\hline Mindfulness Groups (MG) & 1 & 172.12 & $5.21^{*}$ & 0.025 \\
MG Between-Group Error & 70 & 33.04 & & \\
Instruction Type (IT) & 1 & 5.81 & 0.20 & 0.658 \\
MG X IT & 1 & 49.79 & 1.70 & 0.197 \\
IT Within-Subject Error & 69 & 29.37 & &
\end{tabular}

Note. ${ }^{*} p<.05$

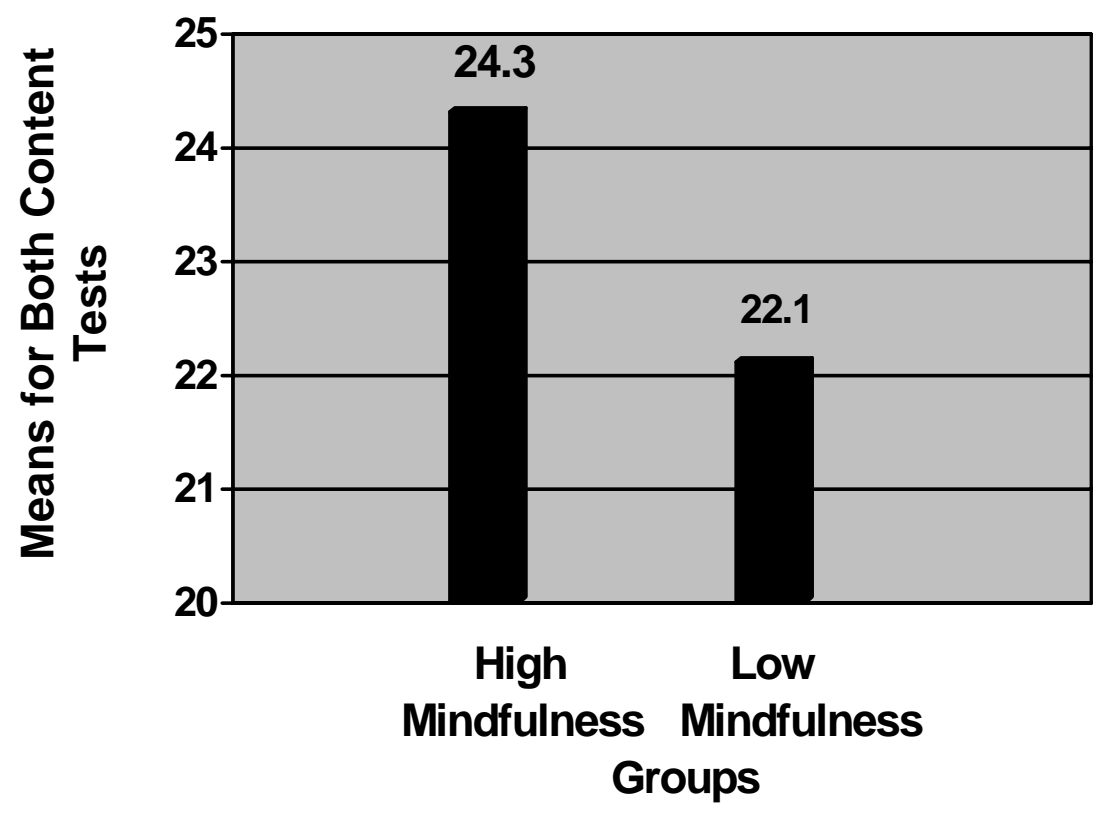

Figure 1. Means for Mindfulness Groups (High Mindfulness versus Low Mindfulness) for Both Content Tests (Math and Disability), $F(1,70)=5.21^{*}$, $p<.05$.

Note. Each participant had a mean for Math and Disability. 
Mindfulness Education

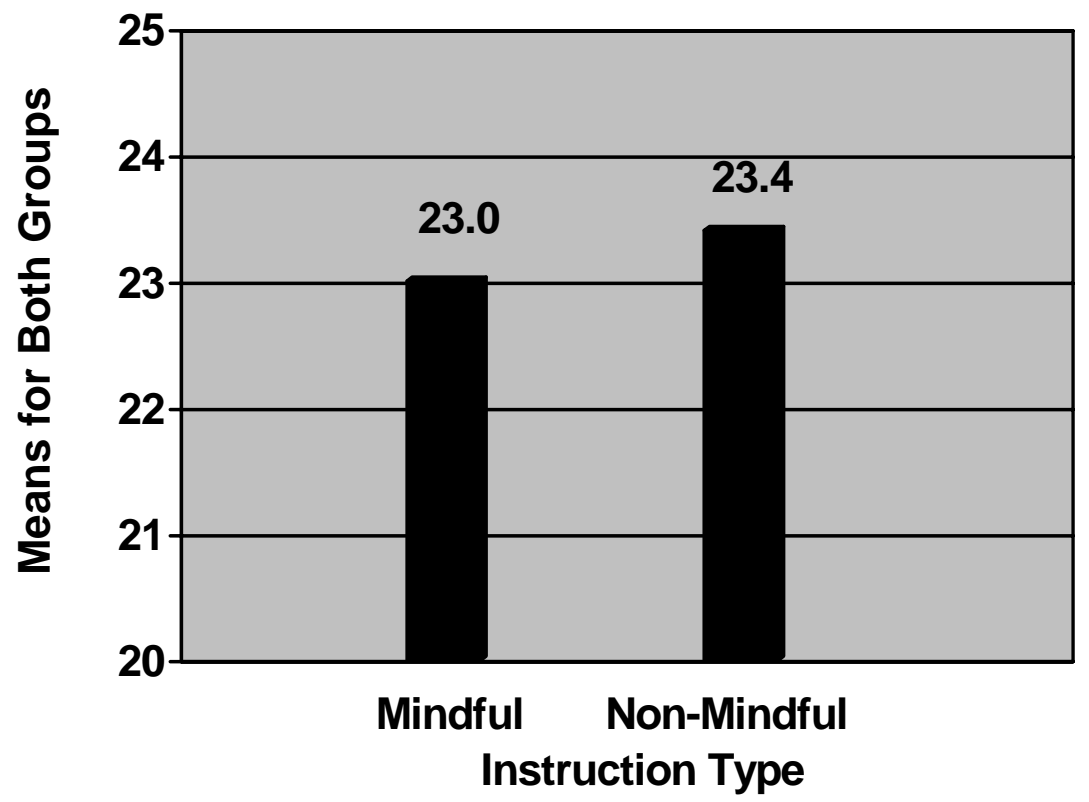

Figure 2. Means for both groups of participants by Instruction Type.

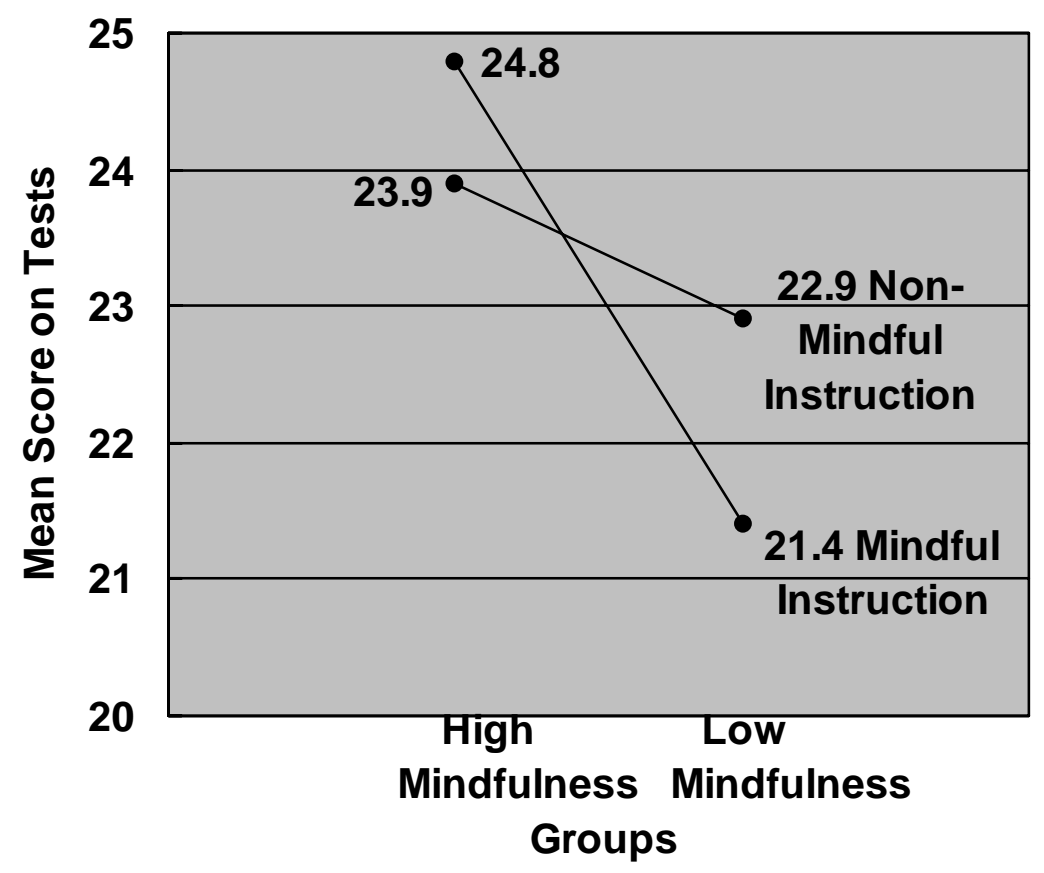

Figure 3. Mean Score on Tests (Disability and Math) with Mindful and NonMindful Instruction by Mindfulness Groups. 
Effects of Previous Knowledge of Subject Matter (Math and Disability) (Research Question 1, Second Part)

In Research Question 1, a participant's propensity for Mindfulness was proposed to have an effect on learning when a participant participated in Mindful Instruction and meditation. To determine the effect of previous knowledge of subject matter (Math and Disability) versus the effect of Mindful Instruction and meditation, participants self-rated their level of previous knowledge for both Topics (Math and Disability) when completing the initial selection questionnaire. Participants rated their previous knowledge of Math on a Likert scale from 1 to 5 (Beginner, Average, Intermediate, Above Average, and Superior, respectively). Participants also rated their previous knowledge of Disability on a Likert scale from 1 to 5 (Very Unfamiliar, Somewhat Unfamiliar, Average, Somewhat Familiar, and Very Familiar, respectively). These ratings were demonstrated to be valid through one-way analyses of variance (one for Math and one for Disability).

The first analysis of variance was for the Math self-rating (independent variable) on Math content test score (dependent variable). Four groups, rather than five groups, were included because a rating of "Beginner" was indicated by only one participant. This analysis yielded a significant difference among the four rating groups, $F(3,67)=5.07, p<.01$. A Tukey test was performed to determine where the difference among the four rating groups was statistically significant. The four rating groups were (a) Rating 2 (Average), (b) Rating 3 (Intermediate), (c) Rating 4 (Above Average), and (d) Rating 5 (Superior). The number of participants in each Rating Group is located in Table 3. The results from the 
Tukey test show that the difference was significant between Rating 2 versus Rating 4, (Difference of Means $=5.39, p<.01$ ) and for Rating 2 versus Rating 5 , (Difference of Means $=6.26, p<.01$ ). Data for this analysis of variance are represented in Figure 4.

The second analysis of variance was for the Disability self-rating (independent variable) on Disability content test score (dependent variable). This analysis yielded a significant difference among the five rating groups, $F(4,66)=$ $3.02, p<.05$ and is reflected in Figure 5. A Tukey test was performed to determine where the difference among the five rating groups was statistically significant. The five rating groups were (a) Rating 1 (Very Unfamiliar), (b) Rating 2 (Somewhat Unfamiliar), (c) Rating 3 (Average), (d) Rating 4 (Somewhat Familiar), and Rating 5 (Very Familiar). The results from the Tukey test show that the difference was significant between Rating 1 versus Rating 5 (Difference of Means $=7.68, p<.05)$. Data for this analysis of variance are represented in Figure 5. 
Table 3

Number of Participants by Mindfulness Groups for Rating Groups by Topic

\begin{tabular}{lccccr} 
& \multicolumn{5}{c}{ Math Rating Group } \\
\cline { 2 - 6 } Mindfulness Groups & 1 & 2 & 3 & 4 & 5 \\
\hline High Mindfulness & 0 & 3 & 9 & 9 & 13 \\
Low Mindfulness & 1 & 7 & 13 & 9 & 8
\end{tabular}

Disability Rating Group

\begin{tabular}{lccccc}
\cline { 2 - 6 } Mindfulness Groups & 1 & 2 & 3 & 4 & 5 \\
High Mindfulness & 3 & 7 & 10 & 12 & 2 \\
Low Mindfulness & 4 & 11 & 12 & 9 & 8 \\
\hline
\end{tabular}

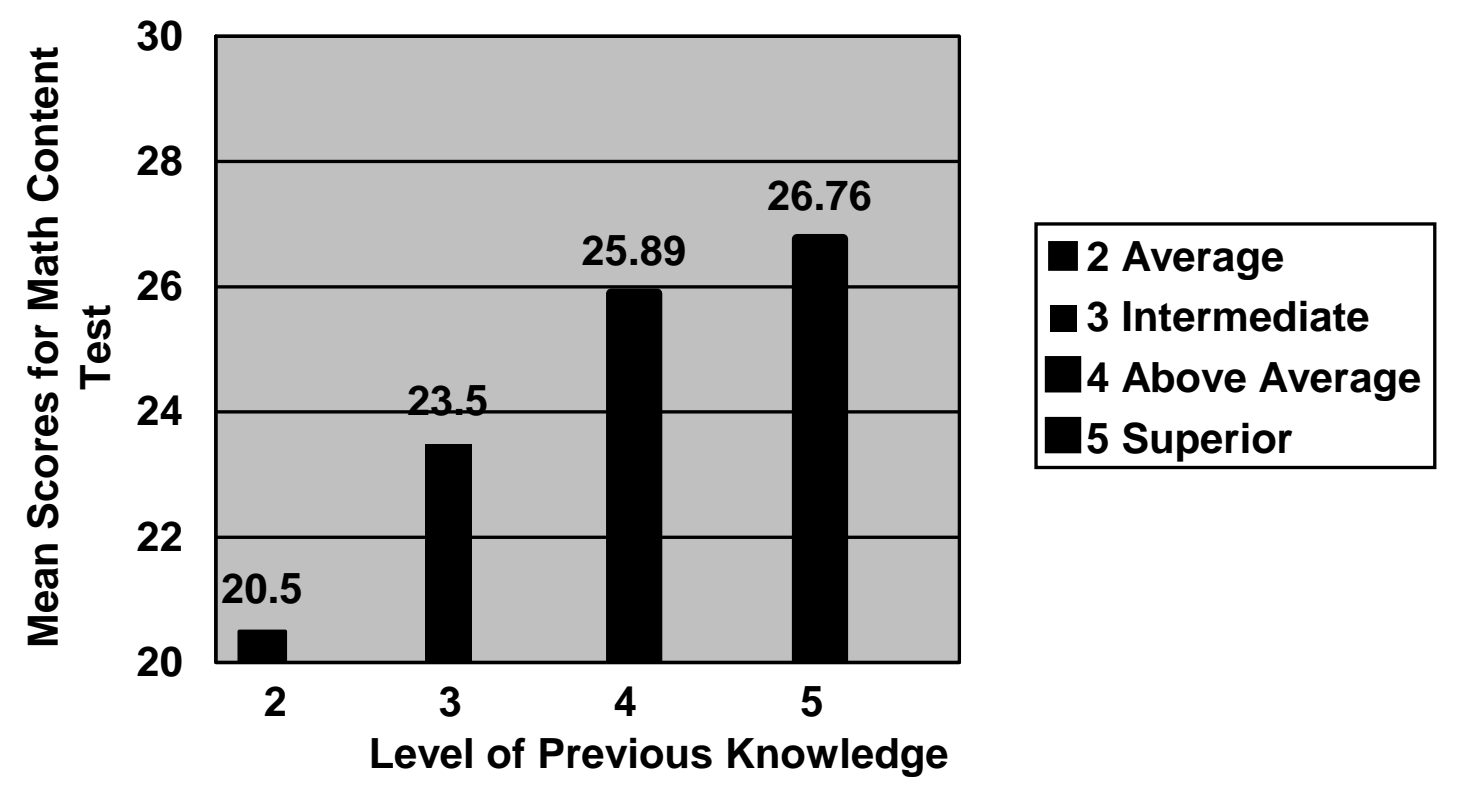

Figure 4. Level of Previous Knowledge and Mean Scores for Math Content Test. Note. Only $n=1$ participant self-reported to have a Beginner level of previous knowledge. This participant's score was not included in the graph. 


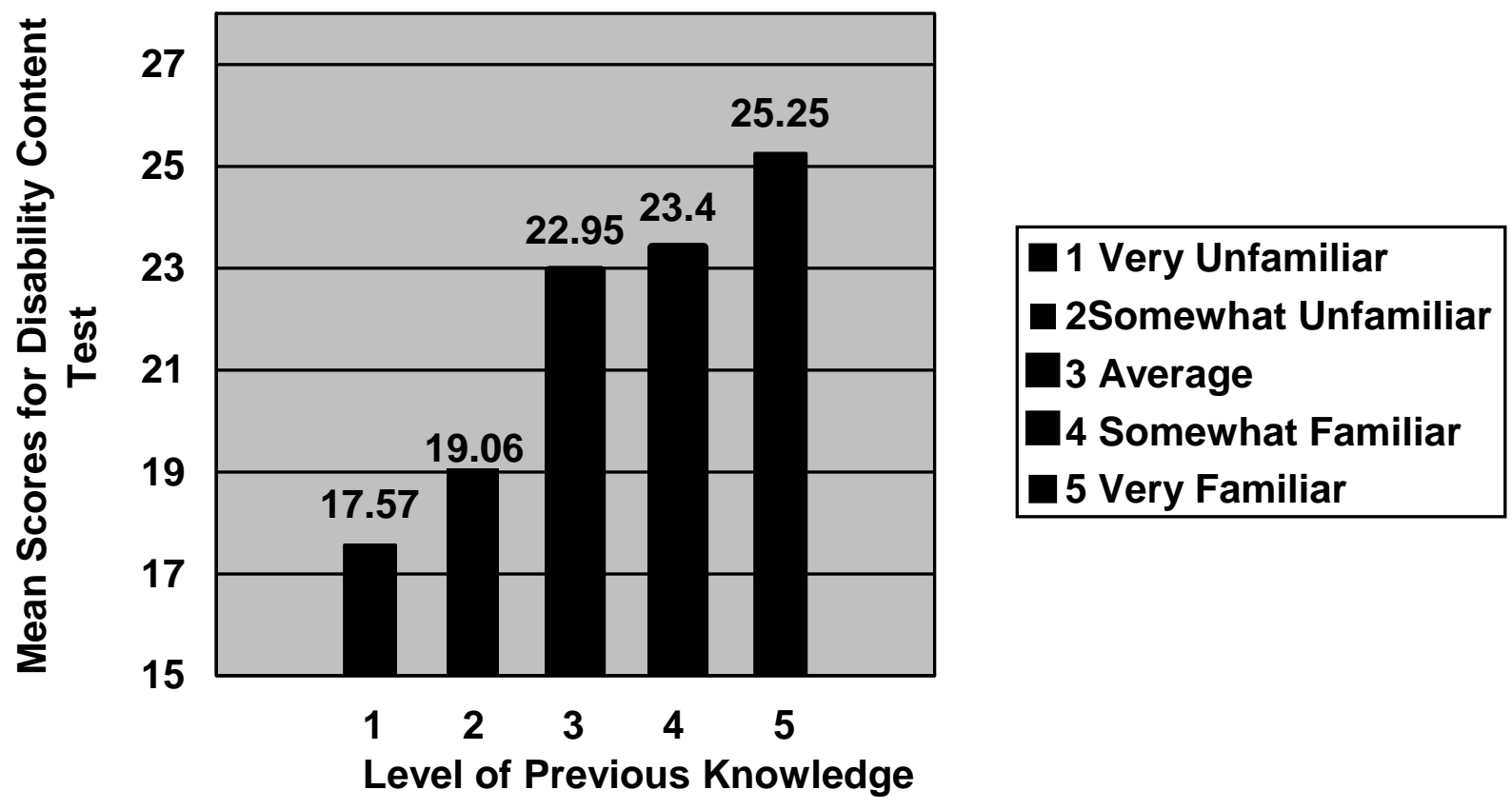

Figure 5. Level of Previous Knowledge and Mean Scores for Disability Content Test.

To determine the potential interaction between self-rating and Mindfulness Groups (High Mindfulness versus Low Mindfulness), two-way analyses of variance were performed for both Math self-rating and Disability self-rating. In order to perform the two-way analysis of variance on the Math self-rating, participants were combined into one of two Math Level Groups. The first Math Level Group was created by combining Rating Group 2 (Average) and Rating Group 3 (Intermediate) together to form an Average/Intermediate Math Level Group. The second Math Level Group was created by combining Rating Group 4 (Above Average) and Rating Group 5 (Superior) to form an Above Average/Superior Math Level Group. Mindfulness Groups was a betweensubjects independent variable, and Math Level Group was a between-subjects 
independent variable. Test scores on the Math content test was the dependent variable in a $2 \times 2$ analysis of variance.

This two-way analysis of variance yielded a non-significant main effect for Mindfulness Groups, $F(1,67)=1.35$, NS. The two-way analysis of variance yielded a statistically significant main effect for Math Level Group, $F(1,67)=$ $10.20, p<.01$. The mean scores for each Math Level Group were mean $=22.56$ for the Average/Intermediate Math Level Group and mean $=26.36$ for the Above Average/Superior Math Level Group. The interaction of Mindfulness Groups by Math Level Group was statistically non-significant, $F(1,67)=0.79$, NS. The mean scores for the interaction were (a) 22.75 for the High Mindfulness Group with an Average/Intermediate Math Level, (b) 27.36 for the High Mindfulness Group with an Above Average/Superior Math Level, (c) 22.45 for the Low Mindfulness Group with an Average/Intermediate Math Level, and (d) 25.06 for the Low Mindfulness Group with an Above Average/Superior Math Level. Data for this analysis of variance are located in Figure 6.

In order to perform the two-way analysis of variance on the Disability selfrating, participants were combined into one of two Disability Level Groups. The first Disability Level Group was created by combining Rating Group 1 (Very Unfamiliar), Rating Group 2 (Somewhat Unfamiliar), and Rating Group 3 (Average) together to form an Unfamiliar/Average Disability Level Group. The second Disability Level Group was created by combining Rating Group 4 (Somewhat Familiar) and Rating Group 5 (Very Familiar) to form a Familiar Level Group. Mindfulness Groups was a between-subjects independent variable and 
Disability Level Group was a between-subjects independent variable. Test scores on the Disability content test was the dependent variable in a $2 \times 2$ analysis of variance.

This two-way analysis of variance yielded a non-significant main effect for Mindfulness Groups, $F(1,67)=2.27$, NS. The two-way analysis of variance yielded a trend toward a statistically significant main effect for Disability Level Group, $F(1,67)=3.65, p=.06$. The mean scores for each Disability Level Group were mean $=20.66$ for the Unfamiliar/Average Disability Level Group and mean $=23.71$ for the Familiar Disability Level Group. The interaction of Mindfulness Groups by Disability Level Group was statistically non-significant, $F(1,67)=0.27$, NS. The mean scores for the interaction were (a) 21.5 for the High Mindfulness Group with an Unfamiliar/Average Disability Level, (b) 25.08 for the High Mindfulness Group with a Familiar Disability Level, (c) 20.04 for the Low Mindfulness Group with an Unfamiliar/Average Disability Level, and (d) 22.09 for the Low Mindfulness Group with a Familiar Disability Level. Data for this analysis of variance are depicted in Figure 7. 

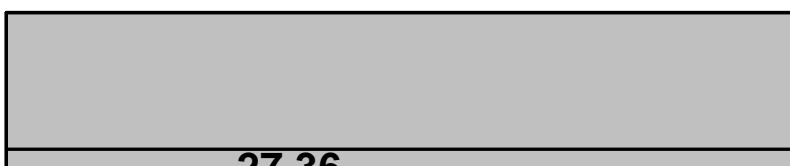

28

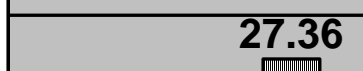

22

20

High

Mindfulness

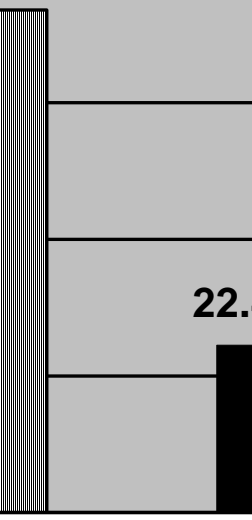

22.45

\subsection{6}

Superior

Averagel Intermediate

Above Averagel

Figure 6. Mean Scores for Math Content Test for Math Level Groups by Mindfulness Groups.

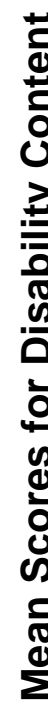

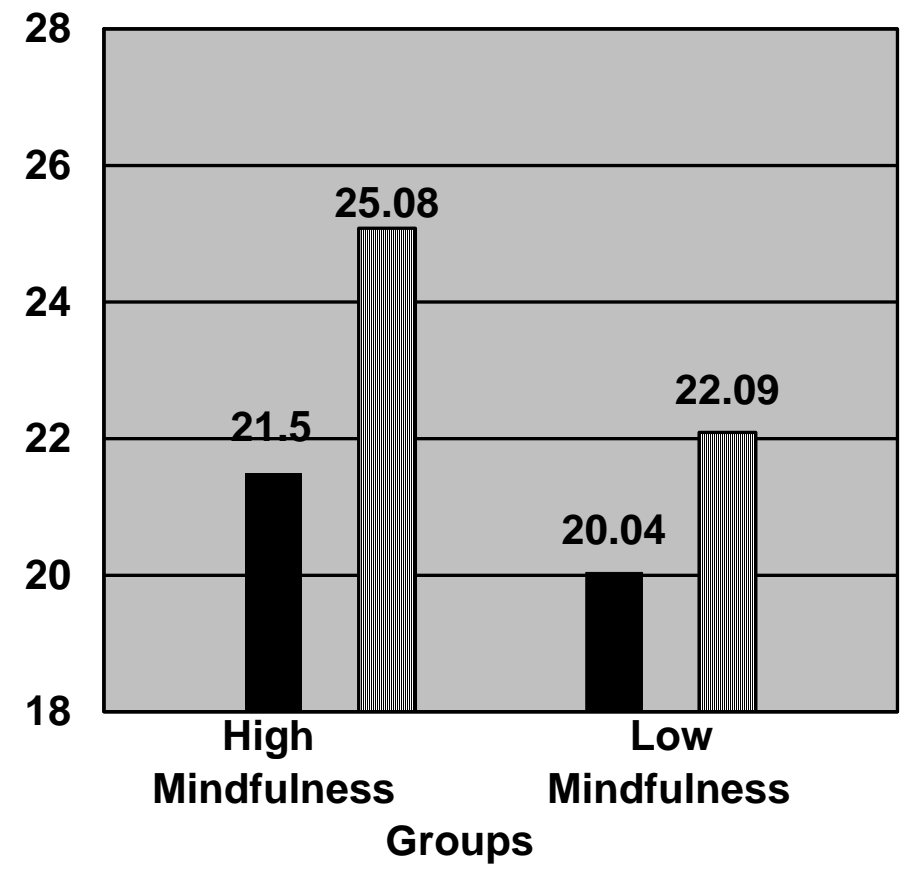

Unfamiliarl Average

四 Familiar

Figure 7. Mean Scores for Disability Content Test for Disability Level Groups by Mindfulness Groups. 
Test-Retest Consistency on the Langer Mindfulness Scale (LMS) and Correlation to the Mindfulness Attention-Awareness Scale (MAAS) (Research Question 1, Third Part).

In Research Question 1, a participant's propensity for Mindfulness was proposed to have an effect on learning when a participant participated in Mindful Instruction and meditation. To better understand the construct of propensity for Mindfulness and the effect of propensity for Mindfulness on learning, participants completed a pre-test LMS, a post-test LMS, and the MAAS. Participants were administered the LMS as part of the initial email response (pre-test) by the researcher for selecting participants for the study. Participants then were administered the LMS upon arriving at the research study (post-test) prior to any Mindful Instruction or Non-Mindful Instruction. The LMS was designed to measure a student's propensity for Mindfulness. The maximum score possible on the LMS is 147 . The range of scores on the pre-test of the LMS was 87 to 139. The range of scores on the post-test of the LMS was 81 to 139. Participants also were administered the Mindfulness Attention-Awareness Scale (MAAS) upon arriving at the research study prior to any Mindful Instruction or Non-Mindful Instruction. The MAAS was designed to measure a student's disposition (trait) of Mindfulness. The maximum possible score on the MAAS is 90. The range of scores on the MAAS was 35 to 83 .

A Pearson Product-Moment Correlation was computed to assess the testretest consistency of the LMS. This comparison yielded an $r(70)=0.787, p<$ .01 , indicating a significant level of consistency. The pre-test LMS classified 
$\mathrm{n}=38$ participants for the Low Mindfulness Group (scores $<110$ ) and $\mathrm{n}=34$ participants for the High Mindfulness Group (scores $>116$ ). The post-test LMS would have reclassified $n=4$ participants from the Low Mindfulness Group into the High Mindfulness Group. The post-test LMS also would have reclassified $n=2$ participants from the High Mindfulness Group into the Low Mindfulness Group. The post-test LMS would have placed a total of $n=11$ participants into the midrange (scores 110 to 116), between the Low Mindfulness Group $(<110)$ and the High Mindfulness Group (>116). Generally, the LMS proved a relatively consistent measure of Mindfulness for the participants. Thus, a participant's propensity for Mindfulness was relatively the same from selection (pre-test) to the participation (post-test) in the study. This consistency may suggest that propensity for Mindfulness is a disposition (trait).

Pearson Product-Moment Correlations also were computed to assess (a) the correlation between the Langer Mindfulness Scale (pre-test) and the Mindfulness Attention-Awareness Scale and (b) the correlation between the Langer Mindfulness Scale (post-test) and the Mindfulness Attention-Awareness Scale. The comparison between the pre-test LMS and MAAS yielded an $r(70)=$ $0.246, p<.05$, indicating a significant relationship between the pre-test LMS and the MAAS, but a non-significant relationship at the $p<.01$ level. Consequently, due to the low $r$ value, the relationship between the pre-test LMS and the MAAS is not a strong relationship. The comparison between the post-test LMS and the MAAS yielded an $r(70)=0.319, p<.01$, indicating a significant relationship between the post-test LMS and the MAAS. Again, due to the low $r$ value, the 
relationship between the post-test LMS and the MAAS is not a strong relationship. The MAAS was created to measure the more traditional, Buddhist definition of Mindfulness defined by Thich Nhat Hanh (1991) and used in the therapeutic/counseling setting. The LMS was designed to measure the Mindfulness described by Langer (1993) and applied to the educational environment. The weak relationship between these two different assessment tools suggests that Mindfulness is viewed somewhat differently when defined and applied across various settings.

Interaction of Mindfulness Groups with Topic (Research Question 1, Fourth Part) In Research Question 1, the high or low level of a student's propensity for Mindfulness was proposed to interact with Mindful Instruction and meditation. Topics (Math and Disability) were analyzed to better understand the interaction of Mindfulness Groups (High Mindfulness and Low Mindfulness) according to performance on test scores for both Topics As stated, each participant received two Types of Instruction (Mindful and Non-Mindful) within one of two Mindfulness Groups (High Mindfulness versus Low Mindfulness). The Topics for both the Mindful and Non-Mindful Instruction were Math and Disability. The subject that the participants were taught for the Mathematics Topic was the Pythagorean Theorem. The subject that the participants were taught for the Disability Topic was People First Language, which is the use of appropriate speech when communicating to or about people with disabilities. Mindfulness Groups (High Mindfulness versus Low Mindfulness) was a between-subjects independent 
variable and Topic (Math and Disability) was a within-subjects independent variable in a $2 \times 2$ mixed-model analysis of variance. Mindfulness Groups (High Mindfulness versus Low Mindfulness) was a between-subjects independent variable in a one-way analysis of variance for Math scores and in a one-way analysis of variance for Disability scores. The dependent variable for (a) the twoway analysis of variance, (b) the one-way analysis of variance for Math scores, and (c) the one-way analysis of variance for Disability scores was scores on the content tests (Range $=0$ to 30 for Math test and Range $0=30$ for Disability test).

The two-way analysis of variance yielded a statistically significant main effect for Topic, $F(1,69)=12.29, p<.01$. This main effect is illustrated in Figure 8. Participants scored higher for both the High Mindfulness Group and the Low Mindfulness Group on the Math Topic than the Disability Topic. The main effect for Mindfulness Groups was also statistically significant, $F(1,70)=4.95, p<.05$. The means for the Groups are the same as those previously shown in Figure 1 (High Mindfulness $=24.3$ and Low Mindfulness $=22.1)$. As may be noted in Figure 8, participants in the High Mindfulness Group scored significantly higher statistically on the content tests (Math and Disability) than participants in the Low Mindfulness Group. In Figure 8, it is apparent that there were parallel effects for the Groups on these two Topics. The interaction of Mindfulness Groups by Topic was not statistically significant, $F(1,69)=0.00$, NS.

Two additional one-way analyses of variance (between subjects) were computed to determine (1) if the difference between Math scores for the High Mindfulness Group versus the Low Mindfulness Group is significant and (2) if the 
difference between Disability scores for the High Mindfulness Group versus the Low Mindfulness Group is significant. The first one-way analysis of variance for Math scores yielded a trend toward a statistically significant main effect for Mindfulness Groups, $F(1,70)=3.25, p=.075$. The mean score (Math) for the High Mindfulness Group was 25.74, and the mean score (Math) for the Low Mindfulness Group was 23.66 (Figure 8). The second one-way analysis of variance for Disability scores yielded a trend toward a statistically significant main effect for Mindfulness Groups, $F(1,69)=2.61, p=.11$. The mean score (Disability) for the High Mindfulness Group was 22.91, and the mean score (Disability) for the Low Mindfulness Group was 20.63 (Figure 8).

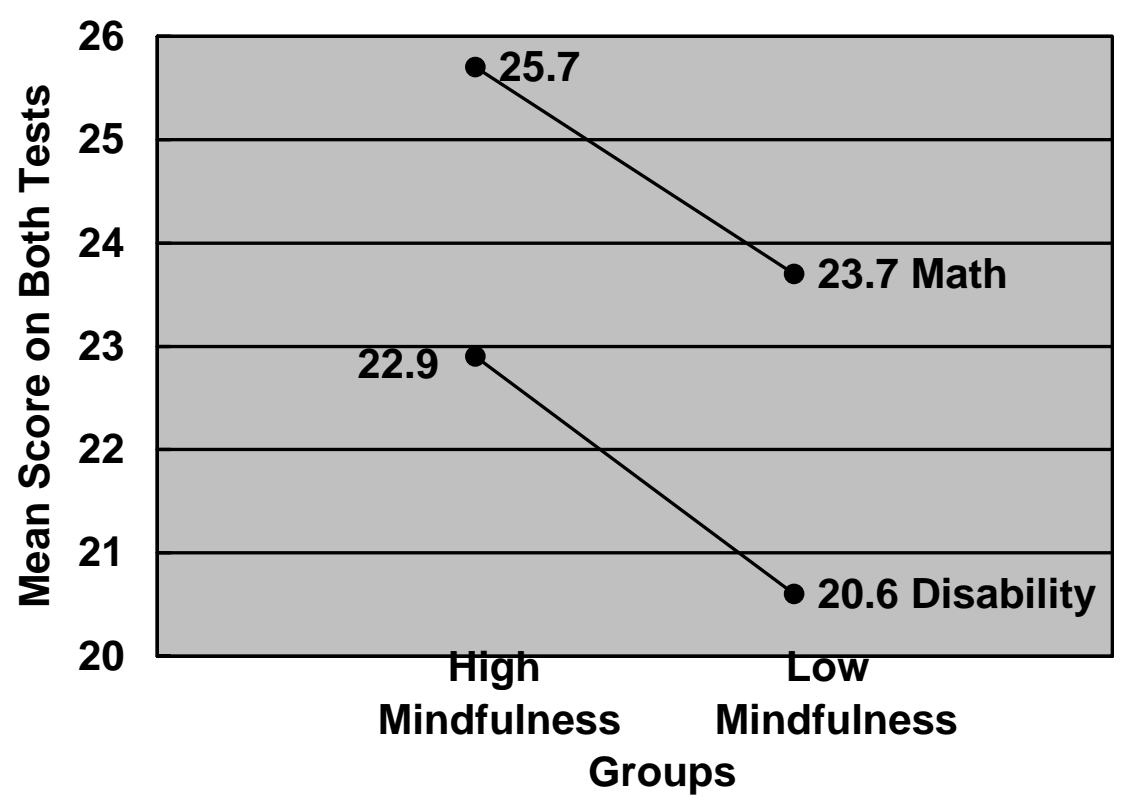

Figure 8. Mean Scores for Both Topics (Math and Disability) by Mindfulness Groups (High Mindfulness versus Low Mindfulness). 
Mindfulness Education

Effects of Mindful and Non-Mindful Instruction on the "Modified Guilford Test of Alternate Uses" (Research Question 2, First Part)

Does Mindful Instruction and meditation affect a student's state of Mindfulness? In Research Question 2, Mindful Instruction and meditation was proposed to affect a participant's state of Mindfulness. To better understand the effect of Mindful Instruction and Meditation on a student's state of Mindfulness, participants were given the "Modified Guilford Test of Alternate Uses" after Mindful and Non-Mindful Instruction to measure the fluency construct of Mindfulness. The "Modified Guilford Test of Alternate Uses" was modified from the original Guilford and adapted to measure a participant's state of Mindfulness. Participants were shown four everyday items (brick, newspaper, shoe, and paperclip) and asked to list as many possible uses for each item. Fluency was assessed by the total number of responses given by the participant. According to the Langer (2000) definition, Mindfulness is a "flexible state of mind" where one looks at information from new perspectives. Thus, the purpose of this test was to measure whether Mindful Instruction and meditation affected a participant's fluency score on the "Modified Guilford Test of Alternate Uses." Participants were given the "Modified Guilford Test of Alternate Uses" after either a Mindful Instruction or Non-Mindful Instruction of Math. Mindfulness Groups (High Mindfulness versus Low Mindfulness) was a between-subjects independent variable and Instruction Type (Mindful versus Non-Mindful) was a between-subjects independent variable in a $2 \times 2$ analysis of variance. The 


\section{Mindfulness Education}

dependent variable was the fluency scores on the "Modified Guilford Test of Alternate Uses" (Range 35 to 83).

The mean fluency scores of the "Modified Guilford Test of Alternate Uses" for the Mindfulness Groups main effect were mean $=37.94$ for the High Mindfulness Group and mean $=35.58$ and for the Low Mindfulness Group, $F(1$, $68)=0.85$, NS. The mean scores for the Instruction Type main effect were mean $=37.08$ after the Mindful Instruction and mean $=36.31$ after the Non-Mindful Instruction, $F(1,68)=0.03$, NS. The mean scores for the interaction were (a) 36.22 for the High Mindfulness Group after Mindful Instruction, (b) 39.88 for the High Mindfulness Group after Non-Mindful Instruction, (c) 37.94 for the Low Mindfulness Group after Mindful Instruction, and (d) 33.45 for the Low Mindfulness Group after Non-Mindful Instruction, $F(1,68)=2.56$, NS. Data for this analysis are represented in Figure 9. 


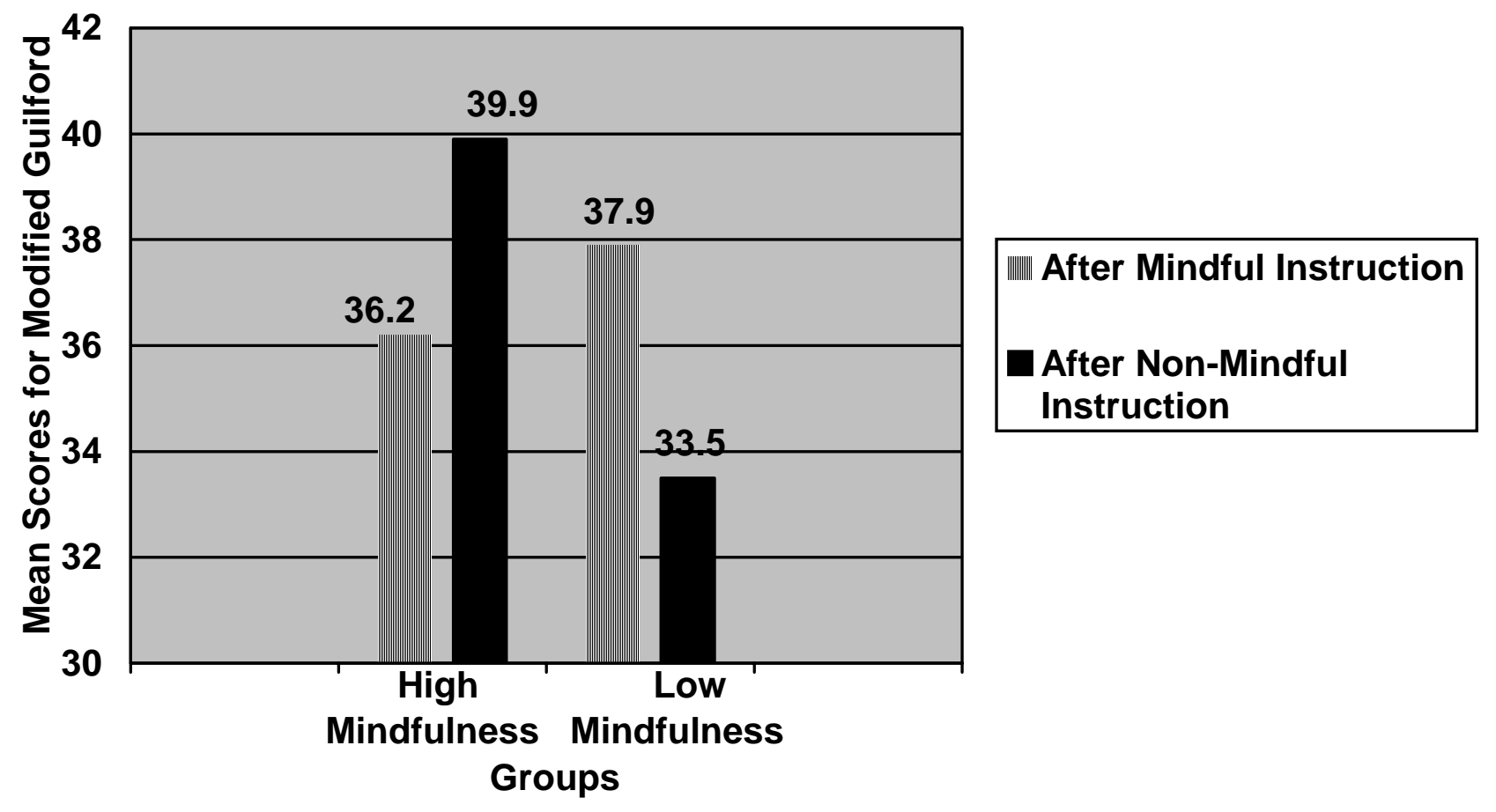

Figure 9. Mean scores for Modified Guilford by Instruction Type and Mindfulness Groups.

Effects of Mindful and Non-Mindful Instruction on Embedded Measures of Mindfulness (Research Question 2, Second Part)

In Research Question 2, Mindful Instruction and meditation was proposed to affect a participant's state of Mindfulness. To better understand the effect of Mindful Instruction and meditation on a student's state of Mindfulness, participants were assessed on the attention and awareness aspects of Mindfulness through embedded measures of Mindfulness. The embedded measures of Mindfulness were developed by the researcher to measure a participant's state of Mindfulness. These embedded measures of Mindfulness were located on a Math pre-test and within the content tests. Because of the placement of the embedded measures of Mindfulness within both content tests 
(Math and Disability), the participants were assessed on the embedded measures after both Mindful Instruction and Non-Mindful Instruction. Mindfulness Groups was a between-subjects independent variable and Instruction Type was a within-subjects independent variable in two $2 \times 2$ mixed-model analyses of variance. The dependent variable for these two analyses was (a) scores on embedded measures of Mindfulness (Math) and (b) scores on embedded measures of Mindfulness (Disability). A one-way analysis of variance also was performed on the total score of the embedded measures (Math + Disability) after both Types of Instruction (Mindful and Non-Mindful). Mindfulness Groups was a between-subjects independent variable, and the total score of the embedded measures (Math + Disability) was the dependent variable in that analysis.

For the 2 (Mindfulness Groups) by 2 (Instruction Type) analysis of variance, the mean scores of embedded measures of Mindfulness for Math Topic main effect were mean $=1.38$ for the High Mindfulness Group and mean $=1.45$ for the Low Mindfulness Group, $F(1,68)=0.02$, NS. The mean scores (embedded Math) for the Instruction Type main effect were 1.14 for Mindful Instruction and 1.69 for Non-Mindful Instruction, $F(1,68)=5.66, p<.05$. The mean scores (embedded Math) for the interaction were (a) 1.06 for the High Mindfulness Group after Mindful Instruction, (b) 1.75 for the High Mindfulness Group after Non-Mindful Instruction, (c) 1.22 for the Low Mindfulness Group after Mindful Instruction, and (d) 1.65 for the Low Mindfulness Group after Non-Mindful Instruction, $F(1,68)=0.32$, NS. Data for this analysis of variance are depicted in Figure 10. 


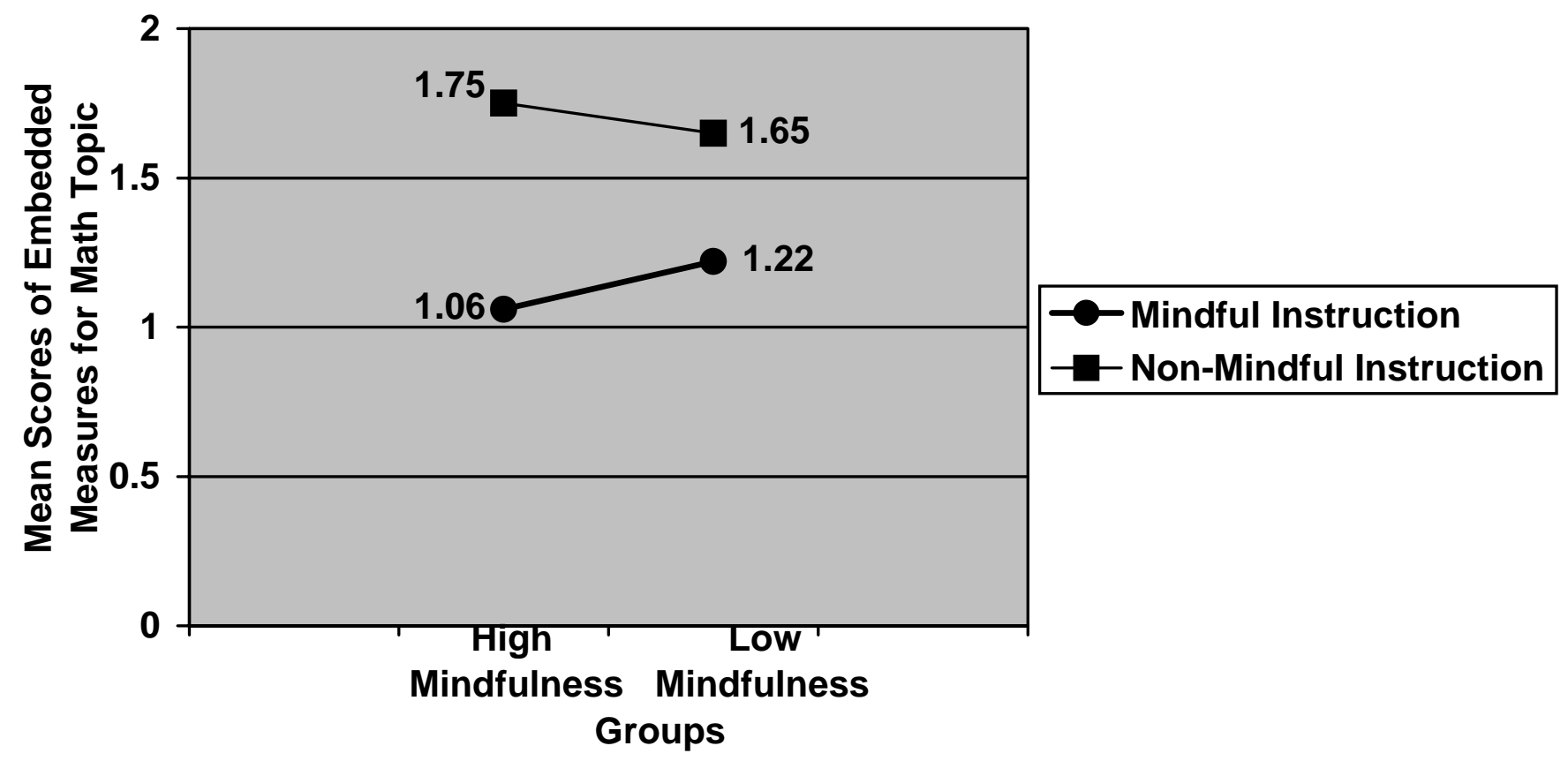

Figure 10. Mean Scores of Embedded Measures of Mindfulness for Math Topic by Instruction Type (Mindful versus Non-Mindful).

For the 2 (Mindfulness Groups) by 2 (Instruction Type) analysis of variance, the mean scores of embedded measures of Mindfulness for Disability Topic main effect were mean $=0.26$ for the High Mindfulness Group and mean $=$ 0.34 for the Low Mindfulness Group, $F(1,68)=0.35$, NS. The mean scores (embedded Disability) for the Instruction Type main effect were 0.31 for Mindful Instruction and 0.31 for Non-Mindful Instruction, $F(1,68)=0.00$, NS. The mean scores (embedded Disability) for the interaction were (a) 0.25 for High Mindfulness Group after Mindful Instruction, (b) 0.28 for High Mindfulness Group after Non-Mindful Instruction, (c) 0.35 for Low Mindfulness Group after Mindful Instruction, and (d) 0.33 for Low Mindfulness Group after Non-Mindful Instruction, $F(1,68)=0.03$, NS. Data for this analysis of variance are represented in Figure 11. 


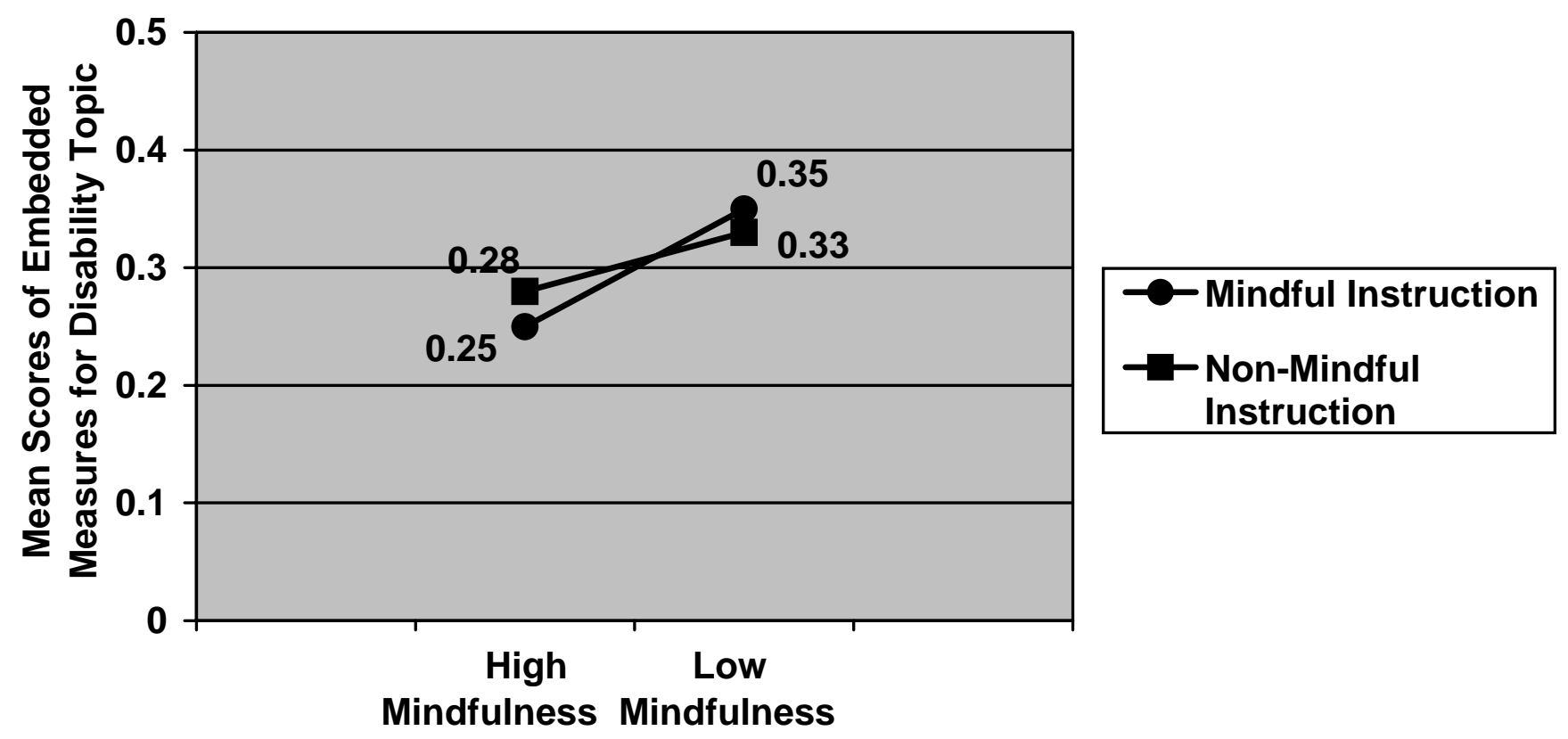

Figure 11. Mean Scores of Embedded Measures of Mindfulness for Disability topic by Instruction Type and Mindfulness Groups.

A one-way analysis of variance also was performed with the combined scores of all embedded measures of Mindfulness (Math + Disability).

Mindfulness Groups was a between-subjects independent variable. The dependent variable was the combined scores on all the embedded measures of Mindfulness (Range 0 to 5 ). The results of the analysis show that the variable Mindfulness Groups was statistically non-significant, $F(1,70)=0.26$, NS. The mean for the High Mindfulness Group was 1.65, and the mean for the Low Mindfulness Group was 1.79. Thus, placement into one of the two Mindfulness Groups was non-significant in determining performance on all the combined embedded measures of Mindfulness. 


\section{Chapter 4}

\section{Discussion}

The current study attempted to examine whether there are instructional or learning implications in education based on the level of a student's propensity of Mindfulness after participating in Mindful Instruction and meditation. The Mindful Instruction and meditation examined in the current study was a novel attempt to bridge the traditional Mindfulness as defined by Hanh (1991) with the Mindfulness as defined by Langer (1989). The Mindfulness Instruction and meditation included a 10-minute Buddhist meditation and aspects of Mindful education as defined by Langer (1989), while the Non-Mindful Instruction did not involve the 10-minute Buddhist meditation and included aspects of Mindlessness as defined by Langer (1989). Langer's (1989) application of Mindful Instruction and Mindlessness in the current study incorporated the use of conditional language versus absolute language, relevant material versus irrelevant material, and engagement of problem-solving behavior versus rote memorization. Research Question 1 asked if a student's propensity for Mindfulness has an effect on learning when a student participates in Mindful Instruction and meditation. Research Question 2 asked if Mindful Instruction and meditation affects a student's state of Mindfulness. Analyses and inferences from the data suggest some possible answers to these research questions. 


\section{Research Question 1}

Does a student's propensity for Mindfulness have an effect on learning when a student participates in Mindful Instruction and meditation? Participants were selected from high or low scores on the initial LMS questionnaire sent to students requesting that they participate in the research study. Participants were classified into one of two Mindfulness Groups (High Mindfulness versus Low Mindfulness). The Langer Mindfulness Scale measures a student's "propensity" for Mindfulness (Langer Mindfulness Scale, 2005). Webster's Dictionary defined propensity as "A natural inclination; innate or inherent tendency" (Merriam Webster's Third New International Dictionary, 1981). The High Mindfulness Group can be described as individuals with a high propensity for Mindfulness. The Low Mindfulness Group can be described as individuals with a low propensity for Mindfulness. Test-retest consistency on a measure of propensity for Mindfulness could imply that high or low propensity for Mindfulness is dispositional (trait-like) behavior.

The results of the analyses for this study suggest that placement into either the High Mindfulness Group or Low Mindfulness Group had some effect on the content test scores. The analyses yielded a trend toward a statistically significant main effect for Mindfulness Groups as suggested by the data. The High Mindfulness Group tended to have higher mean scores on the Math and Disability content tests versus the Low Mindfulness Group mean scores on the Math and Disability content tests. One explanation for this difference found in the literature and among current theories of intelligence suggests that Mindfulness 
theory and intelligence theory share the important construct of cognitive flexibility. Other explanations for the difference in performance between the two groups (High Mindfulness versus Low Mindfulness) are offered in the literature and research as well.

One such explanation for the difference in performance between the two groups is the conflicting view of Mindfulness as (1) a personality trait, (2) a cognitive ability, or (3) a cognitive style. While this study did not initially attempt to measure Mindfulness in terms of (1) personality trait, trait-like aspects of Mindfulness are suggested by the data from the test-retest consistency of the participants' scores on the Langer Mindfulness Scale. Predisposition (what the participants had when they came into the study) was stronger than either the Mindful Instruction and meditation or Non-Mindful Instruction. Sternberg (2000) defined (2) cognitive ability as "the identification of the unique processing component that accounts for differences in performance of a given individual on various tasks or task variants" (p. 12). Constructs of intelligence are similar to constructs of Mindfulness as a cognitive ability. In his studies providing construct validity for the recently developed Langer Mindfulness Scale, Bodner (2001) suggested there are relationships between the LMS measure of Mindfulness and some measures of intelligence. However, Sternberg (2000) argued that Mindfulness most closely resembles (3) a cognitive style, or "preferred ways of using one's abilities" (p. 22). The current research study examined a student's abilities based on test scores and did not measure how the student processed his or her ability. Nevertheless, the relationship between test scores and 


\section{Mindfulness Education}

Mindfulness Groups may suggest in some ways that Mindfulness is a cognitive ability. Further research is needed to relate how the cognitive style or the cognitive ability of Mindfulness is developed.

Each Mindfulness Group (High Mindfulness and Low Mindfulness) received the same subject matter according to the criteria for each Topic (Math and Disability) and Instruction Type (Mindful versus Non-Mindful) found in Appendix $\mathrm{E}$ and Appendix $\mathrm{F}$ respectively. Upon completion of each of the four lessons, the researcher and trained observers reviewed a checklist of criteria and content to determine whether the same content had indeed been taught for both Topics (Math and Disability) across Types of Instruction (Mindful and NonMindful). A videotaped recording of each lesson was reviewed, and the researcher and trained observers determined that the content subject matter was consistently taught in all four lessons. The content tests measured participant performance in answering questions correctly. The content tests measured a participant's performance on learning the subject matter more than measuring how the participant used his or her cognitive abilities (i.e., cognitive style). Thus, the mean scores on the content tests and the differences in performance between the two Mindfulness Groups (High Mindfulness versus Low Mindfulness) might suggest that an individual's high or low propensity for Mindfulness could indeed be viewed as a cognitive ability. Further research is needed to examine the extent that cognitive style, or how an individual uses these abilities, may have impacted participant performance. 


\section{Mindfulness Education}

The results of the analyses also suggest that participants were cognizant and accurate in their self-rating level of previous knowledge of the subject matter (Math and Disability). Analyses were conducted to examine the relationship between previous knowledge of the subject matter (Math and Disability) and content test scores. As shown in Figure 4 and Figure 6 in Chapter 3, participants in the Average/Intermediate Self-Rating Group for both Mindfulness Groups (High Mindfulness and Low Mindfulness) correctly self-rated their level of Math previous knowledge lower, in comparison to the Above Average/Superior SelfRating Group for both Mindfulness Groups (High Mindfulness and Low Mindfulness). Similarly, as shown in Figure 5 and Figure 7 in Chapter 3, participants in the Unfamiliar/Average Self-Rating Group for both Mindfulness Groups (High Mindfulness and Low Mindfulness) correctly self-rated their level of Disability previous knowledge lower in comparison to the Familiar Self-Rating Group for both Mindfulness Groups (High Mindfulness and Low Mindfulness). Participant self-rating also was useful in determining the level of impact this variable had on participant performance (learning). The data suggest that the level of previous knowledge of subject matter may have significantly affected student performance. While level of previous knowledge of the subject matter may have affected participant performance (learning), Mindful Instruction and meditation did not appear to make a significant impact on participant learning. Mindful Instruction and meditation was proposed to interact with Mindfulness Groups, this interaction proved to be insignificant. 
According to the data, the interaction between Mindfulness Groups (High Mindfulness versus Low Mindfulness) and Instruction Type (Mindful versus NonMindful) was not significant. As the content scores suggest, a combined Mindful Instruction and Mindfulness meditation did not significantly impact participant learning. In fact, means for both groups of participants were lower after Mindful Instruction and meditation than Non-Mindful Instruction. The High Mindfulness Group and Low Mindfulness Group had lower mean scores on the Math content tests after Mindful Instruction and meditation than Non-Mindful Instruction. The High Mindfulness Group and Low Mindfulness Group had no significant difference in scores on the Disability content tests after Mindful Instruction and meditation and Non-Mindful Instruction.

\section{Research Question 2}

Does Mindful Instruction and meditation affect a student's state of Mindfulness? This research study was novel in its attempts to explore a version of Mindfulness previously not examined. Historically, Mindfulness has been a Buddhist tradition of meditation which has only recently permeated into Western and American society. The Mindful Instruction and meditation used in this study was based on an entirely different application of Mindfulness than the Mindfulness practiced through Mindfulness meditation. The Mindful or NonMindful Instruction of this study incorporated elements of Mindfulness and Mindlessness as defined by Langer (1993). These elements included the use of conditional language versus absolute language (e.g., This is a book, versus, 
This could be a book). Similarly, conditional instruction versus absolute instruction was used in the study. Conditional instruction allows for more student interaction and cognitive flexibility in creating learning experiences. Absolute instruction is more rigid and asks for "Yes" or "No" responses instead of creative, unstructured explanations or answers. This current study attempted to combine the traditional form of Mindfulness with the Mindfulness applied to educational psychology.

The researcher developed and modified measures of Mindfulness to assess the participant's state of Mindfulness. These measures are (1) the embedded measures of Mindfulness and (2) the "Modified Guilford Test of Alternate Uses." In order to determine whether a student's state of Mindfulness had been affected, the researcher created the embedded measures of Mindfulness which were located on the Math pre-test, in the Math content test, and in the Disability content test. These measures can be located in Appendix D. Overall, the effect of Instruction Type on the embedded measures of Mindfulness suggests that the Mindful Instruction and meditation did not significantly affect the participant's state of Mindfulness as demonstrated by scores on the embedded measures of Mindfulness. This suggests (a) that the embedded measures of Mindfulness were not accurate in measuring a participant's state of Mindfulness or (b) that the Mindful Instruction and meditation did not produce a change in student behavior, i.e., become more Mindful. When the embedded measures were combined into a single score after both Types of Instruction (Mindful and Non-Mindful), there was no significant difference between the High Mindfulness 


\section{Mindfulness Education}

Group and the Low Mindfulness Group in overall performance on the combined embedded measures. Bodner (2001) found in his studies on the construct validity of the Langer Mindfulness Scale, that those scoring high versus low on the LMS were more likely overcoming constraining mindsets on insight problem solving tasks. The results from the data of the current research study suggest that (1) this is inconsistent with Bodner (2001) or that (2) the embedded measures of Mindfulness did not accurately assess student attention and awareness. The lack of a significant difference on the embedded measures of Mindfulness after Mindful Instruction and meditation could be the result of the limitations involving the measures of Mindfulness used in this research study.

\section{Limitations}

Limitations in the current study may have contributed positively and negatively to the results. These limitations came from various sources. The sources of the limitations found in this study included (a) the lack of established

and appropriate measures to assess Mindfulness, (b) design flaws in the study, and (c) Mindfulness as a relatively recent construct of educational psychology research and literature.

Thich Nhat Hanh (1991) defined Mindfulness as awareness of the present moment. Dr. J. Kabat-Zinn's adaptation of this traditional form of Mindfulness meditation in the therapeutic setting has demonstrated effectiveness in treatment of a variety of disorders and disabilities (Kabat-Zinn, et al. 1992; Miller, Fletcher, \& Kabat-Zinn, 1995; Ramel, Goldin, \& Carmona, 2004; Teasdale, et al 2000). In 


\section{Mindfulness Education}

education, Mindfulness as an instructional strategy and in educational psychology has largely been defined by Dr. Ellen Langer (Langer, 1989). Langer (1993) defined Mindfulness as "a state of mind that results from drawing novel distinctions, examining information from new perspectives, and being sensitive to context” (p. 44). Langer (1989) argued that her definition and application of Mindfulness come from different sources than the traditional form. This study involved a combination of the traditional Mindfulness meditation and an applied version of Mindful Instruction and learning as defined according to Langer (1989). This attempt to combine these historically different forms of Mindfulness, though novel, was demonstrated to have little effect or impact on learning. To what extent, if any, a combination of Hanh's Mindfulness meditation and Langer's application to education and psychology might impact education can only be determined if adequate and validated tools of assessment exist. The lack of established measures of Mindfulness severely limited the research potential of this study.

The first major limitation of this study was (a) the lack of adequate measures of assessing Mindfulness. Due to the lack of established measures of Mindfulness, the researcher used two measures of Mindfulness developed or modified specifically for this study. The measures used were (1) the embedded measures of Mindfulness and (2) the "Modified Guilford Test of Alternate Uses."

The first measure of Mindfulness the researcher developed was (1) the embedded measures of Mindfulness. The location and descriptions of the embedded measures of Mindfulness can be found in Appendix D. The 


\section{Mindfulness Education}

embedded measures of Mindfulness were certainly not established or validated measures. At best, the measures were seen to have more of a novelty effect with the participants rather than being viewed as effective tools for assessing attention and awareness. Assessing attention and awareness has innate difficulties and obstacles. How can attention and awareness be assessed without bringing attention and awareness to that which is being assessed?

The second measure of Mindfulness the researcher modified was (2) the "Modified Guilford Test of Alternate Uses." The "Modified Guilford Test of Alternate Uses" was included in this study to measure the fluency construct of Mindfulness. The "Modified Guilford Test of Alternate Uses" is similar to assessments created and used by Langer and Piper (1987) in which students find alternate uses for everyday objects. The "Modified Guilford Test of Alternate Uses" was modified from its original form by using updated and current prompts for the participants to respond. Also, the "Modified Guilford Test of Alternate Uses" can be used to measure originality and flexibility. Originality and flexibility were not able to be calculated because of the large number of participants in this study. This inability to fully use the "Modified Guilford Test of Alternate Uses" was another limitation of the research study. Though the High Mindfulness Group had slightly higher scores on the "Modified Guilford Test of Alternate Uses" than the Low Mindfulness Group, the analyses of the effects of Instruction Type (Mindful versus Non-Mindful) on the "Modified Guilford Test of Alternate Uses" show a mixed interaction. A lack of consistency in the data suggests that the Mindful Instruction and meditation did not significantly impact the scores on 
the "Modified Guilford Test of Alternate Uses." The High Mindfulness Groups had the highest mean scores on the "Modified Guildford Test of Alternate Uses" after Non-Mindful Instruction, and the Low Mindfulness Groups had the lowest mean scores on the "Modified Guilford Test of Alternate Uses" after Non-Mindful Instruction. Whether this lack of consistent results of significant effects is due to the "Modified Guilford Test of Alternate Uses" not being an adequate or appropriate measure of Mindfulness is not known. Thus, the lack of adequate and appropriate measures of Mindfulness negatively impacted possible inferences from this study.

The second major limitation of this study was (b) design flaws in the study. These design flaws included (1) the limited time of the study to allow for a meaningful Mindful learning experience, (2) timing difficulties associated with the sample population of college students, (3) the demographic differences of participants, and (4) no structure or direction by the researcher on how to meditate during the 10-minute Buddhist meditation. The first design flaw was (1) the limited time of the study to allow for a meaningful Mindful learning experience. Participants were only required to attend a two-hour research study during which they were taught two 25 -minute lessons. This research study may have been able to produce more meaningful results had the students been taking a semester long course involving Mindful Instruction and meditation. In a semester long course, the Mindfulness meditation may have had greater impact or significance in student learning. Another design flaw of the study was (2) timing difficulties associated with the sample population of college students. 


\section{Mindfulness Education}

Each lesson of this study was conducted over the course of four days in the early evening (5:30 p.m. - 7:30 p.m.). Also, the research study was conducted the week before Finals Week which is often a time of test preparation and anxiety for college students. The third design flaw was (3) the demographic differences of participants. Numerous demographic differences existed among the participants that may have impacted results. For example, these differences included class rank (freshman, sophomore, junior, senior, graduate student) and age. The fourth design flaw was the (4) lack of structure or direction by the researcher on how to meditate during the 10-minute Buddhist meditation. Research participants were not instructed on meditation techniques. For example, during the 10-minute Buddhist meditation, some participants had their eyes open while other participants had their eyes closed. These subtle differences could have varied the level of meaningfulness and effectiveness of the meditation among participants. Thus, this research study could have been conducted in a ways would have placed better controls on variables which may have impacted the results.

The third limitation of this research study involved (c) Mindfulness as a relatively recent construct of educational psychology research and literature. Since the examination of Mindfulness as a construct of educational psychology research and literature is recent, the study was impacted because of (1) limitations in only having two measures of Mindfulness and (2) lack of understanding on how to study Mindfulness. Mindfulness as a relatively recent construct of educational psychology research and literature may have affected 
results because of (1) limitations in only having two measures of Mindfulness. The Langer Mindfulness Scale (LMS) and the Mindfulness Attention-Awareness Scale (MAAS) are the only scales of Mindfulness that have been created and validated for assessing Mindfulness. The LMS was designed by Dr. Ellen Langer to measure a student's propensity for Mindfulness. The MAAS was designed by Drs. Ryan and Brown to measure a student's disposition (trait) of Mindfulness. Not only do these scales measure different constructs (propensity versus disposition) of Mindfulness, these scales were designed to measure different "types" of Mindfulness altogether. The LMS was created to measure the Mindfulness as defined by Langer (1993) and applied to educational psychology. The MAAS is more of a measure of the traditional form of Mindfulness with questions relating to awareness of the present moment. This weak relationship between the pre-LMS, post-LMS, and the MAAS suggests that Mindfulness is viewed somewhat differently when defined and applied across various settings.

Another problem associated with Mindfulness as a relatively recent construct of educational psychology research and literature is (2) the lack of understanding in how to study Mindfulness. For example, participants were classified into one of two Mindfulness Groups (High Mindfulness and Low Mindfulness). All variations of Mindfulness Groups (High Mindfulness and Low Mindfulness) receiving both Types of Instruction (Mindful and Non-Mindful) for each of the two Topics (Math and Disability) were present in the study. However, this type of research design only allowed for homogenous groups of either all High Mindfulness participants or all Low Mindfulness participants. The effects of 
Mindful Instruction and meditation on heterogeneous groups of students with both high and low levels of Mindfulness need to be examined. Does a student with a low propensity for Mindfulness increase his or her propensity for Mindfulness when the student participates in Mindful Instruction and meditation with groups of students with high levels of propensity for Mindfulness? Similarly, does a student with a high propensity for Mindfulness decrease his or her propensity for Mindfulness when the student participates in Mindful Instruction and meditation with groups of students with low levels of propensity for Mindfulness? Langer's current research involves examining the impact of an instructor with high levels of Mindfulness on other students' levels of Mindfulness. Thus, heterogeneous groups of mixed high and low Mindfulness may affect a student's level of propensity for Mindfulness. The results of the study may have differed had the research design allowed for heterogeneous groups of mixed High Mindfulness and Low Mindfulness Groups.

\section{Implications for Learning and Instruction}

Despite limitations in the study, implications for learning and instruction are suggested by the data. Implications for learning are suggested by the significant and non-significant results of some of the analyses. Implications for student learning from the present Mindfulness research study suggested by the data include (a) the role and influence of propensity for Mindfulness as a behavior trait and (b) the effect of previous knowledge on a student's propensity for Mindfulness. Implications for instruction are suggested by the significant and 
non-significant results of some of the analyses as well. Implications for instruction from this Mindfulness research study are (a) the need for further research that applies Mindful Instruction to actual classrooms over an extended period of time and (b) the need for further research into a combined form of Mindful Instruction and Mindfulness meditation.

Implications for student learning from the present Mindfulness research study are suggested by the data from the test-retest consistency of the Langer Mindfulness Scale. The test-retest consistency may offer insight (a) on the role and influence of propensity for Mindfulness as a trait. The significant test-retest consistency suggests that an individual's propensity for Mindfulness is a disposition (trait) since individuals scored relatively consistent from test to retest on the LMS over a period of time ( 4 weeks). The data suggest a trend toward a significant difference in content test scores between students with high or low propensity for Mindfulness. This trend offers insight on the role and influence of propensity for Mindfulness as a trait. The implications on student learning for developing propensity for Mindfulness as a trait suggest the outcome may be improved student performance.

The data from this investigation suggest that placement into the Mindfulness Groups (High Mindfulness versus Low Mindfulness) was influential in determining performance on content test scores. Developing Mindfulness as a trait might enable students to perform better on tests. However, Ritchhart and Perkins (2000) suggested that the real educational potential of Mindfulness lies not in the immediacy of higher test scores, but in developing the "flexible transfer 


\section{Mindfulness Education}

of skills and knowledge to new contexts, the development of deep understanding, student motivation and engagement, the ability to think critically and creatively and the development of more self-directed learners" (p. 29). More research is needed in understanding the processes of Mindfulness that result in higher test scores as suggested by this research study. Understanding the processes of Mindfulness may ultimately confirm Sternberg (2000) and his argument that Mindfulness most closely resembles a cognitive style, or "preferred ways of using one's abilities" (p. 22).

Implications for student learning from the current Mindfulness research study are suggested by the data from the effects of previous knowledge of subject matter on a student's propensity for Mindfulness. According to Langer (1993), a Premature Cognitive Commitment is "a rigid belief that results from the mindless acceptance of information as true without consideration of alternative versions of that information" (p. 45). In many instances of instruction, a student automatically "commits" information in preconceived and predetermined ways (Langer, 1993). Thus, previous knowledge of subject matter may hinder a student's performance by reducing the ability for the student to examine or learn information from new perspectives. Does a student's propensity for Mindfulness affect student learning of subject matter which the student has or does not have previous knowledge? The research study attempted to examine the effects of a student's previous knowledge of subject matter and propensity for Mindfulness on student learning. The results suggest differences between levels of previous knowledge of subject matter (Math and Disability) and performance on the 
content tests (Math and Disability). This indicates that a student's perceived level of previous knowledge of subject matter is consistent with the student's performance on test scores. However, the interaction of Mindfulness Groups (High Mindfulness versus Low Mindfulness) on levels of previous knowledge as determined by the content test scores (Math and Disability) was not significant. This lack of significance in the interaction may suggest that a student's propensity for Mindfulness combined with the student's level of previous knowledge of subject matter does not affect student learning. An implication for student learning inferred from the results of this study may suggest that a student's previous knowledge of subject matter does not negatively impact his or her performance. However, it should be noted that the study examined the student performance and did not attempt to examine student ability to problemsolve with the previous knowledge in novel situations. Thus, Premature Cognitive Commitments could possibly have hindered the application of this previous and new knowledge in problem-solving situations. Further research on the application of previous knowledge to problem-solving situations is strongly urged.

Implications for instruction from this Mindfulness research study include the need for further research that applies Mindful Instruction to actual classrooms over an extended period of time. Langer (1993) suggested that Mindful Instruction should involve the use of conditional instruction. Langer (1989) defined conditional instruction as instruction that "allows the processing of information with some uncertainty." In their studies on conditional versus 
absolute instruction, Langer and Piper (1987) argued that instruction which is a "conditional or probabilistic view of the world would enable subsequent cognitive flexibility" (p. 281). Absolute instruction, conversely, implies instruction whereby information and language are presented in discrete categories (e.g., absolute terms) with an unchanging, non-evolving view of the category (e.g., an absolute view of a term's definition) or process. While studies have been conducted in research settings, Mindful Instruction research needs to be examined from actual classroom settings where Mindful Instruction is used over an extended period of time.

Implications for teachers from the current study are suggested as well. For many teachers, "paying attention" is a desired behavior necessary for successful instruction to occur. "Paying attention" for many students implies holding a stimulus constant. In practicing Mindfulness, students are asked to be aware of the stimulus in the present moment. Thus, practicing Mindfulness may be useful in preparing students for problem-solving by allowing students to view the stimulus as constantly changing. By viewing the stimulus as constantly changing, a student may possibly better accept or be open to changes that occur in the stimulus. This view of an ever-changing stimulus may lead the student to think of alternative or multiple solutions to problems, i.e. problem-solving behavior.

As noted in the Limitations section, this research study was limited by the short period of time that the students participated in the Mindful Instruction and Mindfulness meditation. The interaction of Mindfulness Groups (High 


\section{Mindfulness Education}

Mindfulness versus Low Mindfulness) by Instruction Type (Mindful versus NonMindful) was statistically non-significant. This lack of interaction suggests that the Mindful Instruction was not effective in producing significant difference in content scores between Mindfulness Groups. Similarly, the results from the data suggest that the interaction of Instruction Type (Mindful versus Non-Mindful) did not statistically affect the scores on the "Modified Guilford Test of Alternate Uses" or the embedded measures of Mindfulness. In some instances, the Low Mindfulness Group performed slightly better than the High Mindfulness Group after Non-Mindful Instruction. Perhaps if the research study was conducted over an extended period of time (e.g., semester), the results of the research study may have produced more significant results. In reviewing the literature, there are few instances where Mindful Instruction has been studied in actual classroom settings. Similarly, the literature has an abundant amount of qualitative studies and articles on Mindfulness while very few quantitative research studies involving Mindfulness have been conducted.

Another implication for instruction from the Mindfulness research study is the need for further research into a combined form of Mindful Instruction and Mindfulness meditation. This research study was novel in its attempts to examine a combined form of Mindful Instruction and Mindfulness meditation. This research study attempted to combine the traditional, Buddhist form of Mindfulness meditation as defined by Hanh (1991) and the Mindfulness applied to educational psychology as defined by Langer (1989). While attempting to combine two different forms of Mindfulness was unique, creating assessment 


\section{Mindfulness Education}

tools to assess this combined form of Mindfulness proved challenging. The LMS was created to measure the Mindfulness as defined by Langer (1993) and applied to educational psychology. The MAAS is more of a measure of the traditional form of Mindfulness with questions relating to awareness of the present moment. The weak relationship between the pre-LMS, post-LMS, and the MAAS demonstrates that Mindfulness is viewed somewhat differently when defined and applied across various settings. Continuing investigation will be required to effectively combine the traditional form of Mindfulness as defined by Hanh (1991) and the Mindfulness applied to educational psychology as defined by Langer (1989). Appropriate and sufficiently validated assessment tools will need to be created as well.

Implications for the Buddhist community are suggested from the current study as well. The limited research on applying Buddhist principles and traditions such as Mindfulness to education may suggest a need for the Buddhist community to expand the traditional environments in which Buddhism is practiced and applied. By incorporating Buddhism into other environments such as business or industry, Buddhism may prove an effective practice to improve output or in managing work-related stress. Further research on the differences of meditation experiences or the effectiveness of meditation with a person's eyes opened versus eyes closed also may prove beneficial. By examining different methods and techniques of meditation, Buddhist teachers may assist practitioners in creating more meaningful Mindfulness experiences. 


\section{Mindfulness Education}

\section{Conclusion}

The last 20 years have seen the growth of Mindfulness, both in applications to psychology in clinical and educational settings and to society as a form of meditative practice. This study was novel in its attempts to examine a form of Mindfulness that combined the different applications and definitions of Mindfulness. While much literature has been written about Mindfulness, the research of Mindfulness still appears to be in its infancy. As shown in the literature review, the processes and concepts that constitute a Mindful education are not without basis in the foundations of Educational Psychology. At the present moment, existing research and literature offer different perspectives on the effectiveness and appropriateness of Mindfulness in education. Nevertheless, with further research and discussion, the potential value of Mindfulness as an instructional strategy and educational goal appears to be promising. 


\section{Mindfulness Education}

\section{References}

Baird, B. (2005). The internship, practicum, and field placement handbook: A guide for the helping professions. New Jersey: Pearson Prentice Hall.

Barell, J. (1995). Teaching for thoughtfulness. White Plains, NY: Longman Publishers.

Benassi, V., Mahler, H., \& Asdigian, N. (1993). The mindfulness of ostensibly thoughtless action. Journal of Social Behavior \& Personality, 8(6), 67-82.

Bishop, S., Lau, M., \& Shapiro, S. (2004). Mindfulness: A proposed operational definition. Clinical Psychology: Science \& Practice, 11(3), 230-241.

Bodner, T. (2001). On the assessment of individual differences in mindful information processing. Dissertation Abstracts International, 61, 9-B. (UMI No. AAI9988530).

Boggiano, A. K., Main, D. S., \& Katz, P. A. (1988). Children's preference for challenge: The role of perceived competence and control. Journal of Personality and Social Psychology, 54(1), 134-141.

Brown, J., \& Langer, E. (1990). Mindfulness and intelligence: A comparison. Educational Psychologist, 25(3-4), 305-335.

Brown, K. W., \& Ryan, R.M. (2003). The benefits of being present: mindfulness and its role in psychological well-being. Journal of Personality and Social Psychology, 84(4), 822-848.

Bruner, J. (1960). The process of education. Cambridge, MA: Harvard University Press. 
Bruner, J. (1966). Toward a theory of instruction. Cambridge, MA: Harvard University Press.

Bruner, J. (1990). Acts of meaning. Cambridge, MA: Harvard University Press. Bruner, J. (1996). The culture of education. Cambridge, MA: Harvard University Press.

Bruning, R. H., Schraw, G.J., \& Ronning, R. R. (1995). Cognitive Psychology and Instruction ( $2^{\text {nd }}$ ed.). NJ: Prentice Hall Publishers.

Carlson, L., Speca, M., Patel, K., \& Goodey, E. (2004). Mindfulness-based stress reduction in relation to quality of life, mood, symptoms of stress and levels of cortisol, dehydroepiandrosterone sulfate (DHEAS) and melatonin in breast and prostate cancer outpatients. Psychoneuroendocrinology, 29(4), 448-474.

Carson, S., Shih, M., \& Langer, E. (2001). Sit still and pay attention? Journal of Adult Development, 8(3), 183-188.

Chanowitz, B., \& Langer, E. (1981). Premature Cognitive Commitment. Journal of Personality and Social Psychology, 41, 1051-1063.

Chen, Z., \& Mo, L. (2004). Schema induction in problem solving: A multidimenstional analysis. Journal of Experimental Psychology: Learning, Memory, and Cognition, 30(3), 583-600.

Cunningham, T. H., \& Thorkildsen, R. J. (1996). Effects of combining casebased instruction and mindfulness activities on the acquisition, application, and transfer of complex knowledge: An experimental comparison of two multiple-case treatments on videodisc. Paper 
presented at the Annual Meeting of the American Educational Research Association, New York: NY.

Eby, F. (1952). The development of modern education ( $2^{\text {nd }}$ ed.). New York: Prentice-Hall, Inc.

Fahy, P. J. (1999). On-line teaching in distance education and training, MDDE 621, Study Guide. Athabasca, Canada: Athabasca University.

Folkes, V. S. (1985). Mindlessness or mindfulness: A partial replication and extension of Langer, Blank, and Chanowitz. Journal of Personality and Social Psychology, 48(3), 600-604.

Getzels, J., \& Czikszentmihalyi, M. (1976). The creative vision: A longitudinal study of problem finding in art. NY: Wiley.

Gilbert, A. (1973). An essay on the history of Asian psychology. Proceedings of the Annual Convention of the American Psychological Association, 937938.

Gillepsie, M. (2002). EFF research principles: A contextualized approach to curriculum and instruction. Washington, D.C.: National Institute for Literacy.

Grant, A. M., Langer, E., \& Falk, E. (2004). Mindful creativity: Drawing to draw distinctions. Creativity Research Journal, 16(2-3), 261-265.

Greenberg, D., \& Witztum, E. (1991). Problems in the treatment of religious patients. American Journal of Psychotherapy, 45(4), 554-565. 


\section{Mindfulness Education}

Grossman, P., Niemann, L., \& Schmidt, S. (2004). Mindfulness-based stress reduction and health benefits: A meta-analysis. Journal of Psychosomatic Research, 57(1), 35-43.

Halpern, D. (1998). Teaching critical thinking for transfer across domains: Dispositions, skills, structure training, and metacognitive monitoring. American Psychologist. 53(4) 449-455.

Hanh, T. N. (1976). The miracle of mindfulness. Boston, MA: Beacon Press. Hanh, T. N. (1987). Being peace. Berkeley, CA: Parallax Press.

Hanh, T. N. (1990a). Present moment, wonderful moment. Berkeley, CA: Parallax Press.

Hanh, T. N. (1990b). Transformation and healing. Berkeley, CA: Parallax Press.

Hanh, T. N. (1991). Peace is every step. New York: Bantam Books.

Hanh, T. N. (1997). Teachings on love. Berkeley, CA: Parallax Press.

Hanh, T. N. (2001). Anger: Wisdom for cooling the flames. New York: Riverhead Books.

Henson, R. (2001). The effects of participation in teacher research on teacher efficacy. Teaching and Teacher Education, 17(7), 819-836.

Holland, D. (2004). Integrating mindfulness meditation and somatic awareness into a public educational setting. Journal of Humanistic Psychology, 44(4), 468-484. 


\section{Mindfulness Education}

Kabat-Zinn, J. (2003). Mindfulness-based interventions in context: Past, present, and future. Clinical Psychology: Science \& Practice, 10(2), 144156.

Kabat-Zinn, J., Massion, A. O., Kristeller, J., Peterson, L.G., Fletcher, K., Pbert, L., Linderking, W., \& Santorelli, S. F. (1992). Effectiveness of a meditation-based stress reduction program in the treatment of anxiety disorders. American Journal of Psychiatry, 149, 936-943.

Kaplan, K. H., Goldenberg, D. L., \& Galvin-Nadeau, M. (1993). The impact of a meditation-based stress reduction program on fibromyalgia. General Hospital Psychiatry 15, 284-289.

Koestner, R., Ryan, R. M., \& Bernieri, F. (1984). Setting limits on children's behavior: The differential effects of controlling vs. informational styles on intrinsic motivation and creativity. Journal of Personality, 52(3), 233-248.

Langer, E. (1989). Mindfulness. Reading, MA: Addison-Wesley.

Langer, E. (1993). A mindful education. Educational Psychologist, 28(1), 43-50.

Langer, E. (1997). The power of mindful learning. Reading, MA: AddisonWesley.

Langer, E. (2000). Mindful learning. Current Directions in Psychological Science: A journal of the American Psychological Society, 9(6), 220-223.

Langer, E., Bashner, R., \& Chanowitz, B. (1985). Decreasing prejudice by increasing discrimination. Journal of Personality and Social Psychology, 49(1), 113-120. 
Langer, E., \& Brown, J. (1992). Mindful learning: A world without losers. New Directions for Adult and Continuing Education, 53, 11-20.

Langer, E., \& Chanowitz, B. (1988). Mindfulness/mindlessness: A new perspective for the study of disability. In Yuker, H. E., Attitudes toward people with disabilities (p.68-81). New York: Springer Publishing Co.

Langer, E., Hatem, M., Joss, J., \& Howell, M. (1989). Conditional teaching and mindful learning: The role of uncertainty in education. Creativity Research Journal, 2, 139-150.

Langer Mindfulness Scale. Retrieved February $10^{\text {th }}, 2005$, from http://www.idspublishing.com/langers.htm

Langer, E., \& Moldoveanu, M. (2000). The construct of mindfulness. Journal of Social Issues, 56(1), 1-9.

Langer, E., Perlmuter, L., Chanowitz, B., \& Rubin, R. (1988). Two new applications of mindlessness theory: Aging and alcoholism. Journal of Aging Studies, 2, 289-299.

Langer, E., \& Piper, P. (1987). The prevention of mindlessness. Journal of Personality and Social Psychology, 53, 280-287.

Levy, B., Jennings, P., \& Langer, E. (2001). Improving attention in old age. Journal of Adult Development, 8(3), 189-192.

Long, J. D., \& Biggs, J. C. (1999). Perceptions of education majors and experienced teachers regarding factors that contribute to successful classroom management. Journal of Instructional Psychology, 26, 105110. 


\section{Mindfulness Education}

Ma, S.F., \& Teasdale, J.D. (2004). Mindfulness-based cognitive therapy for depression: Replication and exploration of differential relapse prevention effects. Journal of Consulting and Clinical Psychology, 72, 31-40.

Macaulay, C., \& Cree, V. (1999). Transfer of learning: Concept and process. Social Work Education, 18(2), 183-194.)

Merriam Webster's Third New International Dictionary. (1981). Springfield, MA: Merriam-Webster Inc.

Merriam Webster's Third New International Dictionary. (1993). Springfield, MA: Merriam-Webster Inc.

Miller, J. (2004). Contemplation, presence, and mindfulness in teacher education. Paper presented to the American Educational Research Association, San Diego, CA.

Miller, J., Fletcher, K., \& Kabat-Zinn, J. (1995). Three-year follow-up and clinical implications of a mindfulness-based stress reduction intervention in the treatment of anxiety disorders. General Hospital Psychiatry 17, 192-200.

Mindfulness meditation. (2005). Retrieved April 25-28, 2005, from http://www.beliefnet.org.

Ramel, W., Goldin, P. R., \& Carmona, P. E. (2004). The effects of mindfulness meditation on cognitive processes and affect in patients with past depression. Cognitive Therapy \& Research, 28(4), 433-455.

Reiss, S. (2000). A mindful approach to mental retardation. Journal of Social Issues, 56(1), 65-80. 
Rieber, R.W., \& Carton, A.S. (1987). The collected works of L.S. Vygotsky. New York Plenum Press.

Ritchhart, R., \& Perkins, D. (2000). Life in the mindful classroom: Nurturing the disposition of mindfulness. Journal of Social Issues, 56(1), 27-47.

Rosenzweig, S., Reibel, D., Greeson, J., Brainard, G., \& Hojat, M. (2003). Mindfulness-based stress reduction lowers psychological distress in medical students, Teaching \& Learning in Medicine, 15(2), 88-93.

Rybak, C. J., \& Russell-Chapin, L. A. (1998). The teaching well: Experience, education and counseling. International Journal for the Advancement of Counseling, 20(2), 131-139.

Scherer-Dickson, N. (2004). Current developments of metacognitive concepts and their clinical implications: Mindfulness-based cognitive therapy for depression. Families, Systems, \& Health, 22(2), 193-203.

Schwartz, D., \& Martin, T. (2004). Inventing to prepare for future learning: The hidden efficiency of encouraging original student production in statistics instruction. Cognition and Instruction, 22(2), 129-184.

Segal, Z.V., Williams, J.M.G., \& Teasdale, J.D. (2002). Mindfulness-based cognitive therapy for depression: A new approach to preventing relapse. Psychotherapy Research, 13(1), 123-125.

Shapiro, S., Schwartz, G., \& Bonner, G. (1998). Effects of mindfulness-based stress reduction on medical and premedical students. Journal of Behavioral Medicine, 21(6), 581-599. 
Singh, N., Wahler, R., Adkins, A., \& Myers, R. (2003). Soles of the feet: A mindfulness-based self-control intervention for aggression by an individual with mild retardation and mental illness. Research in Developmental Disabilities, 24, 58-169.

Sternberg, R. (2000). Images of mindfulness. Journal of Social Issues, 56(1), $11-26$.

Tacon, A., Caldera, Y., \& Ronaghan, C. (2004). Mindfulness-based stress reduction in women with breast cancer. Families, Systems, \& Health, 22(2), 193-203.

Teasdale, J.D., Segal, Z.V., Williams, J.M.G., Ridgeway, V., Soulsby, J., \& Lau, M. (2000). Prevention of relapse/recurrence in major depression by mindfulness-based cognitive therapy. Journal of Consulting and Clinical Psychology 68, 615-623.

Tudge, \& Scrimsher. (2003). Lev S. Vygotsky on eduction: A cultural-historical, interpersonal, and individual approach to development. In Zimmerman, B., \& Schunk, D., Educational Psychology: A century of contributions (p. 207-228). Mahwah, NJ: Lawrence Erlbaum Associates.

White, W. (1998). Chasing the Buddha: Bringing Meditation to Experiential Education. Association for Experiential Education.

Williams, M., \& Swales, M. (2004). The use of mindfulness-based approaches for suicidal patients. Archives of Suicidal Research, 8(4), 315-329. 


\section{Mindfulness Education}

Wong, B. Y. L. (1994). Instructional parameters promoting transfer of learned strategies in students with learning disabilities. Learning Disability Quarterly, 17(2), 110-120.

Worthington, E., \& Sandage, S. (2001). Religion and spirituality. Psychotherapy, 38(4), 473-478. 


\section{Appendix A}

\section{Langer Mindfulness Scale}

\section{Instructions and Scoring Information}

\section{Personal Outlook Scale}

Instructions: Below are a number of statements that refer to your personal outlook. Please rate the extent to which you agree with each of these statements. If you are confused by the wording of an item, have no opinion, or neither agree nor disagree, use the "4" or "NEUTRAL" rating. Thank you for your assistance.

$\begin{array}{ccccccc}1 & 2 & 3 & 4 & 5 & 6 & 7 \\ \text { Strongly } & \text { Disagree } & \text { Slightly } & \text { Neutral } & \text { Slightly } & \text { Agree } & \text { Strongly } \\ \text { Disagree } & & \text { Disagree } & & \text { Agree } & & \text { Agree }\end{array}$

1. I like to investigate things.

2. I generate few novel ideas.

3. I am always open to new ways of doing things.

4. I "get involved" in almost everything I do.

5. I do not actively seek to learn new things.

6. I make many novel contributions.

7. I stay with the old tried and true ways of doing things.

8. I seldom notice what other people are up to.

9. I avoid thought-provoking conversations.

10. I am very creative.

11. I can behave in many different ways for a given situation.

12. I attend to the "big picture."

13. I am very curious.

14. I try to think of new ways of doing things.

15. I am rarely aware of changes.

16. I have an open-mind about everything, even things that challenge my core beliefs.

17. I like to be challenged intellectually.

18. I find it easy to create new and effective ideas.

19. I am rarely alert to new developments.

20. I like to figure out how things work.

21. I am not an original thinker.
Disagree

$\begin{array}{lllllll}1 & 2 & 3 & 4 & 5 & 6 & 7 \\ 1 & 2 & 3 & 4 & 5 & 6 & 7 \\ 1 & 2 & 3 & 4 & 5 & 6 & 7 \\ 1 & 2 & 3 & 4 & 5 & 6 & 7 \\ 1 & 2 & 3 & 4 & 5 & 6 & 7 \\ 1 & 2 & 3 & 4 & 5 & 6 & 7 \\ 1 & 2 & 3 & 4 & 5 & 6 & 7 \\ 1 & 2 & 3 & 4 & 5 & 6 & 7 \\ 1 & 2 & 3 & 4 & 5 & 6 & 7 \\ 1 & 2 & 3 & 4 & 5 & 6 & 7 \\ 1 & 2 & 3 & 4 & 5 & 6 & 7 \\ 1 & 2 & 3 & 4 & 5 & 6 & 7 \\ 1 & 2 & 3 & 4 & 5 & 6 & 7 \\ 1 & 2 & 3 & 4 & 5 & 6 & 7 \\ 1 & 2 & 3 & 4 & 5 & 6 & 7 \\ 1 & 2 & 3 & 4 & 5 & 6 & 7 \\ 1 & 2 & 3 & 4 & 5 & 6 & 7 \\ 1 & 2 & 3 & 4 & 5 & 6 & 7 \\ 1 & 2 & 3 & 4 & 5 & 6 & 7 \\ 1 & 2 & 3 & 4 & 5 & 6 & 7 \\ 1 & 2 & 3 & 4 & 5 & 6 & 7\end{array}$

\section{Scoring Information}

- $\quad$ To score the scale, reverse score item numbers 2, 5, 7, 8, 9, 15, 19, and 21 and simply compute a mean of the 21 items. 
Appendix B

Math and Disability Content Tests

\section{Content Test on Math}

Directions: Answer the following questions on the Pythagorean Theorem as best as you can.

1.

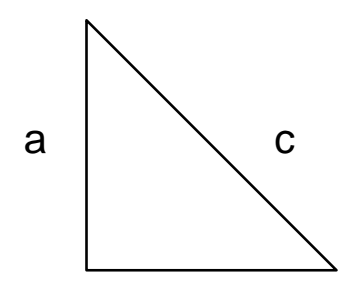

b

If $a=12$ and $c=15$, what is the value for side $b$ ?

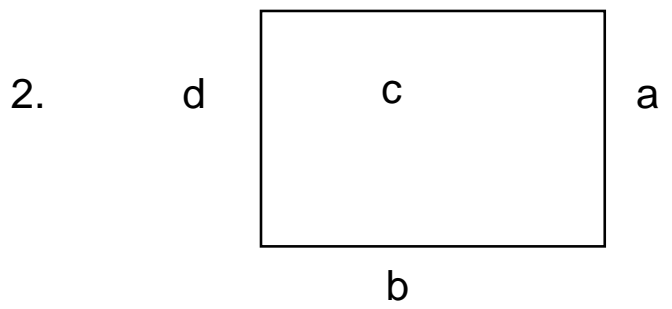

If $a=3, b=4, c=5$, what is the value for side $d$ ? 
3. You are walking to your friend's house. In order to do so, you could walk around the block that is $32 \mathrm{ft}$ by $24 \mathrm{ft}$ or you could cut through the yard (no fence to block your way). How much shorter will you walk if you cut through the yard instead of walking around on the sidewalk?

Friend's House

32 Feet
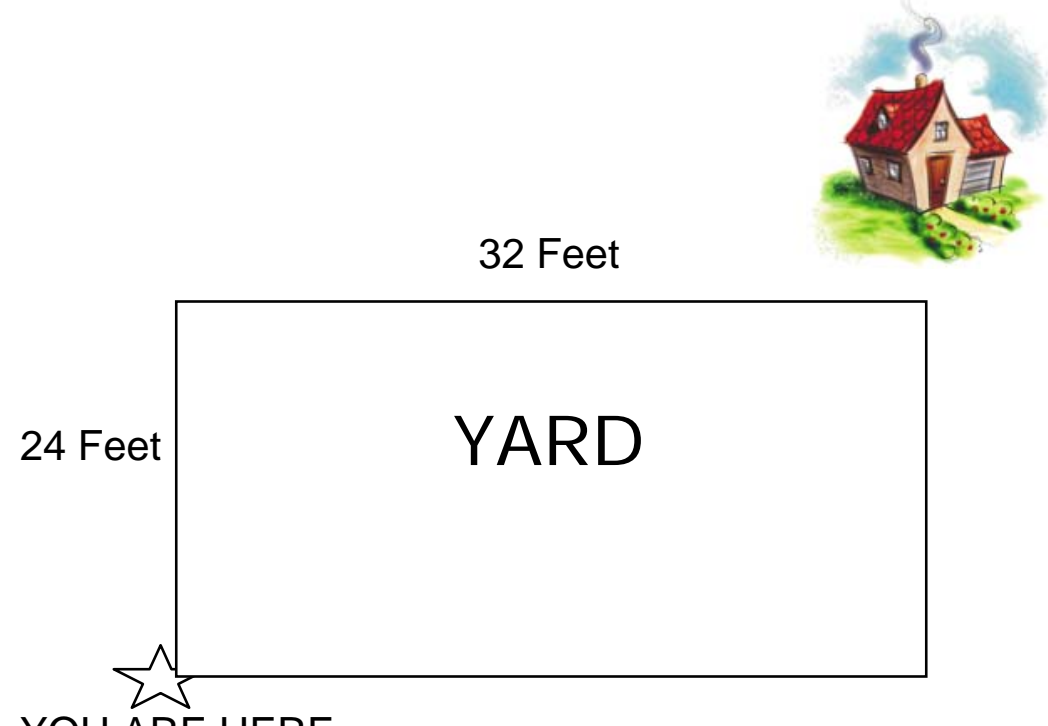

YOU ARE HERE

4. You are going to Circuit City later to buy a television (you just graduated and have lots of money from presents). The entertainment system that you received as a gift has a space for the television that is 30 in by 40 in. How big of a television set can you buy to still fit in the entertainment system? (Remember: television manufacturers measure them using the diagonal measurement.) 
5. An airplane traveling from Charleston, West Virginia to Erie, Pennsylvania crashes with 12 Massachusetts' citizens aboard. The Pennsylvania border is 350 miles from Charleston, West Virginia. The plane was off the radar screen, but the plane fell from the sky somewhere around the West VirginiaPennsylvania border. If the plane's take off was gradual and the plane fell 400 miles straight down from the sky having already logged 500 miles, in what state would the survivors be buried and why?

500 Miles

400 Miles
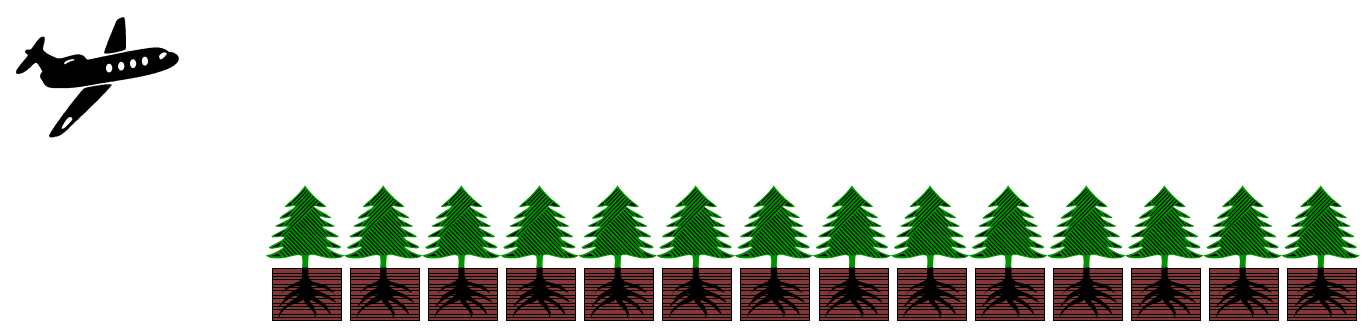
6. You are Prince Charming and you have just killed the dragon that has captured your lovely princess. She is locked away in a tower of the dragon's castle that is 60 feet high. The castle is surrounded by a 30 foot wide moat. Sadly, the dragon made sure the draw bridge was drawn up before he left the the castle to fight you. Fortunately for you, you have $65 \mathrm{ft}$ of rope. Do you have enough to throw to your princess? If not, how much must you wade into the moat in order to reach the princess with the rope? 


\section{Content Test on Disability}

\section{People First Language}

Read the following newspaper excerpt. Circle or underline as many words or phrases that do not reflect the use of People First Language in the following story. Write a correct word or phrase that DOES reflect the use of People First Language above the incorrect word or phrase. Also, please mark any grammatical or syntax errors on the entire test.

\section{Retarded Man Finds Good Paying J ob and Own Apartment}

\section{The Daily Times}

(Middle-of-Nowhere, West Virginia) An 18 year old city resident with cerebral palsy looks at the clean table at the Burger King and can proudly say he's done more than just a good job. Jimmy Kimmel began working here 5 months ago and is now the new night manager at the Burger King. Jimmy suffers from cerebral palsy, a birth defect that that causes his speech to be slurred and for him to not always have control of his muscles. Unlike most people who are handicapped with cerebral palsy and are wheelchair bound, Jimmy is as active as any normal teenager.

Jimmy is no stranger to success either. Six months ago Jimmy graduated from Blue Ridge High School where he took classes with normal kids and still graduated with a 3.0 average. Not only is he enjoying his new job as night manager, Jimmy just moved into his own apartment. "I figured I was 18 and was time for me to go out on my own," Jimmy struggles to say.

“He sets an example for the other employees,” Josh Miller, store owner said. “He has a great customer relationship. Anything he sets out to do, he has a positive attitude and he goes at it 100 percent.” 
What's next for Jimmy? Jimmy's got more dreams he'd like to accomplish.

Jimmy says he’s saving his money so that he can start college next fall. "I need to work to save some money so that I can get a college degree. I'd like to study architecture.” Well, no doubt this special person will try his best!

What is incorrect about the story title? Explain your answer

\section{What is it?}

Read the following and answer the questions in the space provided. Circle or underline any words or phrases that do not reflect People First Language. Write a correct word or phrase that DOES reflect the use of People First Language above the incorrect word or phrase.

Susan is stricken with cerebral palsy. She is a freshman at WVU and today is the first day of classes. Susan is crippled severely and uses a power wheelchair to get around campus. Upon arriving at the building where the class is located, she finds that the door is not wide enough for her chair to get through the door. Susan is not able to attend this class.

a. What is Susan's impairment?

b. What is her disability as a result of the impairment?

c. How does Susan overcome her disability?

d. What is handicapping Susan?

Tom is mentally challenged and has been working at a bakery for the last 5 years. Tom folds boxes which are used for shipping donuts. Tom really wants to be a server in the bakery's coffee shop so that he could have more contact with customers. Whenever he asks his boss if he can be trained as a server, the bakery owner tells Tom that remembering all the different types of donuts would be too complicated for Tom. Tom had been in a car accident 10 years ago that caused a head injury and resulted in Tom having difficulty remembering names of objects. 
e. What is Tom's Disability?

f. What is handicapping Tom from becoming a waiter? 


\section{Appendix C \\ Modified Guilford Test of Alternate Uses \\ Instructions and Scoring Information}

Participants will be asked to list as many possible uses for a common household item. The household items that the students will be presented are (a) a brick, (b) a newspaper, (c) a shoe, and (d) a paperclip.

Instructions:

1. Test Administrator will give students two sheets of wide ruled paper.

2. Test Administrator will ask students to write their ID number on the paper.

3. Test Administrator will hold a shoe and ask, "List as many possible uses for this object, a shoe, that you can think of."

4. Test Administrator will hold a brick and ask, "List as many possible uses for this object, a brick, that you can think of."

5. Test Administrator will hold a newspaper and ask, "List as many possible uses for this object, a newspaper, that you can think of."

6. Test Administrator will hold a paper clip and ask, "List as many possible uses for this object, a paper clip, that you can think of."

7. Answer sheets will be collected.

\section{Scoring Information}

- $\quad$ To score for the fluency construct of Mindfulness, total all the responses for each participant. The number of responses is the score of fluency. 
Appendix D

Embedded Measures of Mindfulness

Explanation of Embedded Measures of Mindfulness

While the Modified Guilford Test of Alternative Uses measured the fluency construct of Mindfulness, different, less prompted measures to assess the attention and awareness components of Mindfulness were included as well. Assessing attention and awareness is difficult due to the inherent characteristics and definitions of these domains. Difficulty arises in finding appropriate means of assessing attention and awareness without inherently alerting the consciousness (i.e., attention and awareness) of the participant. To measure attention and awareness, subtle elements requiring attention and awareness were embedded into the content tests (Disability and Mathematics). These elements will reflect whether the participant is attending or aware of what he or she is reading. For example, the participants were asked to spell "SPOT." The researcher then followed with the question, "What do you do at a green light?" and instructed the participants to write down their response quickly. The following two subheadings state where the embedded measures of Mindfulness are located and how they are scored.

Location and Scoring of Embedded Measures of Mindfulness Math Topic

- Participants were asked on the Math Pre-Test to answer the following question:

When I was going to St. Ives, 
I met a man with seven wives;

And every wife had seven sacks,

And every sack had seven cats,

And every cat had seven kits.

Kits, cats, sacks, wives;

How many were going to St. Ives?

Participants were given a one for a correct answer that reflects the first sentence and answer, "When I was going to St. Ives." Thus, the answer is "I" or the number one. Participants received a zero for any other answer besides "I" or the number one.

- $\quad$ Participants were asked on the Math Pre-Test to spell "SPOT." The participants then were asked to write down an immediate answer to the question, "What do you do at a green light?" Participants were given a one for writing the correct answer "go" and given a zero for the word "stop" written anywhere on his or her paper.

- $\quad$ A word problem on the Math content test (See Appendix B) states:

An airplane traveling from Charleston, West Virginia to Erie, Pennsylvania crashes with 12 Massachusetts' citizens aboard. The Pennsylvania border is 350 miles from Charleston, West Virginia. The plane was off the radar screen, but the plane fell from the sky somewhere around the West Virginia-Pennsylvania border. If the plane's take off was gradual and the plane fell 400 miles straight 
down from the sky having already logged 500 miles, in what state would the survivors be buried and why?

Participants were given a one for noticing that the word "survivor" is counterintuitive to being buried. Participants were given a zero if he or she mathematically completed the problem or do not notice that the word "survivor" is counterintuitive to being buried.

Location and Scoring of the Embedded measures of Mindfulness for Disability Topic

- The word "that" is repeated at the end of the fourth line and the beginning of the fifth line of the first paragraph on the Disability content test (See Appendix B). Participants were given a one for identifying "that" as repeated and zero for not identifying "that."

- The title of the story in the Disability content test (See Appendix B) states that Jimmy has mental retardation and implies that he is not of average mental ability. Yet, a Disability content test question asks what is incorrect about the title and asks the participant to explain his or her response. Participants were given a one for correctly stating that Jimmy's disability is physical not mental. Participants were given a zero for saying that the title did not use PFL or not identifying his disability as physical not mental. 
Appendix E

Directions, Criteria, and Content of Mindful and Non-Mindful Instruction on Math Mindful Instruction Directions

Materials needed: Chalk, chalkboard, scratch paper, pencils, and calculators Equipment needed: Internet access with speakers

Directions and Content:

- Instructor will ask students to participate in a Mindfulness meditation as part of the instruction.

- Instructor will play Mindfulness meditation.

- Instructor will pose the word problem about Mountaineers:

You are the West Virginia Mountaineer Mascot and with a paint ball musket. You are at the stadium in the Press Box. The Press Box is $40 \mathrm{ft}$ high. You see the Miami Hurricanes Mascot on the football field. You know from previous experience that the football field is $100 \mathrm{ft}$ away from the bottom of the Press Box. What must be the range of the paint ball musket in order to shoot the Hurricanes Mascot from where you are standing?

- Instructor will answer the Mountaineer problem by explaining the Pythagorean Theorem. Explain the Pythagorean Theorem by defining the sides of a right triangle according to the Mountaineer story and showing that $A$ and $B$ are the legs and $C$ is the hypotenuse.

- Instructor will pose the problem solving strategy used in solving the Mountaineer problem by: 
o Drawing a picture.

o Labeling all known lengths.

o Filling in knowns into appropriate places of Pythagorean Theorem.

o Solving for the missing side.

o Answering the question.

o Using rulers and special right triangle numbers to satisfy curiosity.

- Instructor will prompt students for ideas in which the Pythagorean

Theorem can be applied to everyday life examples using the following

numbers: $3,4,5 \quad 5,12,13 \quad 7,24,25 \quad 8,15,17$

- Instructor will ask students for any additional questions in order to clarify understanding of the subject matter. 


\section{Criteria for Mindful Instruction of Math}

- Instructor will engage students in a 10-minute Mindfulness meditation.

- Instructor will begin by making the information relevant to students' lives.

- Instructor will use conditional language at least 15 times. For example, "This could be an example of a right triangle."

- Instructor will prompt students at least 10 times for ideas on content.

- Instructor will apply word problem to Pythagorean Theorem.

- Instructor will use example as a guide for problem solving similar word problems.

- Instructor will use examples from everyday, contemporary life.

- Instructor will pose at least two alternative ways to solve a problem. 


\section{$\underline{\text { Non-Mindful Instruction Directions }}$}

Materials needed: Chalk, chalkboard, scratch paper, pencils, and calculators Directions and Content:

- Instructor will show what a right triangle is and name the sides.

- Instructor will demonstrate the Pythagorean Theorem using the chalkboard.

- Instructor will read history of Pythagorean Theorem.

- Instructor will have students memorize Pythagorean Theorem.

- Instructor will teach the Pythagorean Theorem according to rules and numbers.

- Instructor will list steps to problem solve and review each step with the students.

- Instructor will use numbers for examples in at least five problems.

- Instructor will do at least two word problems using archaic examples with little or no relevance to the students' everyday lives.

- Instructor will ask students for any additional questions in order to clarify understanding of the subject matter. 


\section{Criteria for Non-Mindful Instruction of Math}

- Instructor will use absolute language at least 15 times during the instructional activity. For example, "This is a right triangle."

- Instructor will teach using rules and numbers.

- Instructor will use at least two irrelevant, archaic examples which do not relate to the students' everyday lives.

- Questions will be asked requiring Yes or No answers.

- Students will be taught using memorization.

- The content will not be made relevant to the students. 
Appendix $\mathrm{F}$

Directions, Criteria, and Content of Mindful and Non-Mindful Instruction of

Disability

\section{Mindful Instruction Directions}

Equipment needed: Microsoft PowerPoint and projector

Directions and Content:

- Instructor will ask students to participate in a 10-minute Mindfulness meditation as part of the instruction.

- Instructor will play 10-minute Mindfulness meditation.

- Instructor will ask students if they have a disability or know someone with a disability.

- Instructor will ask students if anyone familiar with the words "impairment," "disability," and "handicap."

- Instructor will ask for several students to give examples and definitions of “impairment," "disability," and "handicap."

- Instructor will define "impairment."

- Instructor will give examples of "impairment."

- Instructor will define "disability."

- Instructor will give examples of "disability."

- Instructor will define "handicap."

- Instructor will give examples of "handicap."

- Instructor will have students generate sentences with examples of each term relevant to everyday life. 
- Instructor will define People First Language (PFL).

- Instructor will give PFL examples.

- Instructor will ask students for any additional questions in order to clarify understanding of the subject matter. 


\section{Criteria for Mindful Instruction of Disability}

- Instructor will engage students in a 10-minute Mindfulness meditation.

- Instructor will use conditional language at least 15 times during instructional activity. For example, Walking could be an example of a disability for a person with Cerebral Palsy.

- Instructor will ask students for their own original answers at least 10 times during lesson.

- Instructor will make the information relevant at least 4 times.

- Instructor will demonstrate relevance of information at the beginning of the instructional activity.

- Instructor will problem solve with students for possible solutions to at least four questions prompted by instructor.

- Instructor will draw novel distinctions for at least three words that are already familiar to the student. 


\section{$\underline{\text { Non-Mindful Instruction Directions }}$}

- Instructor will give students a definition of "impairment"

- Instructor will give examples of "impairment."

- Instructor will have students memorize definition of "impairment."

- Instructor will give examples of "impairment."

- Instructor will give students definition of "disability"

- Instructor will give examples of "disability."

- Instructor will have students memorize definition of "disability."

- Instructor will give examples of "disability."

- Instructor will give students definition of "handicap."

- Instructor will have students memorize definition of "handicap."

- Instructor will give examples of "handicap."

- Instructor will define PFL.

- Instructor will give examples of PFL.

- Instructor will have students memorize definition of PFL.

- Instructor will give examples of PFL.

- Instructor will ask students for any additional questions in order to clarify understanding of the subject matter. 


\section{Criteria for Non-Mindful Instruction of Disability}

- Instructor will not apply relevance of information to students or their daily lives.

- Instructor will ask Yes or No questions at least 15 times during the instructional activity.

- Instructor will use absolute language at least 15 times during the instructional activity. For example, Walking is an example of a disability for someone with cerebral palsy.

- Instructor will ask students to memorize at least three definitions.

- Instructor will use at least five irrelevant or archaic examples.

- Instructor will rely on students' current knowledge of at least three definitions and correct (if incorrect) the information to fit the current lesson or restate (if accurate) the definitions using the same language as the student.

- Instructor will rely on historical context of disability in defining People First Language. For example, "During the early modern history of the 1700's and 1800's people with disabilities were sometimes regarded as being 'evil' or 'possessed'." 
Appendix $G$

Mindfulness Attention-Awareness Scale

Instructions and Scoring Information

Day-to-Day Experiences

Instructions: Below is a collection of statements about your everyday experience. Using the 1-6 scale below, please indicate how frequently or infrequently you currently have each experience. Please answer according to what really reflects your experience rather than what you think your experience should be. Please treat each item separately from every other item.

\begin{tabular}{|c|c|c|c|c|c|}
\hline 1 & 2 & 3 & 4 & 5 & 6 \\
\hline $\begin{array}{l}m \\
w\end{array}$ & $\begin{array}{c}\text { Very } \\
\text { frequently }\end{array}$ & $\begin{array}{l}\text { Somewhat } \\
\text { Frequently }\end{array}$ & $\begin{array}{l}\text { Somewhat } \\
\text { Infrequently }\end{array}$ & $\begin{array}{c}\text { Very } \\
\text { Infrequently }\end{array}$ & \\
\hline
\end{tabular}

I could be experiencing some emotion and not be conscious of it until some time later.

I break or spill things because of carelessness, not paying attention, or thinking of something else.

123456

I find it difficult to stay focused on what's happening in the present.

123456

I tend to walk quickly to get where I'm going without paying attention to what I experience along the way.

123456

I tend not to notice feelings of physical tension or discomfort until they really grab my attention.

123456

I forget a person's name almost as soon as I've been told it for the first time.

123456

It seems I am "running on automatic," without much awareness of what I'm doing.

123456

I rush through activities without being really attentive to Them

I get so focused on the goal I want to achieve that I lose touch with what I'm doing right now to get there

I do jobs or tasks automatically, without being aware of 
what I'm doing.

I find myself listening to someone with one ear, doing something else at the same time

123456

I drive places on "automatic pilot" and then wonder why I went there.

123456

I find myself preoccupied with the future or the past.

123456

I find myself doing things without paying attention.

123456

I snack without being aware that I'm eating.

123456

\section{Scoring information}

- To score the scale, simply compute a mean of the 15 items. Higher scores reflect higher levels of dispositional mindfulness 


\section{Appendix $\mathrm{H}$}

Checklists for Mindful Instruction of Math and Disability

\section{Checklist for Mindful Instruction of Math}

- Instructor will begin by making the information relevant to students' lives using words like "You" and "In your life".

CIRCLE: YES OR NO

- Instructor will use conditional language at least 15 times. For example, "This could be an example of a right triangle."

\begin{tabular}{|l|l|l|l|l|l|l|l|l|l|l|l|l|l|l|}
\hline & & & & & & & & & & & & & & \\
\hline
\end{tabular}

- Instructor will prompt students at least 10 times for ideas on content and answers.

\begin{tabular}{|l|l|l|l|l|l|l|l|l|l|}
\hline & & & & & & & & & \\
\hline
\end{tabular}

- Instructor will apply word problem to Pythagorean Theorem.

CIRCLE: YES OR NO

- Instructor will use example as a guide for problem solving similar word problems.

CIRCLE: YES OR NO 
- Instructor will use examples from everyday, contemporary life.

\begin{tabular}{|c|l|l|}
\hline EXAMPLE & YES & NO \\
\hline 1 & & \\
\hline 2 & & \\
\hline 3 & & \\
\hline 4 & & \\
\hline 5 & & \\
\hline 6 & & \\
\hline 7 & & \\
\hline
\end{tabular}




\section{Checklist for Mindful Instruction of Disability}

- Instructor will use conditional language at least 15 times during instructional activity.

For example, Walking could be an example of a disability for a person with Cerebral Palsy.

\begin{tabular}{|l|l|l|l|l|l|l|l|l|l|l|l|l|l|l|}
\hline & & & & & & & & & & & & & & \\
\hline
\end{tabular}

- Instructor will ask students for their own original answers at least 10 times during lesson.

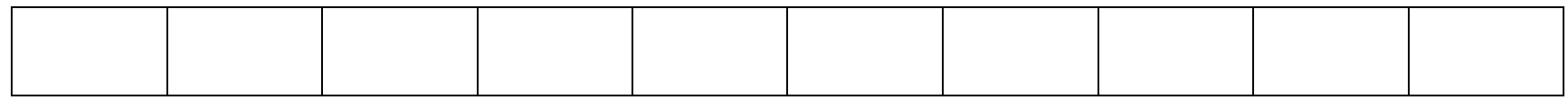

- Instructor will make the information relevant at least 4 times.

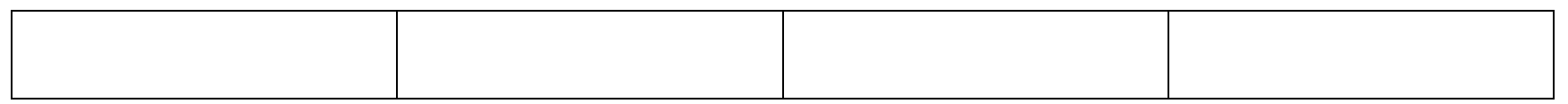

- Instructor will demonstrate relevance of information at the beginning of the instructional activity. $\quad$ CIRCLE: YES OR NO

- Instructor will problem solve with students for possible solutions to at least four questions prompted by instructor.

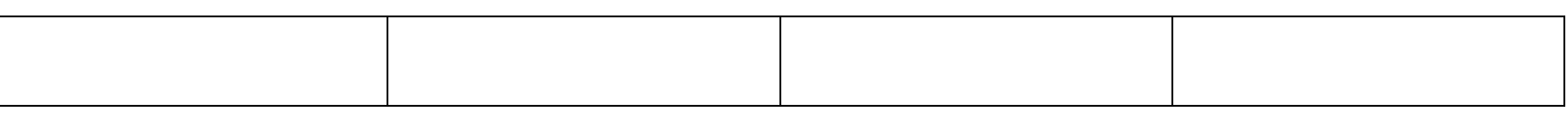

- Instructor will draw novel distinctions for at least three words that are already familiar to the student.

\begin{tabular}{|c|c|c|}
\hline IMPAIRMENT & DISABILITY & HANDICAP \\
\hline YES OR NO & YES OR NO & YES OR NO \\
\hline
\end{tabular}




\section{Appendix I}

Checklists for Non-Mindful Instruction of Math and Disability

Checklist for Non-Mindful Instruction of Math

- Instructor will use absolute language at least 15 times during the instructional activity. For example, "This is a right triangle."

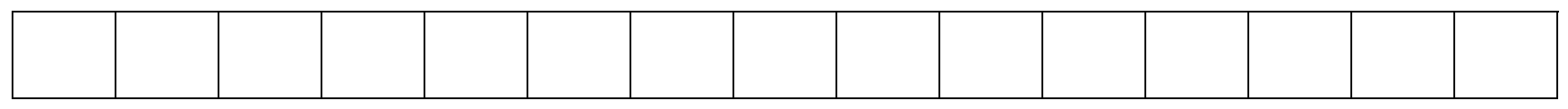

- Instructor will teach using rules and numbers for at least 3 problems.

\begin{tabular}{|c|c|c|}
\hline PROBLEM 1 & YES & NO \\
\hline PROBLEM 2 & YES & NO \\
\hline PROBLEM 3 & YES & NO \\
\hline
\end{tabular}

- Instructor will use at least two irrelevant, archaic examples which do not relate to the students' everyday lives.

\begin{tabular}{|c|c|c|}
\hline EXAMPLE 1 & YES & NO \\
\hline EXAMPLE 2 & YES & NO \\
\hline
\end{tabular}

- 10 Questions will be asked requiring Yes or No answers.

\begin{tabular}{|l|l|l|l|l|l|l|l|l|l|}
\hline & & & & & & & & & \\
\hline
\end{tabular}

- Students will be taught using memorization. CIRCLE: YES OR NO

- The content will not be made relevant to the students. CIRCLE: YES OR NO 
Checklist for Non-Mindful Instruction of Disability

- Instructor will not apply relevance of information to students or their daily lives.

CIRLCE: YES OR NO

- Instructor will ask Yes or No questions at least 15 times during the instructional activity.

\begin{tabular}{|l|l|l|l|l|l|l|l|l|l|l|l|l|l|l|}
\hline & & & & & & & & & & & & & & \\
\hline
\end{tabular}

- Instructor will use absolute language at least 15 times during the instructional activity.

For example, Walking is an example of a disability for someone with cerebral palsy.

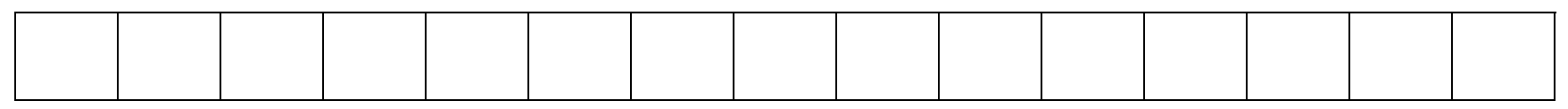

- Instructor will ask students to memorize at least three definitions.

\begin{tabular}{|c|c|c|}
\hline IMPAIRMENT & DISABILITY & HANDICAP \\
\hline YES OR NO & YES OR NO & YES OR NO \\
\hline
\end{tabular}

- Instructor will use at least four irrelevant or archaic examples.

- Instructor will rely on students' current knowledge of at least three definitions and correct (if incorrect) the information to fit the current lesson or restate (if accurate) the definitions using the same language as the student.

\begin{tabular}{|c|c|c|}
\hline IMPAIRMENT & DISABILITY & HANDICAP \\
\hline YES OR NO & YES OR NO & YES OR NO \\
\hline
\end{tabular}


- Instructor will rely on historical context of disability in defining People First Language. For example, 'During the early modern history of the 1700's and 1800's people with disabilities were sometimes regarded as being 'evil' or 'possessed'." CIRCLE: YES OR NO 
Appendix $J$

Recruitment Materials for Study

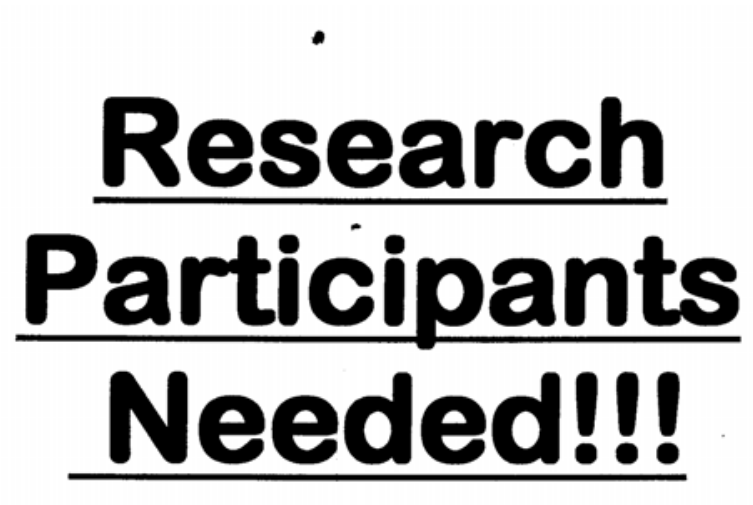

Take part in a 2-hour study on an emerging field of Psychological . research and

\section{EARN \$15.00 CASH}

*NOT A DRUG STUDY-Only requires attending TWO 30-minute lectures! SEND EMAIL TO:

Todd.Stoops@mail.wvu.edu OR CALL 293-3707, EXT. 1354 WV!U IRB APPROVAL ON FILE 


\section{Appendix K}

\section{Email Correspondence to Participants}

$\underline{\text { Initial Email Response for Prospective Participants }}$

Dear ,

Thank you so much for your interest in this research study!

The purpose of this study is to examine the effects of different types of instruction on learning. In order to be selected for the study, please answer the following questions about yourself, select an answer to the 2 multiple choice questions, complete the questionnaire, and select the days you are available from the possible list of dates.

Please type your responses where directed and return these responses to me in the form of a reply email.

Please type your answer next to each of the following identifying information about yourself.

Your Name:

Your Age:

Your College rank (Freshman, Sophomore, etc.):

Your Sex (Male or Female):

Please type your answer (A, B, C, D, or E) next to "Your response" for the following 2 multiple choice questions:

1. Write the letter which best reflects your math ability:

A. beginner

B. average (simple math problems)

C. intermediate (algebra)

D. above average (geometry)

E. superior (calculus)

Your response:

2. How familiar are you with disability-related issues?
A. very unfamiliar
B. somewhat unfamiliar
C. average
D. somewhat familiar
E. very familiar

Your response: 
Instructions for the questionnaire: Below are a number of statements that refer to your personal outlook. Please rate the extent to which you agree with each of these statements. If you are confused by the wording of an item, have no opinion, or neither agree nor disagree, use the "4" or "NEUTRAL" rating. Please type the number of your answer after "Your response:" for each question.

$1=$ Strongly Disagree

$2=$ Disagree

$3=$ Slightly Disagree

$4=$ Neutral

$5=$ Slightly Agree

$6=$ Agree

$7=$ Strongly Agree

1. I like to investigate things. Your response:

2. I generate few novel ideas. Your response:

3. I am always open to new ways of doing things. Your response:

4. I "get involved" in almost everything I do. Your response:

5. I do not actively seek to learn new things. Your response:

6. I make many novel contributions. Your response:

7. I stay with the old tried and true ways of doing things. Your response:

8. I seldom notice what other people are up to. Your response:

9. I avoid thought-provoking conversations. Your response:

10. I am very creative. Your response:

11. I can behave in many different ways for a given situation. Your response:

12. I attend to the "big picture." Your response:

13. I am very curious. Your response:

14. I try to think of new ways of doing things. Your response:

15. I am rarely aware of changes. Your response:

16. I have an open-mind about everything, even things that challenge my core beliefs. Your response:

17. I like to be challenged intellectually. Your response:

18. I find it easy to create new and effective ideas. Your response:

19. I am rarely alert to new developments. Your response:

20. I like to figure out how things work. Your response:

21. I am not an original thinker. Your response:

The study will take place the week of April 25th (Dead Week). I will try my best to select a time and date that is most convenient for you. Please put an X next to the days you are available from 5:30-7:30 PM:

Monday, April 25th

Tuesday, April 26th

Wednesday, April 27th

Thursday, April 28th 
The study will basically involve your participation in 2 lessons and a couple of different pencil/paper tests, all to be held on one evening for no longer than 2 hours. You will be paid $\$ 15.00$ cash the night of the study after it is completed. You will be notified by Saturday, April 9th as to whether you are or are not chosen to be in the study and the date and location of where the study will take place.

Thanks for your interest and I look forward to your email reply with your responses to the above questions. Please tell others about the possibility of taking part in this study.

Sincerely,

Todd Stoops

Doctoral Candidate

Educational Psychology

This research has been approved by the West Virginia University Internal Review Board.

\section{Email Notification Response to Prospective Participant}

Dear Student,

Congratulations! You have been selected to participate in the psychological research study. You have been selected to be in Group which will meet on , April from 5:30-7:30 PM in Room 1113 at the Life Sciences Building on the Downtown Campus. I tried to select the day and time which you indicated as best, but ultimately this is the best schedule for the majority of the participants.

I must receive an email confirming that you are willing to participate in this study as soon as possible. Please send me an email with either the subject heading of "Yes, I am able to participate" (if you are able to attend at that location and time) or "No, I am not able to participate" (if you have a conflict or are unable to attend). If I do not receive confirmation that you are able to participate, then your seat will be filled by another participant who will be compensated for taking part in the study.

The study will take no more than 2 hours. You will be asked to take two short tests, listen to two 30-minute lessons, and then take a few additional tests. After the study is completed, you will be given $\$ 15.00$ cash for participating in the study at that time.

Again, I thank you for your willingness to participate.

Sincerely,

Todd Stoops

Doctoral Student

Educational Psychology 
PS If you are taking a psychology or educational psychology course and your instructor has agreed to give you extra credit, please type a note in the reply email that you will be receiving extra credit so that may provide you the necessary form to receive the extra credit.

Notification of Alternate Participant

Dear Student,

Thank you for applying for the upcoming psychology research study. Unfortunately at this time, all slots have been filled. However, you have been selected as an alternate. If a participant cancels or decides not to take part in the study and there is an opening, I will notify you of the time and location of the study. Again, I thank you for your interest and applaud your attempt to help me further investigate an emerging field of psychological research. Best wishes in your studies.

Sincerely,

Todd Stoops

Doctoral Candidate

Educational Psychology

\section{$\underline{\text { Notification of Not Selected Student }}$}

Dear Student,

Thank you for your interest in participating in the upcoming psychology research study. I regret to inform you that you have not been selected to participate in the study. Should an opening become available, I will keep you in mind as an alternate. Again, thank you for your interest and I applaud your attempt to help me further investigate an emerging field of psychological research.

Sincerely,

Todd Stoops

Doctoral Candidate

Educational Psychology 
Notification of Withdrawal from Study Due to No Response

Dear Student,

Because you have not replied to my emails about whether or not you are able to participate in the study, your name has been withdrawn from the study. You are no longer eligible to participate.

Thank you,

Todd Stoops

Doctoral Candidate

Educational Psychology

\section{$\underline{\text { Reminder Email Notification to Participants }}$}

Dear Student,

Just a reminder that tomorrow (, April ) at 5:30 PM you will be participating in the psychology research study in Room 1113 of the Life Sciences Building!

PLEASE BE ON TIME!!

Thanks again for participating!

Todd Stoops

Doctoral Candidate

Educational Psychology 
Appendix L

Extra Credit Slips for Students Participating in Study

Extra Credit Slip for Psychology Students Participating in Study

PARTICIPANT RECORD SLIP

(complete in ink)

I have participated in the following study conducted in the Psychology Department of West Virginia University.

Study Title: Understanding Mindfulness: Implications for Instruction and Learning

Study \#:

Date of Participation: Number of hours of Participation:

Participant Name (printed):

Researcher Name (printed):

Researcher Name (signed):

Extra Credit Slip for Educational Psychology Students Participating in Study

PARTICPANT RECORD SLIP

(complete in ink)

I have participated in the following study conducted by the Educational Psychology department at West Virginia University.

Study Title: Understanding Mindfulness: Implications for Instruction and Learning.

Date of Participation: Number of hours of participation:

Participant Name (printed):

Researcher Name (printed):

Researcher Name (signed): 